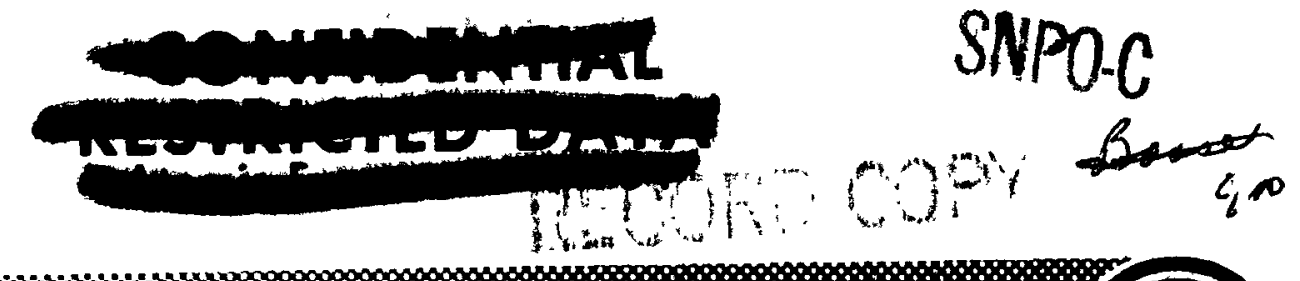
40

WANL-TME-796

MAY 1964 Volume I

\title{
WANL SOURCE TERM PROGRAM STATUS REPORT VOLUME I OF II
}

(Title Unclassified)

DISTRIBUTION OE IHIS DOCUMENT IS UNLMTTED

\section{Astronuclear Laboratory Westinghouse Electric Corporation}

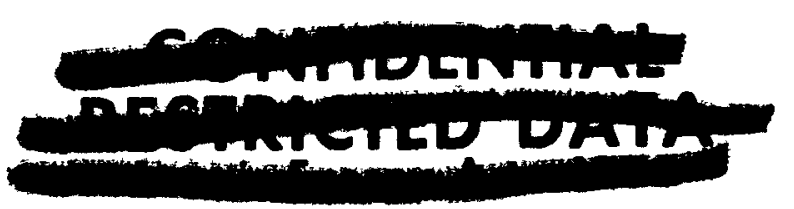




\section{DISCLAIMER}

This report was prepared as an account of work sponsored by an agency of the United States Government. Neither the United States Government nor any agency Thereof, nor any of their employees, makes any warranty, express or implied, or assumes any legal liability or responsibility for the accuracy, completeness, or usefulness of any information, apparatus, product, or process disclosed, or represents that its use would not infringe privately owned rights. Reference herein to any specific commercial product, process, or service by trade name, trademark, manufacturer, or otherwise does not necessarily constitute or imply its endorsement, recommendation, or favoring by the United States Government or any agency thereof. The views and opinions of authors expressed herein do not necessarily state or reflect those of the United States Government or any agency thereof. 


\section{DISCLAIMER}

Portions of this document may be illegible in electronic image products. Images are produced from the best available original document. 


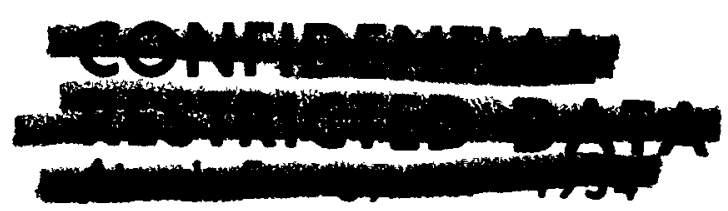

WANL-TME-796, Volume I

\title{
WANL SOURCE TERM PROGRAM
}

\author{
STATUS REPORT
}

VOLUME I OF II

(Title Unclassified)

Prepared By:

W.S. Brown

W. S. Brown

Physical Sciences

Safeguards Engineering

\section{Approved By:}

Solne $Q$. Vaulbme

J. E. Faulkner, Manager

Safeguards Engineering

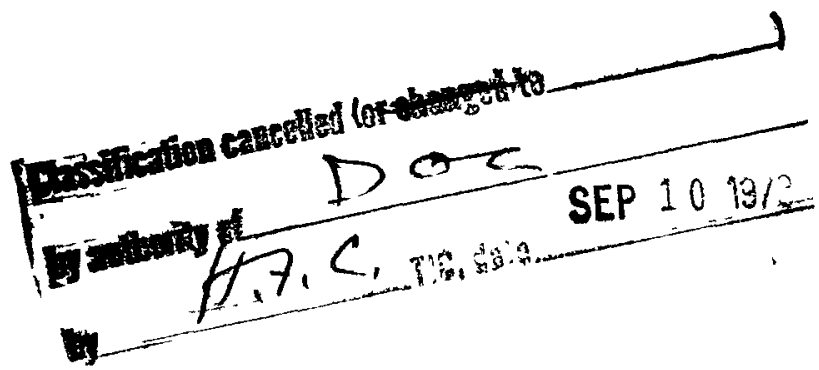

DISTRIBUJJON DE JHIS DOCUMENT IS UNLAHTEO

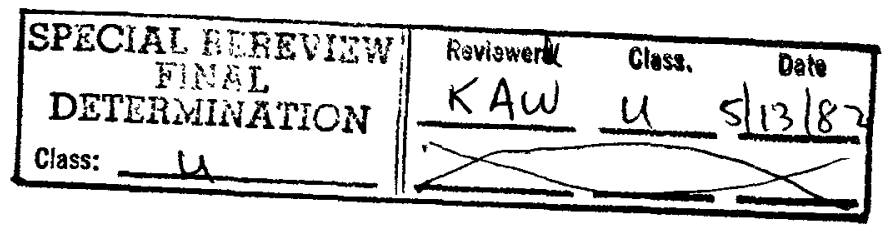

\section{NOTICE}

This report was prepared as an account of work sponsored by the United States Government. Neither the United States nor the United States Energy Research and Development Administration, nor any of their employees, nor any of their contractors, subcontractors, or their employees, makes any warranty, express or implied, or assumes any legal liability or responsibility for the accuracy, completeness or usefulness of any information, apparatus, product or process disclosed, or represents that its use would not infringe privately owned rights.

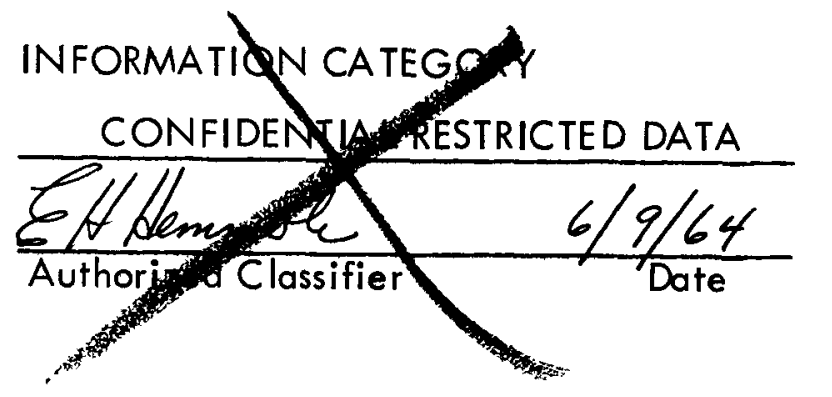




\section{ACKNOW LEDGMENT}

The data used in this report originated in the analytical and experimental work performed by the staff of the WANL Safeguards Engineering Department. The assistance of Mr. G. T. Rymer is acknowledged in the preparation and review of those sections of the report dealing with fission product diffusion. Special thanks are offered to Dr. J. M. Bridges for assistance in editing and for her contribution to the sections on re-entry burnup and chemical destruct. 
TABLE OF CONTENTS

1.0 SUMMARY

2.0 INTRODUCTION

3.0 SOURCE TERM DUE TO FISSION PRODUCTS

3.1 Fission Product Considerations

3.1.1 Generation of a Fission Product Inventory

3.1.1.1 Fission Product Inventory Program (FPIP)

3.1.1.2 Modified FPIP

3.1.2 Fission Product Diffusion

3.1.2.1 Experimental Program

3.1.2.1.1 Experimental Procedure

3.1.2.1.2 Experimental Results

3.1.2.1.3 Comparison of Isotopic Diffusion Rates

3.1.2.1.4 Analysis of Diffusion Rate Data

3.1.2.2 FIPDIF - A Computer Program for Predicting Fission Product Diffusion
Page

$-1-$

$-3-$

$-5-$

$-5-$

$-6-$

$-7-$

$-8-$

$-13-$

$-14-$

$-16-$

$-16-$

$-20-$

$-22-$

$-24-$

$-27-$

3.1.3 Estimates of Diffusion for Different Modes of Reactor Operation

3.1.3.1 Normal Operation

$-27-$

3.1.3.2 Reactor Shutdown with Loss of Coolant

$-31-$

3.1.3.2.1 Analytical Evaluations

$-31-$

3.1.3.2.2 Experimental Evaluations

$-35-$

3.1.3.2.3 Conclusions

$-36-$

3.1.3.3 Reactor Excursions

$-37-$

3.1.3.3.1 Experimental Evaluation 


\section{TABLE OF CONTENTS}

(CONTINUED)

3.1.3.3.2 Conclusions

3.1.4 Diffusion During Re-Entry

3.1.4.1 Analytical Evaluation

3.1.4.2 Experimental Evaluation

3.1.4.3 Conclusion

3.2 Re-Entry Burnup of Fuel Materials

3.2.1.1 Comparison of GE and WANL Analytical Results

3.2.1.2 Comparison of WANL and GE Analytical Approaches

3.2.2 Experimental

3.2.2.1 Graphite OxidatioH

3.2.2.2 Effect of Additives

3.2.2.3 Effect of Irradiation bn Re-Entry Burn-Up of Fuel

3.2.3 General Conclusion

\subsection{SOURCE TERM DUE TO NEUTRON ACTIVATION PRODUCTS}

4.1 Materials Activation Calculations

4.2 Activation Products Source Strength

4.3 Re-Entry Hazards from Activation Products

4.3.1 Ingestion Hazards

4.3.2 Contamination of Ocean Waters

4.3.2.1 Calculations

4.3.2.2 Conclusions
Page

$-38-$

$-40-$

$-40-$

$-43-$

$-46-$

$-46-$

$-46-$

$-48-$

$-48-$

$-55-$

$-55-$

$-57-$

- 57 -

-60 -

$-61-$

-61 -

-63 -

-68 -

- 72 -

- 72 -

-75 - 
TABLE OF CONTENTS

(CONTINUED)

5.0 DESTRUCT - CHEMICAL

5.1 Advantages and Disadvantages of Chemical Destruct

5.2 Summary of Chemical Destruct Studies

Page

$-79-$

$-79-$

$-81-$

BIBLIOGRAPHY

$-83-$ 


\section{LIST OF TABLES}

Number

$\underline{\text { Title }}$

Page

3.1

Per Cent of Total Core Activity Associated with Different

$-9-$

Elements After Ten Minutes Power Operation

3.2 Classification of Fission Product Elements According to

$-10-$ Diffusion Rates in NERVA Fuel

3.3 Effective Release Fractions of Fission Product Isotopes From The NRX Reactor During Five Minutes Normal Operation

3.4 Fractional Release of Fission Nuclides During Transient Irradiation in TREAT

3.5 Re-entry Conditions Simulated in the Investigation of Burn-up Behavior of Irradiated Fuel

3.6 Per Cent Burnup as a Function of Initial Particle Size and Re-entry Angle from WEREC Computer Program

3.7 Per Cent Burnup as a Function of Initial Particle Size and Re-entry Angle from G. E. Computer Program

3.8 Oxidation Rates of NERVA Fuel Containing Additives Fuel and Graphite 


\section{LIST OF FIGURES}

Number

Title

Page

3.1 $\bar{\beta}$-Energy Emission Rate of a $1000 \mu$ Particle Following a 2-Minute Operation at $1120 \mathrm{MW}$ and Destruct

$\bar{\beta}$-Energy Emission Rate of a $1000 \mu$ Particle Following a 9-Minute Power Operation and Destruct

Comparison of $\bar{\beta}$-Energy Emission Rates Produced by FPIP Using 273 and 499 Nuclide Libraries

3.4 Comparison of $\gamma$-Energy Emission Rates Produced By FPIP Using 273 and 499 Nuclide Libraries

3.5 Diffusion Characteristics of Fission Products from NERVA

Fuel. Results for 5 Minutes at Constant Temperature

3.6 Diffusion Characteristics of Fission Products from NERVA

Fuel. Results for 20 Minutes at Constant Temperature

Axial Temperature Distribution for Coolant Channels

3.10 Re-Entry Temperatures of Graphite-UC2 (One Inch Particle) Inch Particle) Under Simulated Re-Entry Conditions 


\section{LIST OF FIGURES}

\section{(CONTINUED)}

Number

Title

Page

4.1

Total $\gamma$-Energy Emission Rate of a $1000 \mu$ Diameter Particle

$-70-$ of Structural Materials and NERVA Fuel Following Suborbital Start with 9 Minutes Full Power Operation Followed by Destruct of Structural Materials and NERVA Fuel Following Suborbital Start with 9 Minutes Full Power Operation Followed by Destruct 


\subsection{SUMMARY}

This document, comprised of two volumes, is a status report on the WANL Source Term Program, which is part of the overall WANL safety effort to define hazards associated with space nuclear propulsion. Volume I describes the analytical and experimental studies performed to date in the areas of fission product diffusion from NERVA fuel, re-entry burn-up, neutron activation of NERVA structural components, and chemical destruct. Volume II describes a computer program designed to integrate the analytical techniques generated by the Source Term Program. This computer program may be utilized to evaluate the hazards as sociated with various operational missions and will serve as a tool to define those missions which are safe.

In Volume 1 the following conclusions are drawn:

(1) The greatest radiological hazards associated with the re-entry of a reactor or of reactor debris arises from the fission products generated during reactor operation. Activity arising from neutron activation of reactor components is appreciably less than that due to the fission product inventory.

(2) Diffusion of fission products will reduce the inventory providing sufficiently high fuel temperatures are achieved.

(3) Post operational heating without coolant flow offers the most promising means of reducing the fission product inventory of the core prior to re-entry. 
(4) Loss of fission products by diffusion during normal operation and during the re-entry of core fragments will not significantly reduce the fission product inventory,

(5) Re-entry burnup will not signficantly reduce the source strength of nuclear debris.

(6) Chemical destruct experiments indicate that only potassium and chlorine trifluoride offer promise as destruct reagents. However, no definite conclusions regarding chemical destruct can be drawn at this time.

A summary of the computer program is given in Volume II. 


\subsection{INTRODUCTION}

The use of a nuclear engine for space propulsion requires consideration of safety problems. A major problem involves the possibility of deposition in the earth's biosphere of radioactive debris formed during reactor operation. In order to evaluate the ground hazards associated with this radioactive material the following factors must be considered:

(1) The size of the debris particles (these particles may range from micronic size up to an entire reactor),

(2) The amount of radioactivity and the energy spectra associated with the radioactive debris,

(3) The location of the debris on the earth's surface,

(4) The concentration of the debris.

To determine the aforementioned factors a Source Term Program has been established. The purpose of this program is to provide a central depository for all source term information generated in the ROVER Flight Safety Program. In addition, it is responsible for providing an integrated computer technique which will supply basic source term information for the evaluation of radiological hazards. The source term information generated in the ROVER Flight Safety Program includes results obtained from both analytical and experimental studies. In this context the following must be considered: fission product production and decay, fission product diffusion, neutron activation, re-entry burn-up of fuel and structural materials, and fli ght mechanics. The ultimate application of all these data culminates in the integrated source term computer program. 
This document represents the status of WANL efforts in the Source Term Program. It is comprised of two volumes--Volume 1, summarizing the analytical and experimental phases of the WANL Source Term Program and Volume II, describing the present WANL Source Term Computer Program.

Future reports will be issued for the purpose of updating both this information and the computer program. In addition, these reports will include data from other agencies involved in the ROVER Flight Safety Program. 


\subsection{SOURCE TERM DUE TO FISSION PRODUCTS}

The major source of radioactivity arising from the operation of a nuclear powered rocket is associated with the fission products retained in the reactor fuel. In order to evaluate this source accurately, it is necessary to consider the means by which the fission products may be lost from the fuel both during and after reactor operation. During the operational and early post-operational history of the reactor, losses will occur by diffusion of the fission products out of the fuel matrix. Additional losses may occur during the reentry process, particularly if reactor destruct is employed and the core is fragmented into small particles. In this event, the mass of the core fragments and hence the associated fission product inventory of the fragments will be diminished by re-entry burnup.

\subsection{FISSION PRODUCT CONSIDERATIONS}

The evaluation of the fission product inventory remaining in the fuel material at any time is dependent on how exactly the mathematical model, which is used for calculations, represents the actual build-up and loss mechanisms. The build-up of fission products is calculated using data on the fission yields and decay rates of the various isotopes. Loss by diffusion is evaluated using experimentally determined isotopic diffusion rates. The extent of diffusion of the fission products is largely dependent on the fuel temperature, with the diffusion rate increasing with increasing temperature. The magnitude of the diffusion rate is also a function of the type of fuel, the chemical and physical properties of the isotope, and the length of time the fuel is at elevated temperatures. 


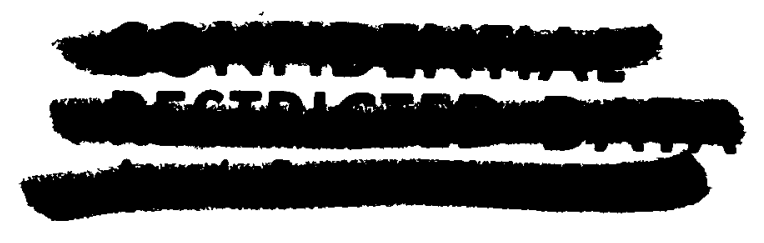

In this section we will consider the analytical techniques and experimental data required to evaluate fission product inventories. In addition, we will attempt to estimate the extent to which fission products will diffuse under operational and post-operational conditions.

\subsubsection{Generation of a Fission Product Inventory}

Tests on NERVA fuel have shown that there is little or no diffusion of fission products at temperatures be low $3200^{\circ} \mathrm{R}\left(1500^{\circ} \mathrm{C}\right)^{(1)}$. Under normal operating conditions with $\mathrm{H}_{2}$ coolant flow, a large fraction of the core does not exceed these temperatures. Therefore, under these operational conditions there will be an appreciable inventory which may be evaluated using conventional fission product inventory computer programs.

Methods of calculating the fission product inventory in the reactor are straight forward but complex. The production and decay of a particular nuclide is considered to be a combination of the direct formation of the nuclide by fission and the formation by production and decay of its precursors in the same mass chain. Because of the complexity of the calculations, evaluations of fission product inventory are usually programmed for high speed digital computer solution.

A number of computer programs are reported in the literature for the calculation of fission product generation and decay $(2,3,4)$. Lockheed Georgia Company has developed a computer code ${ }^{(5)}$ based on the work performed by Perkins and King ${ }^{(6)}$. Application of the Lockheed code for determination of re-entry hazards resulting from nuclear rocket operation is described in Reference 7. In addition, a number of codes have been

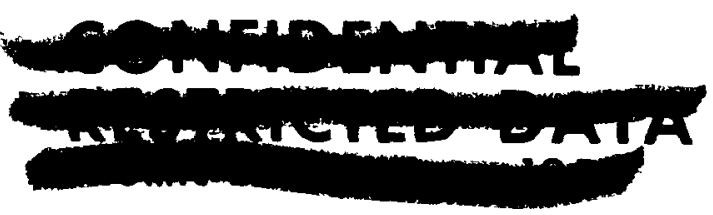


developed in the last few years. Speigler ${ }^{(8)}$ has revised and up-dated the Perkins and King program, extending it to infinite reactor operating time and dividing the gammas into sixteen energy groups. Los Alamos Scientific Laboratory has also issued two new programs recently $(9,10)$

\subsubsection{Fission Product Inventory Program (FPIP)}

A comprehensive program for calculating fission product inventories was developed at WANL and is called the Fission Product Inventory Program (FPIP) ${ }^{(11)}$. This code uses a fission product library which can accommodate up to 499 nuclides. The reactor operating history can consist of as many as five separate operating periods, each at an arbitrary power level. The program calculates the activity for each nuclide and calculates the gamma and beta radiation energy source strengths in each of four gamma and five beta energy groups. The upper and lower bounds defining the gamma and beta energy groups are selected by the user of the program as input information. (The source strengths are calculated for each energy group, and for each nuclide. In addition, the energies are summed for each energy group, and a grand total is calculated.) A comparison of the results of the FPIP program with the work of Perkins and King is given in References 6 and 10. Also, comparison of FPIP with the Los A lamos program is shown in Reference 6.

A particularly valuable feature of this program is the calculation of the beta energies based on the most recent $\beta$-spectra available for individual nuclides. Accurate beta energy source strengths are important in calculating radiological hazards from small particles that are in contact with the skin or ingested by a human being. 
In Figures 3.1 and 3.2, the $\beta$ energies associated with $1000 \mu$ particles following 2 and 9 minute power operations are shown. The data for these curves were calculated using FPIP. These curves are part of a study to determine the radiological hazards associated with the re-entry of small core fragments ${ }^{(12)}$.

\subsubsection{Modified FPIP}

The original fission product library of 499 nuclides used in FPIP has been reduced to 273 nuclides ${ }^{(13)}$. The library was reduced to provide more storage space in the computer when adapting the FPIP program for use in the source term computer program, as described in Volume $U$ of this report. In the original 499 nuclide library there were no energy spectra available for a large number of nuclides. In those cases, and where the nuclide did not contribute significantly to the total activity (less than $0.10 \%$ based on the original 499 nuclide FPIP program), fission yield for that nuclide has been assigned to the next succeeding chain member. This reassignment has been carried out only for chain members, and in no case was an entire chain deleted.

Results of running the computer program with the 273 nuclide library have been compared with the results obtained with the original 499 nuclide library. The total activity, gamma energies, and beta energies were compared between both programs for operating periods from two minutes to 30 minutes followed by shutdown periods from one minute to ten years. A comparison of the total beta and total gamma energies for a two minute operating period are shown in Figures 3.3 and 3.4, respectively. Curves for other operating periods are similar. Curves were also plotted for five beta and four gamma energy 


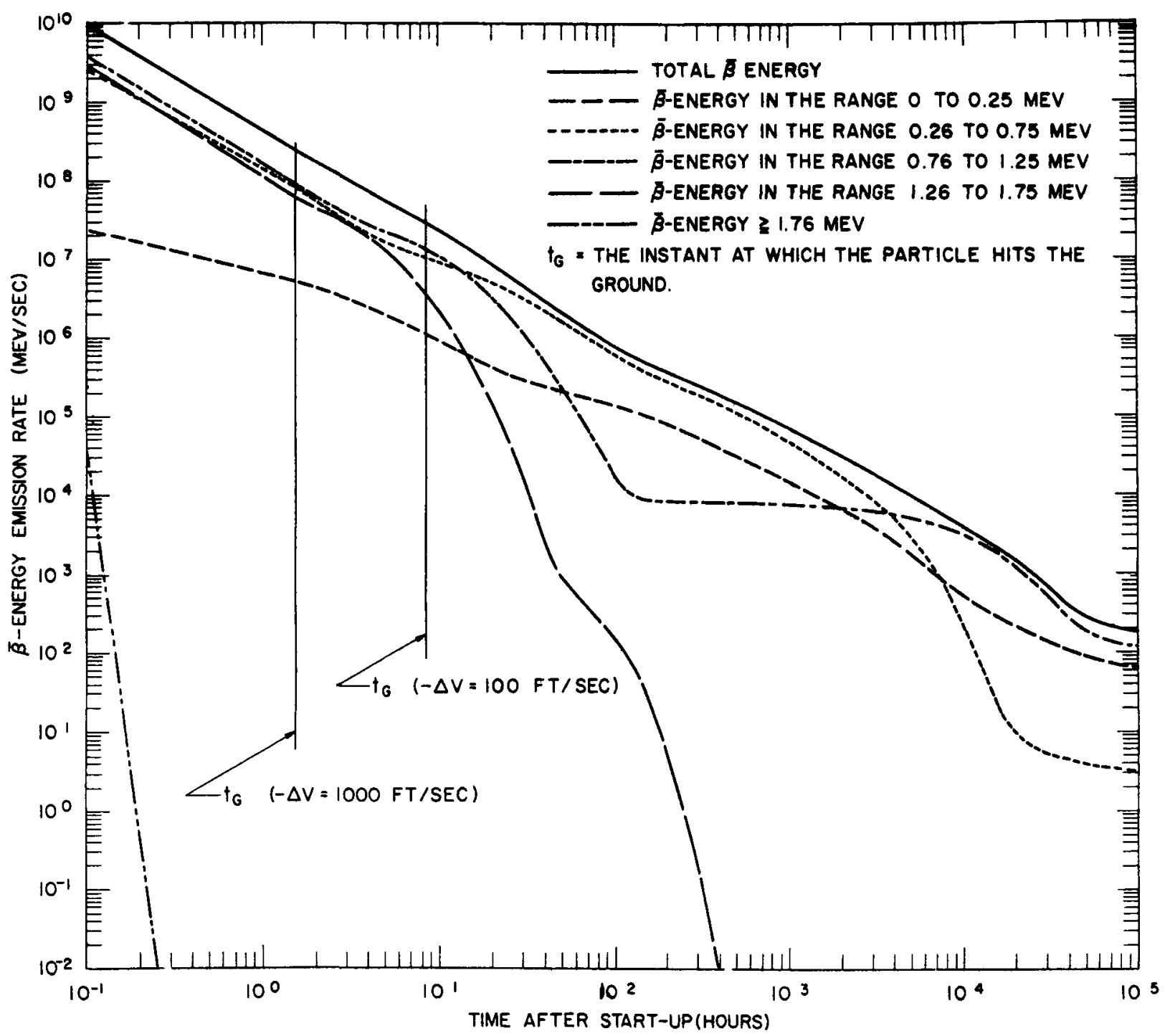

FIGURE 3.1

$\bar{\beta}$-energy EMISSION RATE Of A $1000 \mu$ PARTICLE FOLLOW ING A 2-MINUTE OPERATION AT 1120 MW AND DESTRUCT

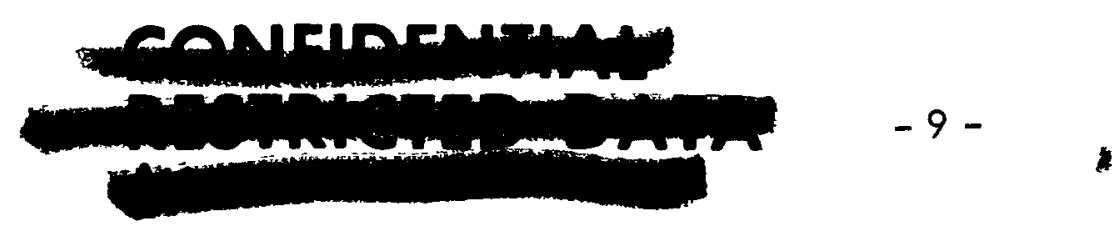




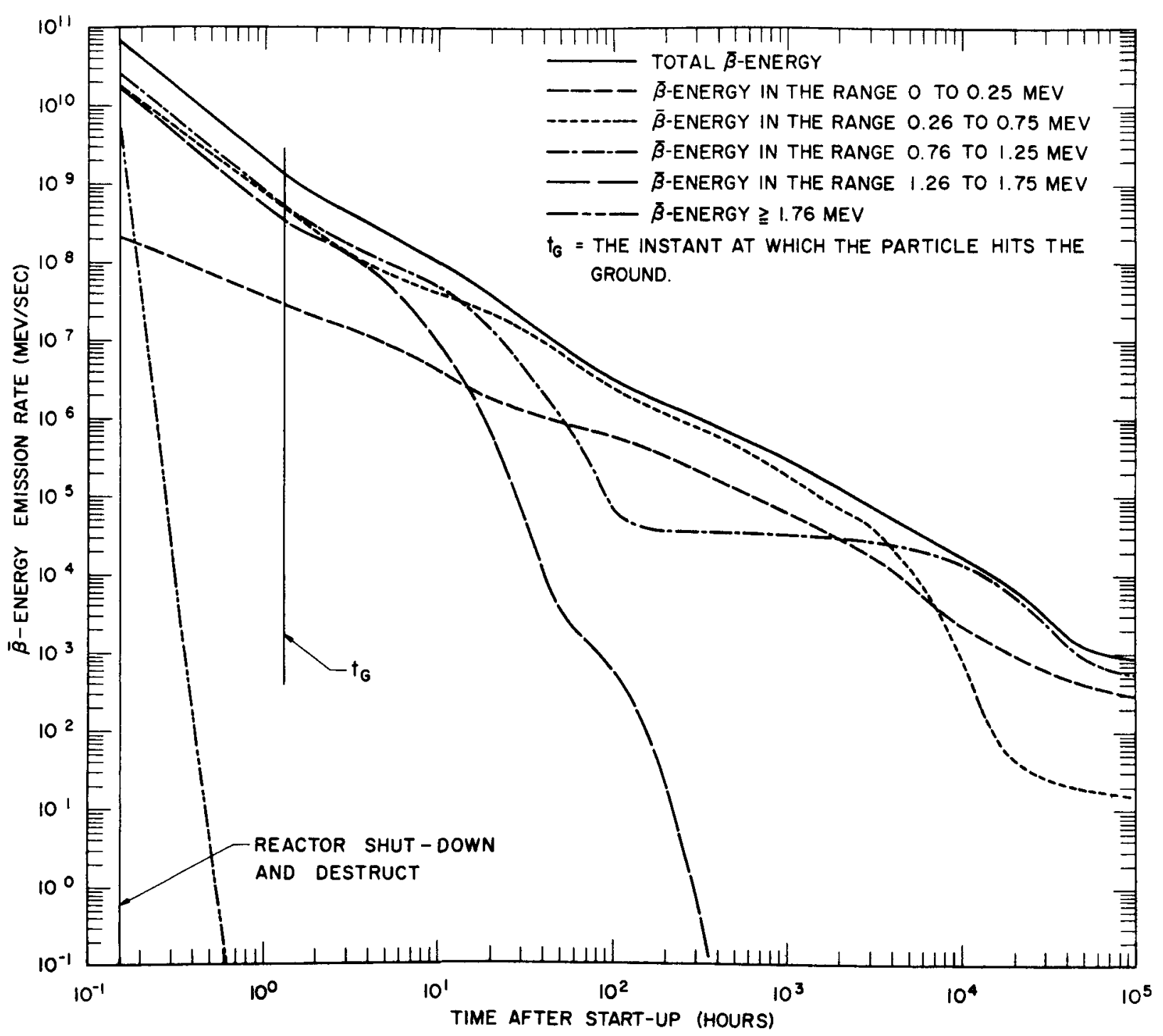

FIGURE $3.2 \quad \bar{\beta}$-ENERGY EMISSION RATE OF A $1000 \mu$ PARTICLE FOLLOWING A 9-MINUTE POWER OPERATION AND DESTRUCT

\section{CONHULETIAL}




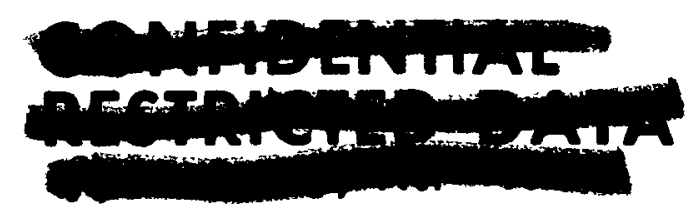

4

4

(ev) Stronuclear

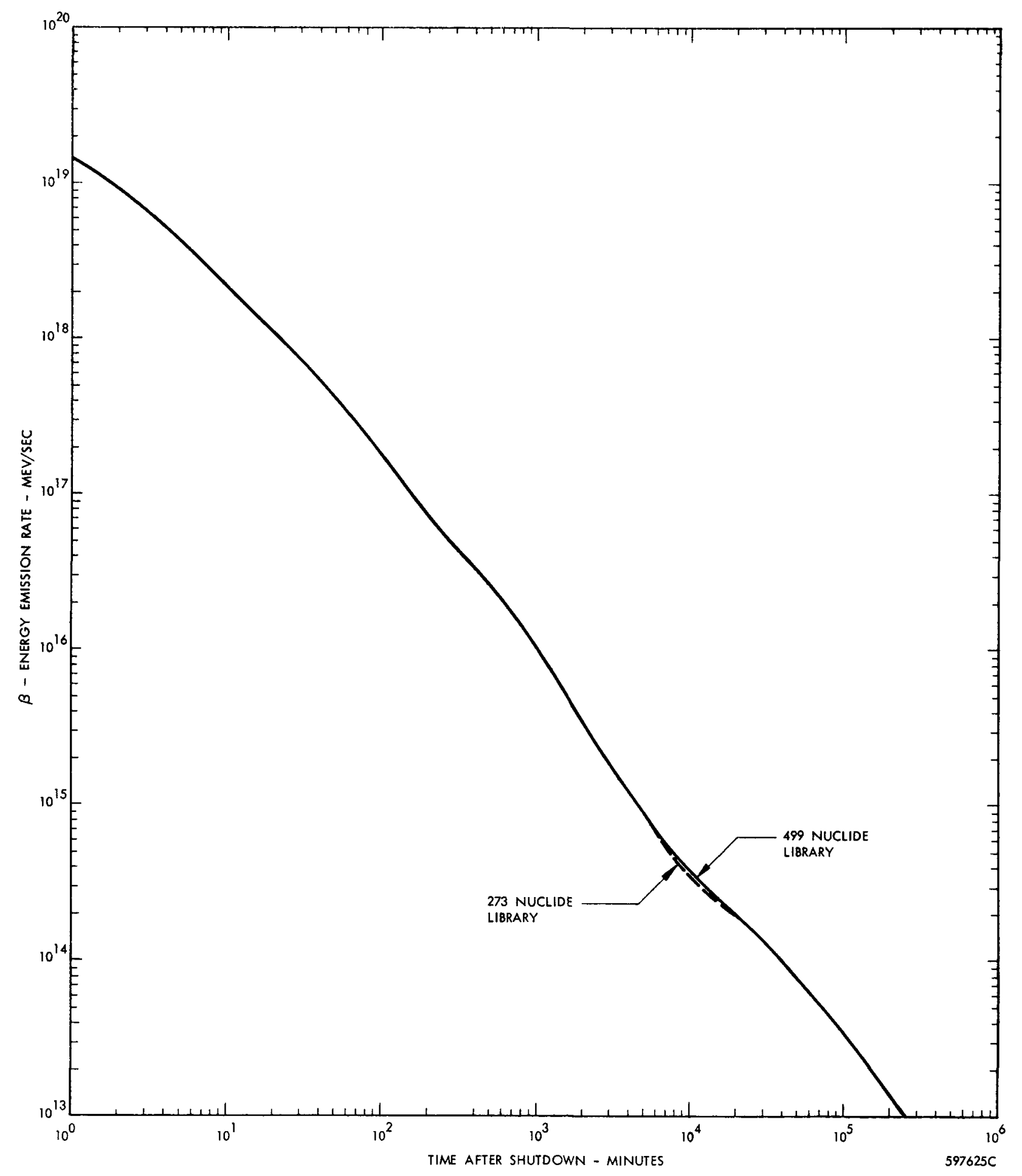

FIGURE 3.3

COMPARISON OF $\bar{\beta}$-ENERGY EMISSION RATES PRODUCED BY

FPIP USING 273 AND 499 NUCLIDE LIBRARIES

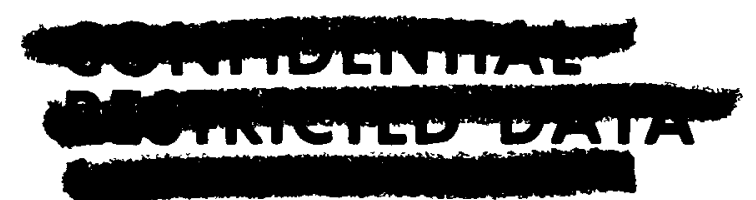




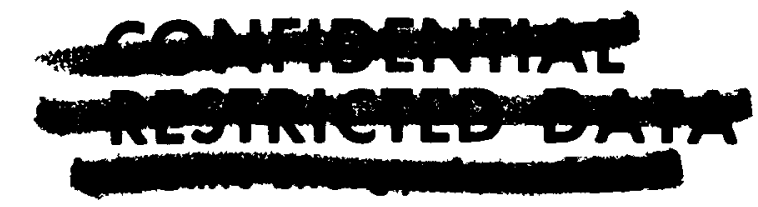

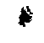

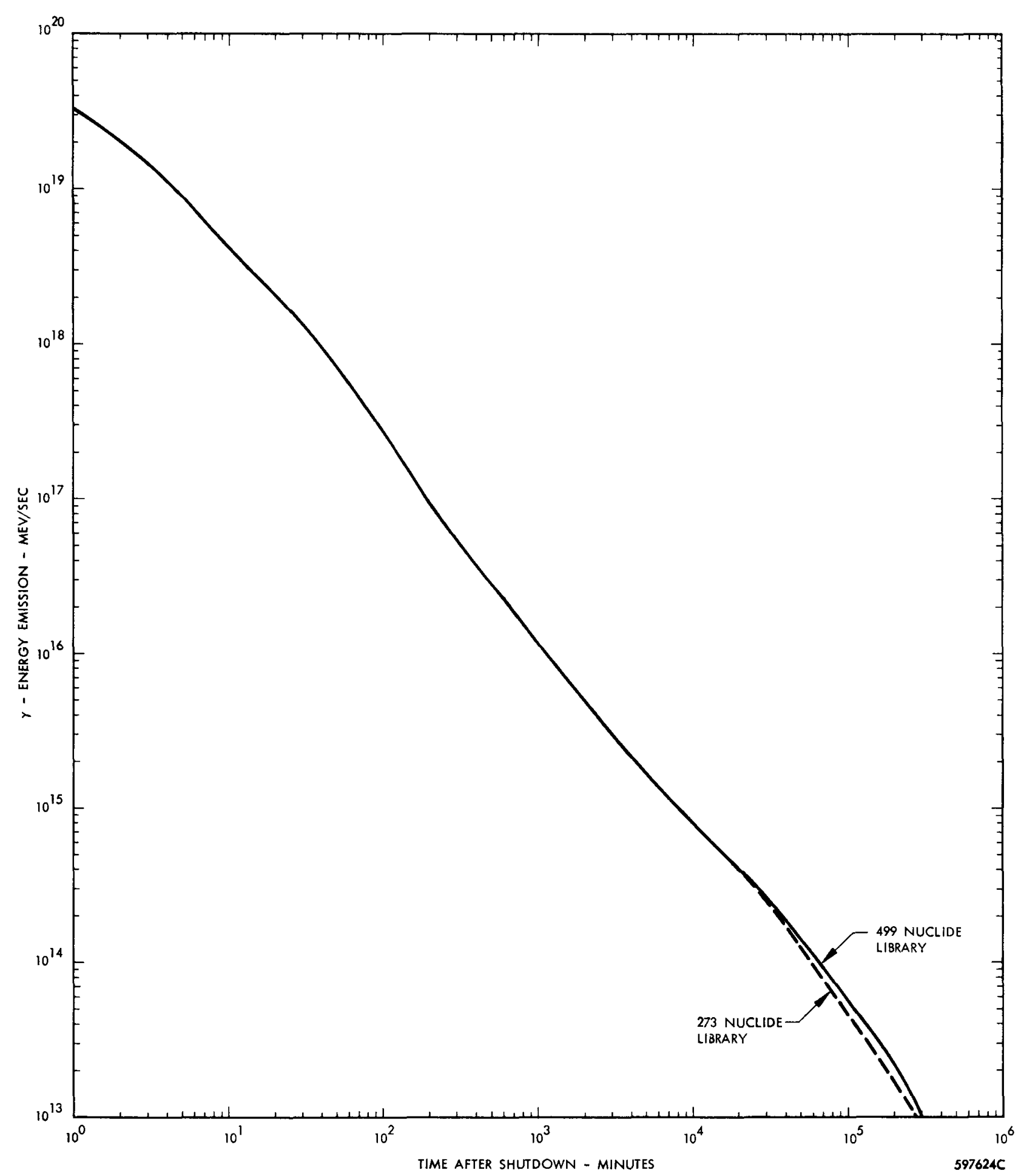

FIGURE 3.4 COMPARISON OF $\gamma$-ENERGY EMISSION RATES PRODUCED BY

FPIP USING 273 AND 499 NUCLIDE LIBRARIES 

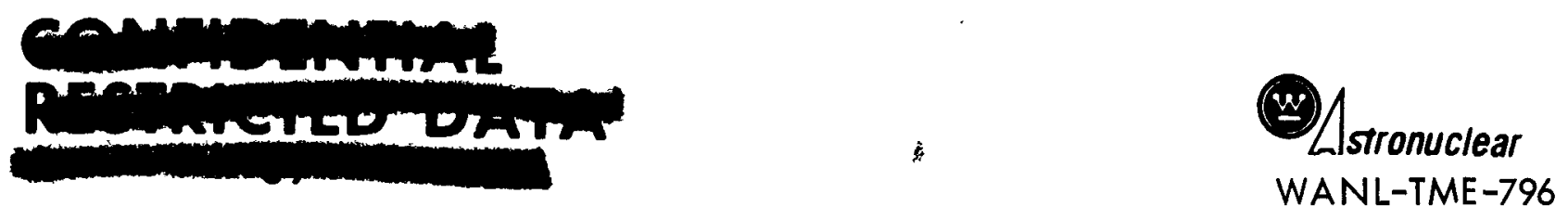

groups. At certain time intervals in the decay, deviations of 15 to $20 \%$ within a single beta or gamma energy group were found. However, for the total energies, as shown in Figures 3.3 and 3.4, the deviation between the two libraries generally was within $3 \%$. The 499 nuclide library gives a greater activity at shutdown and at very short decay periods, as would be expected. However, for times greater than 15 minutes after shutdown, the activities between the two libraries are very close. For determination of radiological hazards resulting from flight operations, the modified library of 273 nuclides is suitable, since the earliest re-entry time is expected to be greater than 15 minutes. Therefore, the 273 nuclide library has been adopted as the standard for calculating fission product inventories. The reduced library gives accuracy comparable to the 499 nuclide library, and has the advantage of reduced computer running time.

\subsubsection{Fission Product Diffusion}

Experiments have shown that diffusion of fission products within NERVA fuel will occur at temperatures above $3200^{\circ} \mathrm{R}\left(1500^{\circ} \mathrm{C}\right)$, with the diffusion rate increasing sharply at temperatures above $4632^{\circ} \mathrm{R}\left(2300^{\circ} \mathrm{C}\right)^{(14)}$. The fuel temperatures expected in the NERVA reactor at normal operating powers will exceed $3200^{\circ} \mathrm{R}\left(1500^{\circ} \mathrm{C}\right)$ in the lower half of the core and will reach approximately $4460^{\circ} \mathrm{R}\left(2200^{\circ} \mathrm{C}\right)$ at the exit end of the core ${ }^{(15)}$. A number of elements will exceed this nominal temperature due to hot channel factors. At these temperatures, the diffusion of fission products affords a mechanism whereby the fission products can be released from the core, thus reducing the flssion product inventory. Analytical studies have shown that considerably higher temperatures will be reached from decay
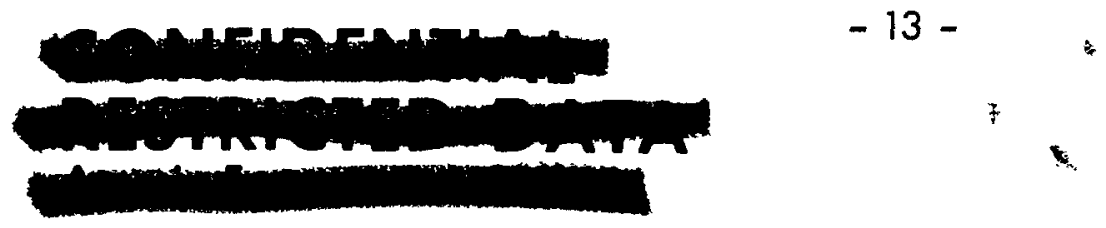
heat after shutdown with loss of coolant. Under these conditions a significant loss of fission products could occur. In order to calculate these losses, the fission product diffusion rates must be experimentally measured, and core temperature profiles must be known.

\subsubsection{Experimental Program}

The diffusion of elements through a solid matrix is an involved physico-chemical process, the rate of which cannot be predicted from a theoretical basis. Only by experimental means may diffusion rates be evaluated. Therefore, in order to determine the extent to which isotopes diffuse from a NERVA core, it is necessary to determine the diffusion rate of each of the 273 isotopes comprising the fission product inventory. At first glance this would appear to be a formidable task. However, two facts reduce the complexity of the problem considerably: (1) the diffusion rates of all isotopes of the same element may be considered to be equal and (2) after two to 30 minutes power operation, $96 \%$ of the total activity in the fuel at shutdown is due to 21 elements comprising 134 isotopes. Each of these elements contributes $0.7 \%$ or more to the total activity. A listing of these elements and the ir relative per cent activity are given in Table 3.1 for a ten minute power operation. Although the relative percentages of individual isotopes vary with decay tim $=$, it has been shown by analys is of data from FPIP that the sum total of activity from these 21 elements comprises greater than $96 \%$ of the total activity for decay times up to one hour.

Thus, the problem of experimentally evaluating fission product diffusion reduces to measuring the diffusion rates of 21 elements. At present, the diffusion rates of ten of these elements are being measured. Isotopes used to study these elements are: $\mathrm{Sr}^{89}, \mathrm{Y}^{91}, \mathrm{Zr}^{95}, \mathrm{Mo}^{99}, \mathrm{Te}^{129}, \mathrm{I}^{131}, \mathrm{Cs}^{137}, \mathrm{Ba}^{140}, \mathrm{La}^{140}$, and $\mathrm{Ce}^{141,144}$. It is planned that eventually all 21 elements will be examined. However, Bryant $(16,17)$ has demonstrated
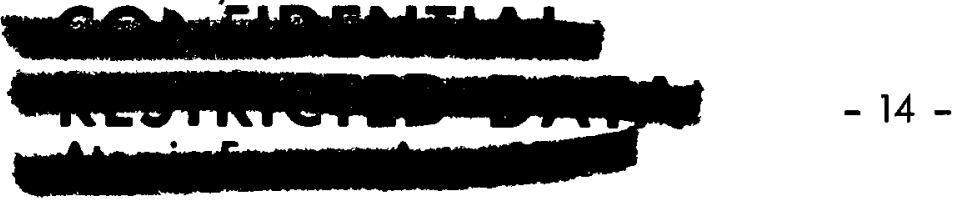


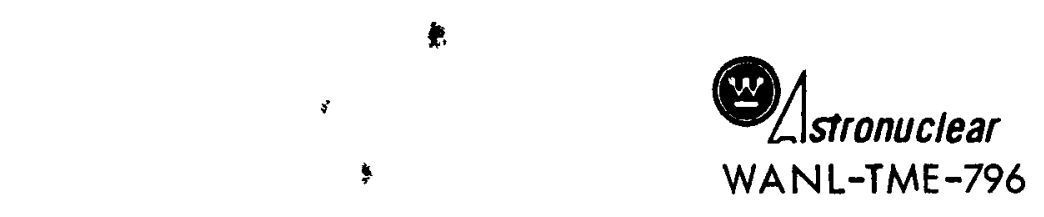

TABLE 3.1

PER CENT OF TOTAL CORE ACTIVITY ASSOCIATED WITH DIFFERENT

ELEMENTS AFTER TEN MINUTES POWER OPERATION

\begin{tabular}{|c|c|c|c|}
\hline ELEMENT & $\%$ & ELEMENT & $\%$ \\
\hline $\mathrm{Rb}$ & 10.01 & La & 3.87 \\
\hline $\mathrm{Nb}$ & 7.94 & 1 & 3.40 \\
\hline $\mathrm{Sr}$ & 7.90 & $S b$ & 3.32 \\
\hline Y & 7.89 & $\mathrm{Ce}$ & 3.21 \\
\hline$Z_{r}$ & 6.70 & Mo & 3.10 \\
\hline Cs & 6.57 & $\mathrm{Te}$ & 2.61 \\
\hline $\mathrm{Kr}$ & 6.57 & $\mathrm{Se}$ & 2.19 \\
\hline $\mathrm{Ba}$ & 5.11 & Tc & 2.17 \\
\hline $\mathrm{Br}$ & 5.14 & $\mathrm{Pr}$ & 1.56 \\
\hline \multirow[t]{3}{*}{$X_{e}$} & 4.81 & Sn & 1.25 \\
\hline & & As & 0.72 \\
\hline & & Total & 96.04 \\
\hline
\end{tabular}




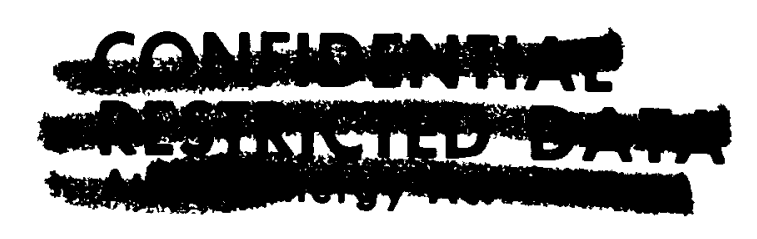

that a number of the 21 elements have similar diffusion rates in $\mathrm{UC}_{2}$-graphite fuel. Although Bryant's studies were not performed on pyro-coated $U_{2}$, it is quite probable, based on his analyses, that the rates of the ten elements now being studied will be fairly representative of the rates of all 21 elements.

\subsection{Experimental Procedure}

In the experimental program the diffusion rates of the aforementioned elements are measured in the laboratory as a function of time and temperature. Fuel samples $0.25^{\prime \prime}$ in diameter and $0.25^{\prime \prime}$ long with a $0.095^{\prime \prime}$ diameter hole along the axis, are cut from NERVA B-4 fuel elements. These samples are irradiated in the GETR, the TREAT reactor, or in the reactor at the Westinghouse Reactor Evaluation Center, Waltz Mills, Pennsylvania. Following the irradiations, many of the specimens are subjected to post-irradiation heating experiments to measure the fractional release of fission products and to determine the basic diffusion parameters. In these series of experiments, the irradiated samples are heated in a vacuum of $10^{-4} \mathrm{~mm} \mathrm{Hg}$ at temperatures ranging from $1500^{\circ} \mathrm{C}$ to $2700^{\circ} \mathrm{C}$ for time intervals up to 30 minutes. A description of the apparatus used for the postirradiation heating, and for the irradiation of the fuel specimens is given in Reference 1.

$$
\text { Following the post-irradiation heating (or reactor ir- }
$$

radiation if no post-heating experiment has been performed), the specimens are completely dissolved and analyzed radiochemically to determine the fractional release of the fission products.

$$
\begin{aligned}
& \text { 3.1.2.1.2 Experimental Results } \\
& \text { Diffusion of } \mathrm{Sr}^{89}, \mathrm{Ba}^{140}, \mathrm{Cs}{ }^{137}, \mathrm{Ce}^{141,144}, \mathrm{Y}^{91}, \mathrm{Zr}^{95} \text {, }
\end{aligned}
$$

and $\mathrm{Mo}^{99}$ as a function of time at femperatures up to $2200^{\circ} \mathrm{C}$ have been reported ${ }^{(1,18 \text { : }}$.

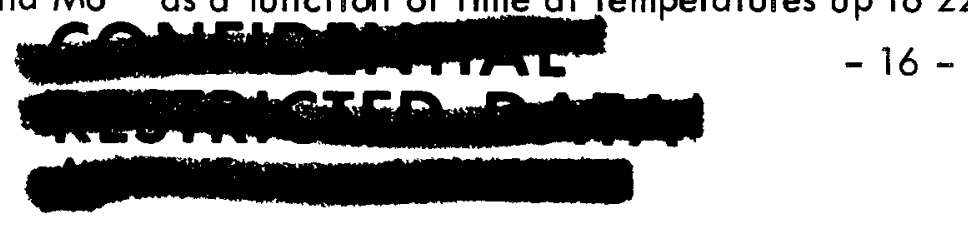


Diffusion of iodine and tellurium in NERVA fuel heated for 20 minutes up to temperatures of $2800^{\circ} \mathrm{C}$ were reported in WANL-TME-589 ${ }^{(19)}$. The most recent measurements of diffusion of nuclides at temperatures up to $2300^{\circ} \mathrm{C}$ will be published in June 1964 , and are summarized here $^{(14)}$. The results of these experiments have shown that the logarithm of the fraction retained of $\mathrm{Y}^{91}, \mathrm{Ce}^{141}$, and $\mathrm{Cs}^{137}$ is a linear function of time at temperatures up to $2200^{\circ} \mathrm{C}$. This relationship can be expressed mathematically as:

$$
\log (1-f)=C_{Z, T^{\dagger}}
$$

where:

$$
\begin{aligned}
& f \quad=\text { fraction of the nuclide released from the fuel, } \\
& (1-f)=\text { fraction of nuclide retained in the fuel, } \\
& C_{Z, T}=\text { a constant for nuclide } Z \text { held at temperature } T, \\
& t \quad=\text { time }(t \leq 30 \text { minutes }) .
\end{aligned}
$$

At $2200^{\circ} \mathrm{C}$, this same behavior is followed up to 20 minutes heating time. Beyond 20 minutes, the release rate increases very rapidly for all of the above nuclides, with $\mathrm{Ba}^{140}$ and $\mathrm{Sr}^{89}$ having nearly complete release after 30 minutes. At $2300^{\circ} \mathrm{C}$, the diffusion rate for these nuclides is constant, very rapid, and about the same as the rapid rate obtained at $2200^{\circ} \mathrm{C}$ after 20 minutes heating.

Data on the release of fission products as a function of temperature ${ }^{(14)}$ are summarized in Figures 3.5 and 3.6. Figure 3.5 indicates the release obtained when holding irradiated fuel for five minute periods at constant temperatures of 
(1)

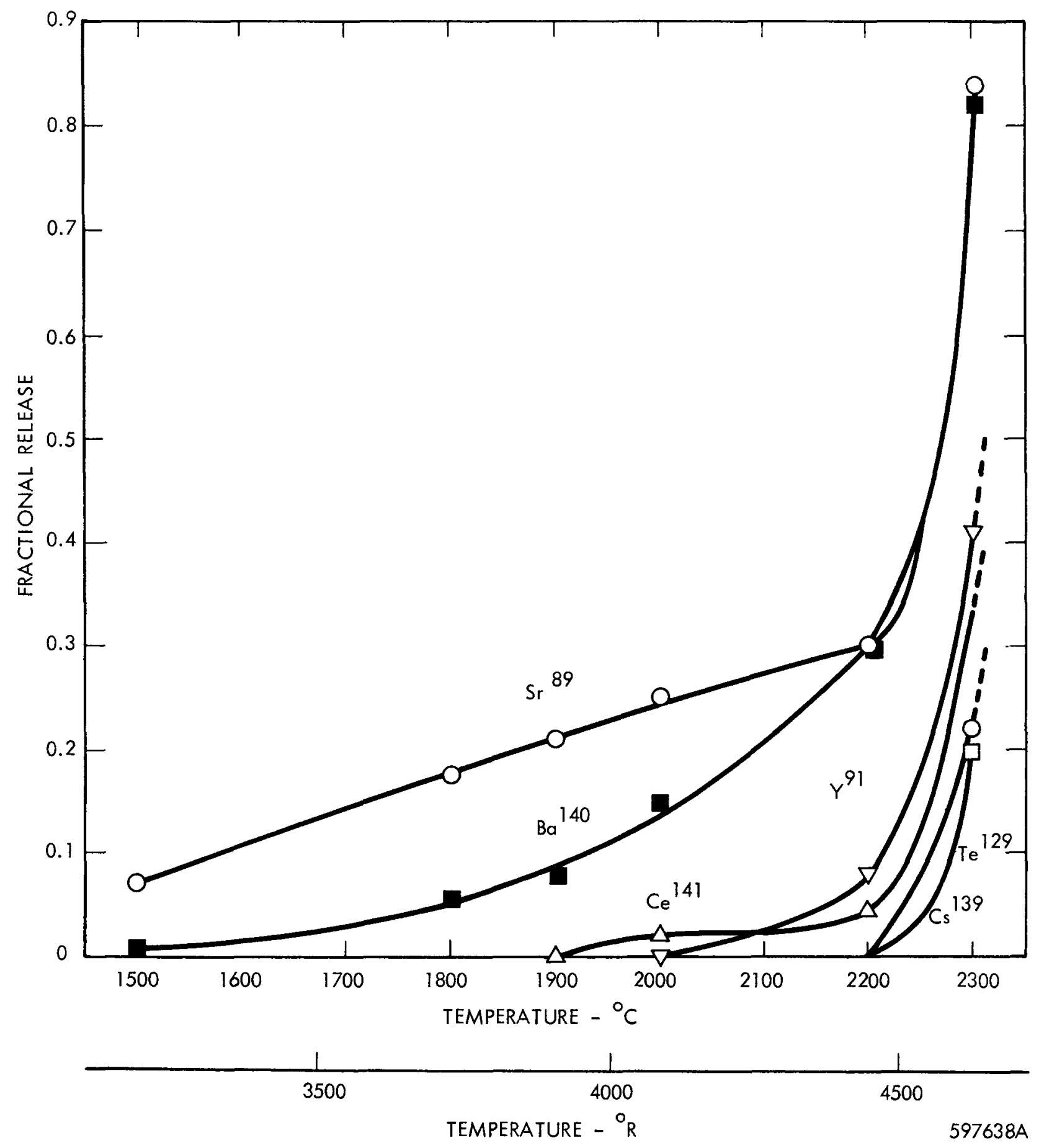

FIGURE 3.5 


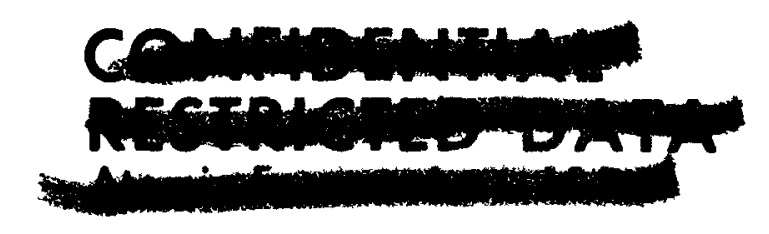

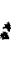

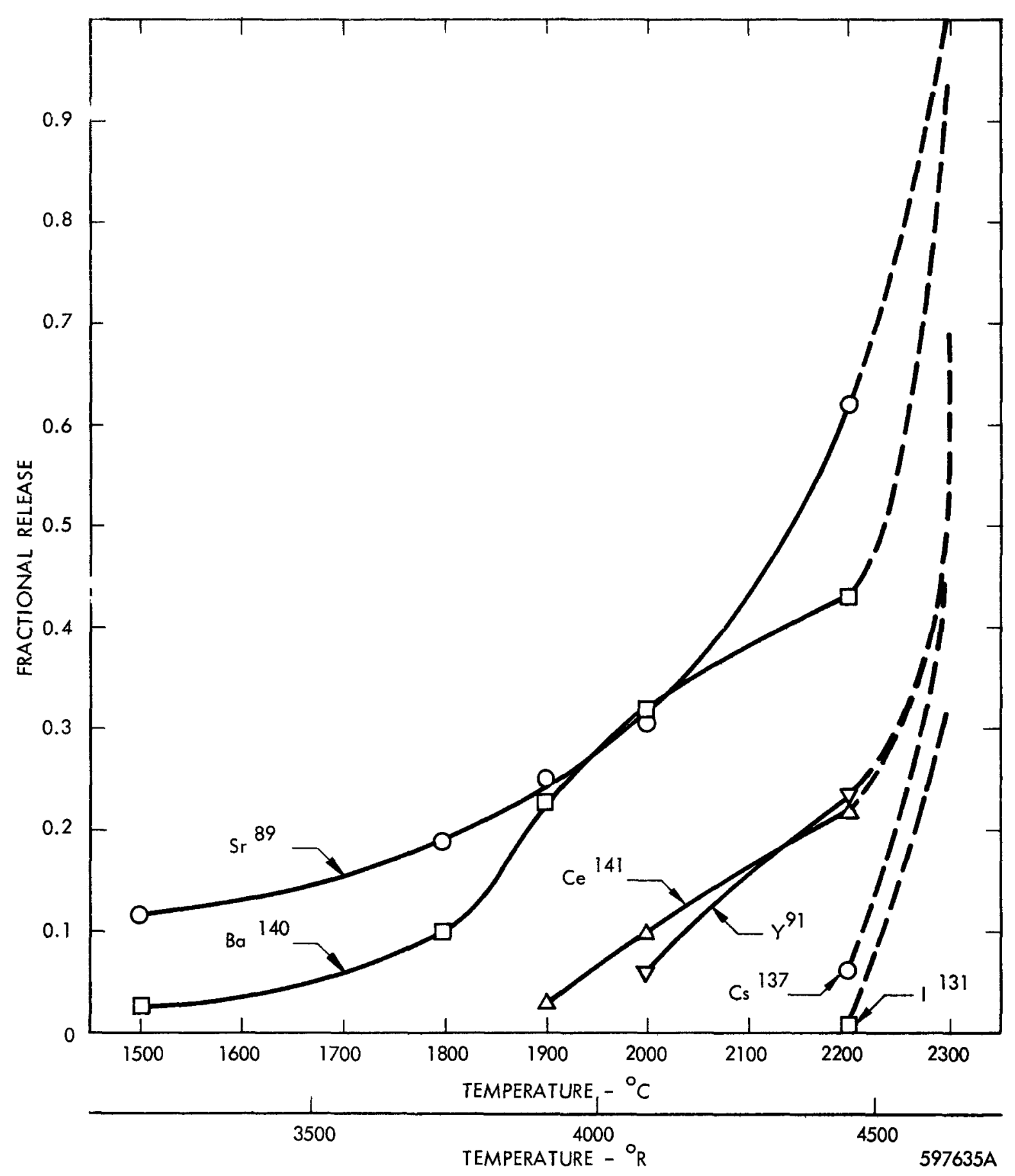

FIGURE 3.6

DIFFUSION CHARACTERISTICS OF FISSION PRODUCTS FROM NERVA

FUEL. RESULTS FOR 20 MINUTES AT CONSTANT TEMPERATURE

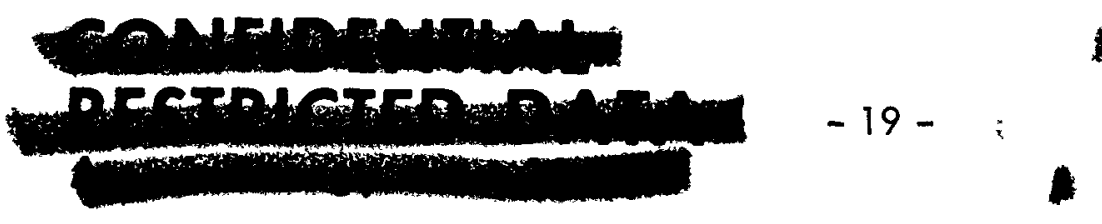



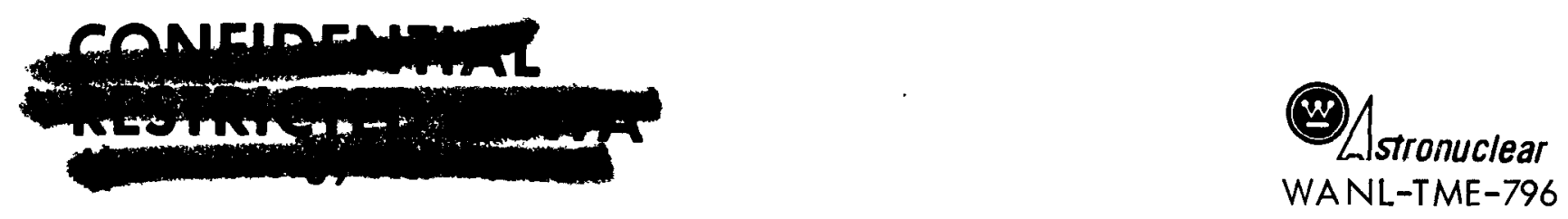

$1500^{\circ}, 1800^{\circ}, 1900^{\circ}, 2000^{\circ}, 2200^{\circ}$, and $2300^{\circ} \mathrm{C}$. Figure 3.6 is similar, but here the fuel has been maintained at each temperature for 20 minutes. The rapid increase in diffusion rate at $2300^{\circ} \mathrm{C}$ is shown in Figure 3.5 by the large fractional release obtained in five minutes at this temperature.

\subsection{Comparison of Isotopic Diffusion Rates}

The results of these experiments have shown that the elements can be classified into four groups according to their diffusion rates. This classification is shown in Table 3.2, in which the groups are listed in order of increasing retention characteristics. Also reported in this table are the particular isotopes in each group for which the irradiated samples were analyzed. Group 1 elements appear to have a diffusion threshold temperature of about $3200^{\circ} \mathrm{R}\left(1500^{\circ} \mathrm{C}\right)$ within the time periods studied (up to one hour). Group 2 elements start diffusing at about $3900^{\circ} \mathrm{R}\left(1900^{\circ} \mathrm{C}\right)$, and Group 3 starts at about $4450^{\circ} \mathrm{R}\left(2200^{\circ} \mathrm{C}\right)$. Group 4 elements have essentially complete retention up to $5700^{\circ} \mathrm{R}$ $\left(2900^{\circ} \mathrm{C}\right)$. It is estimated that after 20 minutes at $2300^{\circ} \mathrm{C}$ essentially all of Group 1, 2, and 3 elements would be released.

This grouping is subject to change as additional experimental data is obtained. For example, the groupings shown in Table 3.2 is a revision of that published previously ${ }^{(18)}$. Cesium has been moved from Group 2 to Group 3, Kr and Xe from Group 1 to Group 2, and Te and I from Group 2 to Group 3. The earlier grouping was based on post-irradiation heating experiments in which the specimens had been irradiated at temperatures up to $2200^{\circ} \mathrm{C}$. Based on other experiments, it appears that at this high irradiation

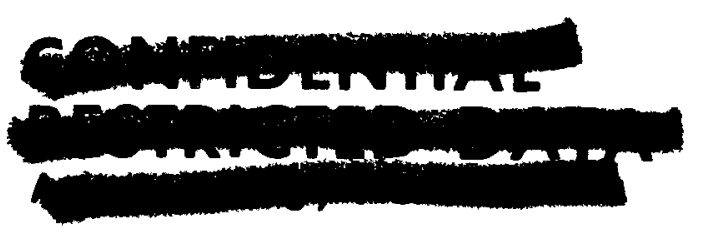


Group No.

1

2

3

4
Elements

$\mathrm{Br}, \mathrm{Rb}, \mathrm{Sr}, \mathrm{Ba}, \mathrm{Sn}, \mathrm{Se}$

$\mathrm{Xe}, \mathrm{Kr}, \mathrm{Sb}, \mathrm{As}$

$$
\text { Ce, Y, La, Cs, Pr, I, Te }
$$

$\mathrm{Zr}, \mathrm{Mo}_{0} \mathrm{Nb}, \mathrm{Ru}, \mathrm{Rh}, \mathrm{Tc}$
$\mathrm{Ba}^{140}, \mathrm{sr}^{89}$

$\mathrm{Ce}^{141,144}, \mathrm{Y}^{91}, \mathrm{Cs}^{137}$,

${ }^{131}, \mathrm{Te}^{124}$

$\mathrm{Zr}^{95}, \mathrm{Mo}^{99}$

Diffusion Rate:

$G p 1>G p 2>G p 3>G p 4$ 


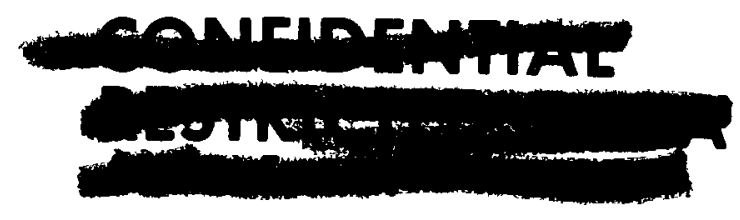

temperature, the pyrographite coating on the $U_{2}$ fuel beads is partially degraded, thereby allowing a greater release of the fission products to the graphite matrix. When these high temperature irradiated specimens were subsequently reheated in the laboratory apparatus, the apparent diffusion rate for several of the nuclides were greater due to the degraded pyrographite coating. The present grouping of Table 3.2 is based on recent post-irradiation heating experiments in which the fuel specimens (Capsules FP-5 and FP-6) had been irradiated in the GETR at temperatures below $900^{\circ} \mathrm{C}$. It was shown that at these lower temperatures, the pyrographite coating remained intact, and the measured lower diffusion rate is more indicative of the fission product retention of the pyrographite coated fuel beads.

\subsection{Analysis of Diffusion Rate Data}

In general the rate expressions applicable in the case of diffusion involve the solution of complex differential equations ${ }^{(20)}$. However, in most cases it is possible to fit empirical equations to the release data which will describe fission product diffusion adequately. This approach has been followed in the present program.

$$
\mathrm{Sr}^{89} \text { and } \mathrm{Ba}{ }^{140}-\text { Below } 2200^{\circ} \mathrm{C} \text { and for time periods }
$$

of 20 minutes or less, the release of $\mathrm{Sr}^{89}$ and $\mathrm{Ba}{ }^{140}$ appears to be a two step process:

Step 1: A fast step from a fraction of the fuel, $\varnothing_{1}$, characterized by a rate constant, $D_{1}$.

Step 2: A slow step from the remaining fraction of the fuel, $\left(1-\phi_{1}\right)$, characterized by a rate constant, $D_{2}$

These two steps can be defined by two exponential functions, and the fraction retained $(1-f)$ in the fuel can be calculated by the equation: 


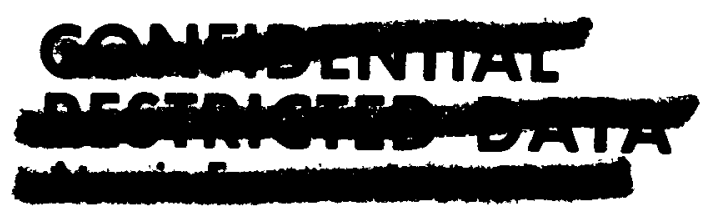

$$
1-f=\phi_{1} e^{-D_{1}{ }^{t}}+\left(1-\phi_{1}\right) e^{-D_{2}{ }^{t}}
$$

$D_{1}$ and $D_{2}$ are apparent diffusion constants with a dimension of reciprocal time. The values $D_{2}$ and $\left(1-\phi_{1}\right)$ are evaluated graphically from the experimentally obtained curves of $\log (1-f)$ vs. time; $D_{1}$ and $\varnothing_{1}$ are then calculated by substitution in the above equation.

$$
\mathrm{Ce}^{144} \text { and } Y^{91} \text { - The diffusion rates of } \mathrm{Ce}^{144} \text { and } Y^{91}
$$

were found to obey a first order rate equation:

$$
1-f=f_{0} e^{-D t}
$$

where:

$$
\begin{aligned}
& f_{0}=\text { fraction of diffusing species initially present }=1.0, \\
& 1-f=\text { fraction retained, } \\
& D \quad=\text { apparent diffusion constant. }
\end{aligned}
$$

The diffusion constant, D, is a function of temperature according to the Arrhenius equation:

$$
D=D_{0} e^{-E / R T}
$$

where:

$$
\begin{aligned}
D_{0} & =\text { Arrhenius frequency factor, } \text { sec }^{-1}, \\
\mathrm{E} & =\text { activation energy, cals/mole, } \\
\mathrm{R} & =\text { gas constant, cals/mole-degree, } \\
\mathrm{T} & =\text { temperature, }{ }^{\circ} \mathrm{K} .
\end{aligned}
$$

Values of $E$ and $D_{0}$ are obtained graphically from a plot of In $D$ vs. $1 / T$. The values of $E$

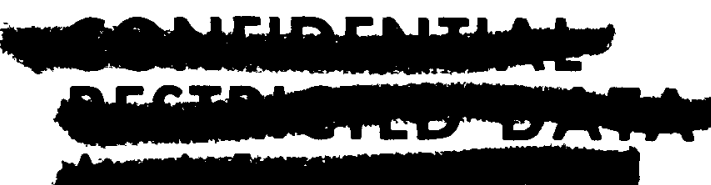


have been found to be in the range of $9-65 \mathrm{~K} \mathrm{cal} / \mathrm{mole}$ and have been interpreted as indicative of the mechanisms of diffusion of $\mathrm{Sr}, \mathrm{Ba}, \mathrm{Y}$, and $\mathrm{Ce}{ }^{(14)}$.

\subsubsection{FIPDIF - A Computer Program for Predicting Fission Product Diffusion}

With the evaluation of diffusion rate equations it is possible to develop a computer program to predict the extent of fission product diffusion occurring under a variety of operational and post-operational conditions. Work is presently in progress to develop an IBM 7094 computer program known as FIPDIF. This program will calculate the inventroy of 273 isotopes in a NERVA core and the diffusion of these isotopes under any combination of the following conditions:
a. Normal operation
b. Normal cooldown
c. Accidental loss of coolant
d. Nuclear excursion.

It is expected that FIPDIF will replace FPIP in the source term evaluation studies, resulting in a more accurate estimate of radiological hazards involved in the ROVER Flight Safety Program.

The basic difference between FIPDIF and FPIP as described in WANLTME-537 lies in the fact that FPIP is concerned only with the rate of change of fission product concentration as a function of fission yield and fission product decay, while FIPDIF includes these factors as well as fission product loss from diffusion. Thus, in FIPDIF, for the following radioactive decay scheme:

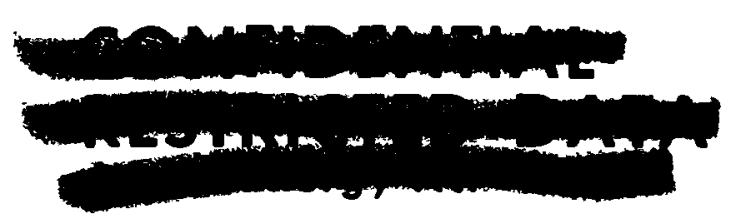



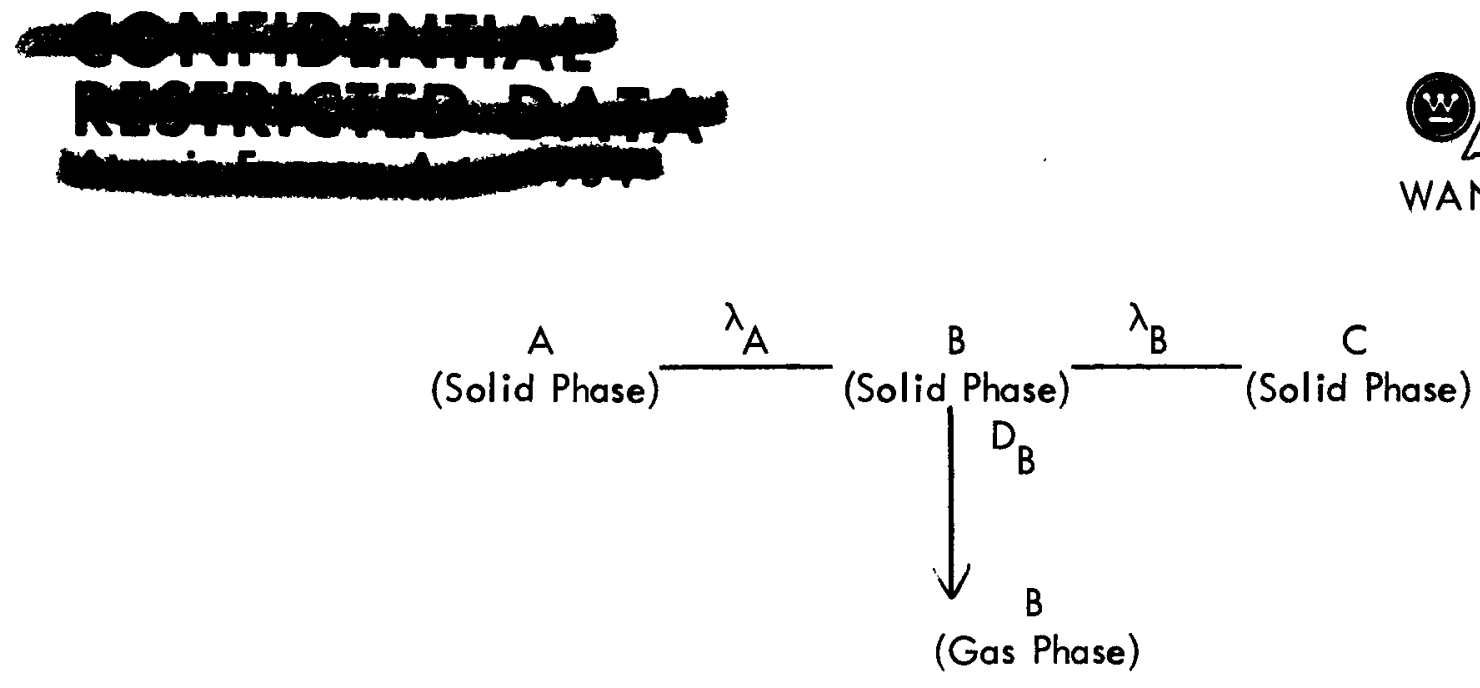

the concentration of nuclide $B$ in the fuel may be represented by the following differential equation:

$$
\frac{d(B)}{d t}=Y_{B} a+\lambda_{A}(A)-\lambda_{B}(B)-D_{B}(B)
$$

where:

$$
\begin{array}{ll}
Y_{B} & =\text { the direct fission yield of isotope (B), } \\
\alpha & =\text { the operating power level, } \\
\lambda_{A} & =\text { the disintegration constant of isotope } A \\
\lambda_{B} & \text { the disintegration constant of isotope } B \\
D_{B} & =\text { the diffusion constant for isotope } B
\end{array}
$$

(A) \& (B) = the atomic number densities of isotopes A \& B, respectively.

Since the diffusion constant $D_{B}$ is a function of temperature, it is necessary to use temperature as an input quantity to the program.

In using FIPDIF the core will be divided into a number of sections in each of which the temperature is essentially constant. Diffusion parameters will be calculated for each of the four categories of isotopes, (listed in Table 3.2) corresponding to the fuel

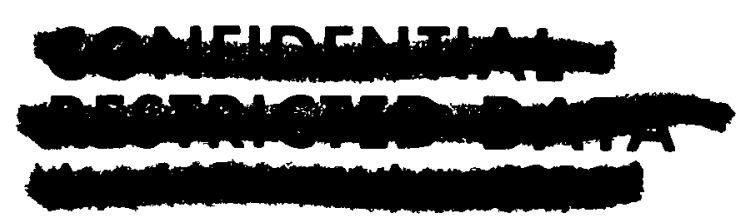



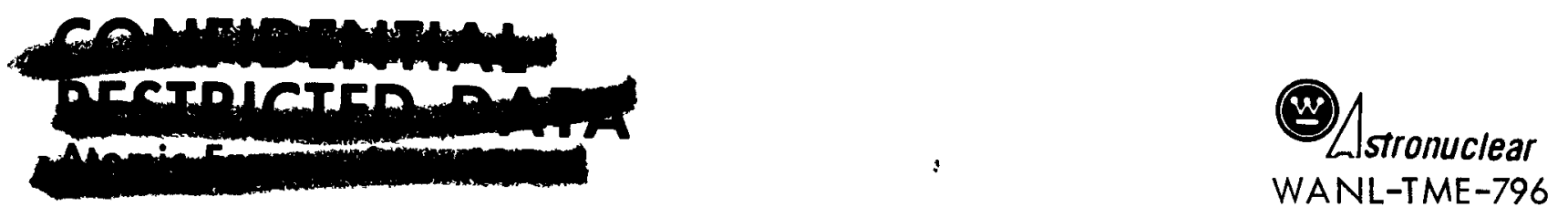

temperatures in each of the core sections. The following approaches will be used for each of the operational modes already mentioned.

(1) In the case of normal operation, a previously computed temperature distribution will be input to the program, it will be assumed that the temperature of the core section will remain constant throughout the running time.

(2) A normal cooldown will be approximated by a series of time increr ments. In each one of these time increments the temperature of the sections will be assumed constant, and the same assumptions will be applied as those used during the normal operation phase. New diffusion parameters will be calculated for each time step corresponding to the temperature at that time.

(3) In the case of accidental loss of coolant, the temperature in the core sections will be determined by calculating rates of decay heat production and dissipation of heat to the atmosphere by use of the $N \varnothing F L \varnothing W$ program discussed in Section 3.1.3.2.1. The rate of decay heat production will be calculated directly from the fission product decay energies and will be reduced as fission products diffuse,

(4) The effects of a nuclear excursion will be approximated by step changes in the integrated power and fission product inventories. 


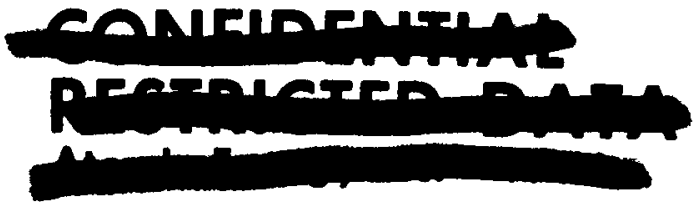

The resulting temperature increases and vapor generation will be determined and and fission product diffusion will be calculated as in the case of loss of coolant. (A description of the proposed use of FIPDIF in the WANL nuclear excursion analysis program is reported in Reference 21.$)$

\subsubsection{Estimates of Diffusion for Different Modes of Reactor Operation}

Although an accurate evaluation of the extent of fission product diffusion occurring under operational and post-operational conditions depends upon the use of FIPDIF, it is possible to estimate these values if one has a knowledge of (1) fuel temperatures and (2) fission product release rates.

\subsubsection{Normal Operation}

The axial temperature profile of the core during normal power operation is reported in Volume III of WANL-TNR-128 ${ }^{(15)}$. Based on the statistical analysis for hot channel factors in the core, the temperature of a number of the fuel elements will exceed the nominal value. Figure 3.7 shows the normal temperature profile, the temperature profiles for those elements exceeding the nominal value, and the fraction of the core in which these excess temperatures exist. It can be seen from this figure that about $15 \%$ of the fuel elements will reach temperatures of $2200^{\circ} \mathrm{C}$ or greater near the ouflet of the core.

To establish the core inventory of fission products remaining at the completion of a mission, during which the reactor was operated under normal power conditions, the total release of all fission products from the core must be estimated. The fission

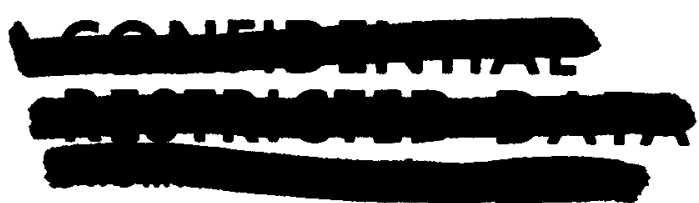




\section{4}

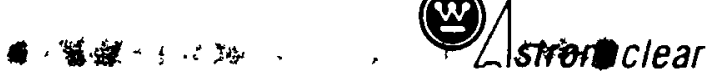

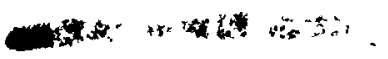

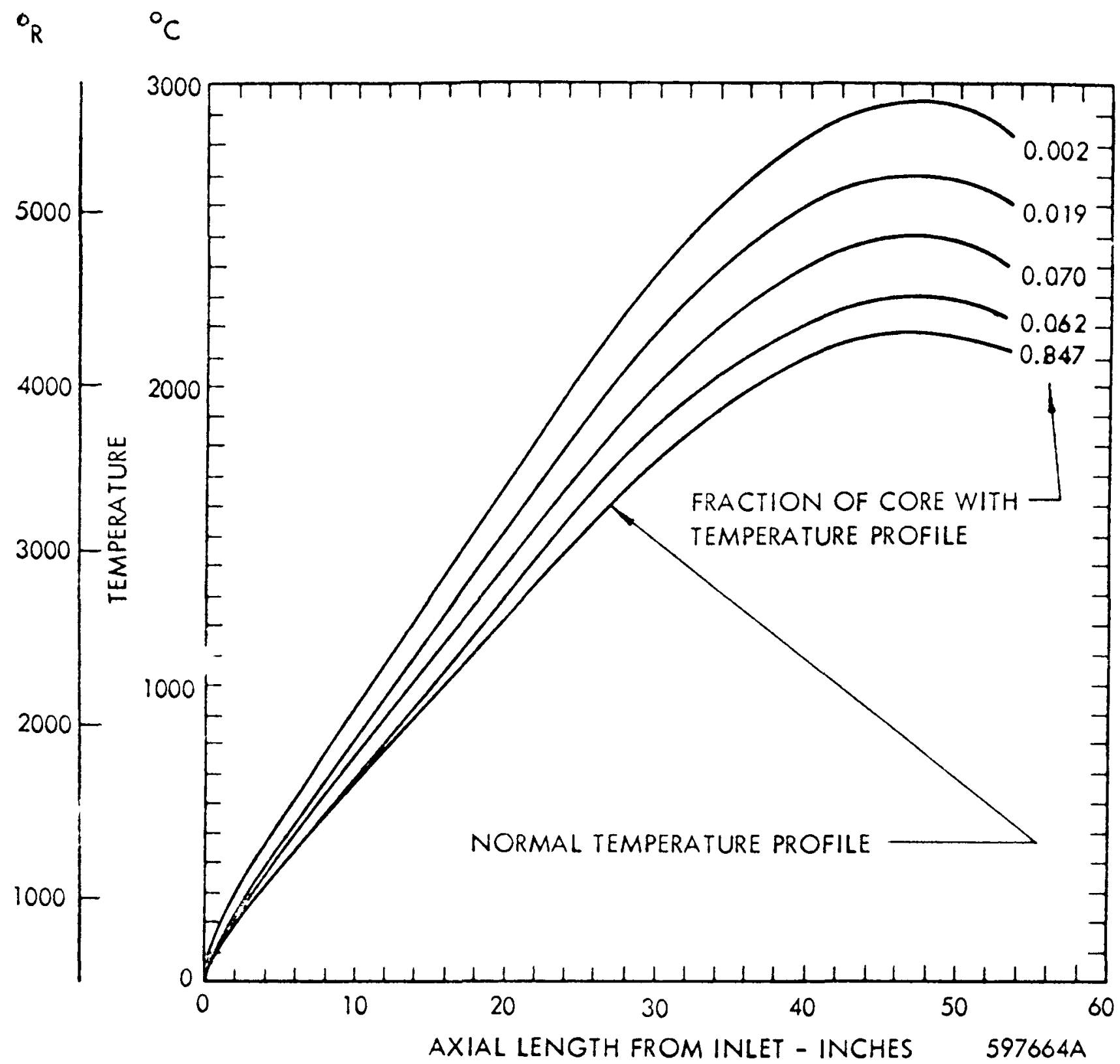

FIGURE 3.7 AXIAL TEMPERATURE DISTRIBUTION FOR COOLANT CHANNELS 

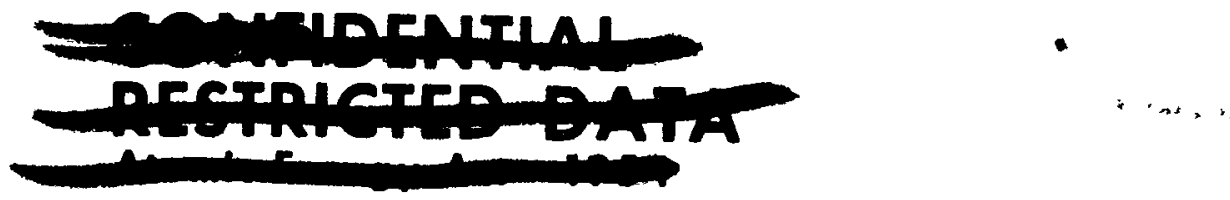

product loss from any section of the reactor core is dependent on the local temperature of the section and the relative power density in the section. The total loss from the core is found by appropriate averaging of these parameters over all sections. An estimate of the effective fractional release from the core for five minutes full power operation has been made to evaluate the hazards associated with the ground testing of the NRX reactors ${ }^{(22)}$. This estimate was based on the following assumptions and calculations:

(1) The axial temperature distribution across the core is that represented by Figure 3.7.

(2) Relative power density is equal to that calculated for the axial power distribution as shown in Figure 8.31 of WANL-TNR-128, Volume $1{ }^{(15)}$.

(3) The core was divided into seven temperature ranges, and the fraction of fission products released in each group in each temperature range is in accordance with the data of Figures 3.5 and 3.6 and the groupings of Table 3.2.

The calculated effective release fractions are given in Table $3.3^{(22)}$. These results indicate that less than $3 \%$ of the total core inventory of fission products will be released during a five-minute full power run. The rate data used in making this estimate had been determined in the WANL experimental diffusion program (Section 3.1.2.1). These data were obtained for small segments of NERVA fuel. Since the present estimate refers to an entire core with $3 / 4$ inch hexagonal fuel rods having nineteen 0.095 inch diameter coolant channels coated with $\mathrm{NbC}$, it is expected that $3 \%$ release evaluation is an overestimate. It is expected that
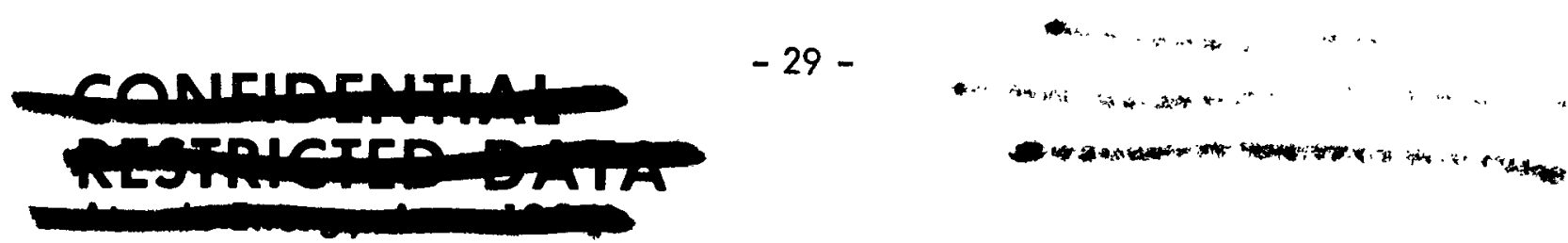


\section{TABLE 3.3}

\section{EFFECTIVE RELEASE FRACTIONS OF FISSION PRODUCT ISOTOPES FROM}

THE NRX REACTOR DURING FIVE MINUTES NORMAL OPERATION

Isotopes*

$\mathrm{Zn}, \mathrm{Ga}, \mathrm{Ge}, \mathrm{As}_{\mathrm{s}} \mathrm{Se}, \mathrm{Br}, \mathrm{Kr}, \mathrm{Rb}, \mathrm{Sr}$,

$Y(89 m, 90,91 \mathrm{~m}, 91,92,93,94,95), \operatorname{Zr}(93,95)$,

$\mathrm{Nb}(93 \mathrm{M}, 95 \mathrm{~m}, 95), \mathrm{Ag}, \mathrm{Cd}, \mathrm{In}, \mathrm{Sn} \mathrm{Sb}, \mathrm{Te}, \mathrm{I}$,

$X e\left(131 m_{p} 133 \mathrm{~m}, 133,135 \mathrm{~m}, 135\right), \mathrm{Cs}, \mathrm{Ba}(137 \mathrm{~m}, 139,140,142)$

La $(140,142) E_{U}, G d, T b$

$\operatorname{Pd}(107,111 \mathrm{~m}, 112,113,114,115), \operatorname{La}(141,143)$

$1.3 \times 10^{5}$

0.022

Xe $(137,138,139,140)$, Ba $(141,143)$, La $(141,143)$

Ce $(141,143), \operatorname{Pr}(143) \mathrm{Sm}(151,153,155,156)$

$Y(96,97), \operatorname{Zr}(97), \operatorname{Ru}(106), \operatorname{Rh}(106)$

$0.6 \times 10^{5}$

0.013

Pd (109m, 109), La (144), Ce (144, 145, 146, 147)

$\operatorname{Pr}(144,145,146,147,148,150), \mathrm{Nd}, \mathrm{Pm}$

$\operatorname{Zr}(98,99), \mathrm{Nb}(97 \mathrm{~m}, 98,99,100,101), \mathrm{Mo}, \mathrm{Tc}$

0

0.000

$\operatorname{Ru}(103,105,107,108)$,

$\operatorname{Rh}(103 \mathrm{~m}, 105 \mathrm{~m}, 105,107,108,109 \mathrm{M}, 109,110)$

* If particular isotopes are not indicated, all isotopes of the element are considered to have the same release fraction. 

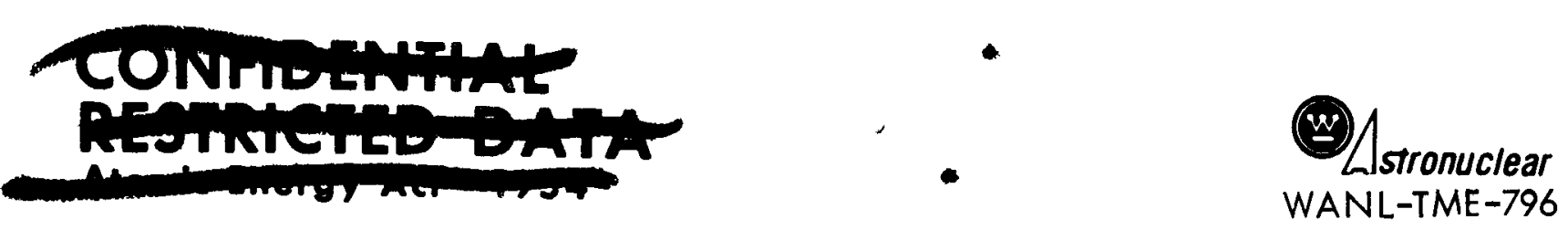

the loss of fission products will be decreased with the use of full size elements and when the $\mathrm{NbC}$ coating is present to act as a barrier.

With increased operating time, the total fission product release will, of course, be greater. However, because of the relatively small fraction of the fuel at higher temperatures, and the low power density at these high temperatures, the increase in release with increased operating time will not be very large. It is conservatively estimated that for 20 minutes full power operation, a maximum of $5 \%$ of the total core inventory of fission products will be released.

For evaluation of the radiological hazard following a space mission and re-entry of the NERVA reactor, the fission product inventory at ground impact must be known. In the case of orbital start of the NERVA reactor, with operating times in excess of 20 minutes at full power, escape velocity is attained and re-entry need no longer be considered. For operating periods less than 20 minutes, the inventory will be at least $95 \%$ of the theoretical inventory, had no diffusion taken place. Estimates of biological dose gind dose rate calculations based on a source activity known within $5 \%$ accuracy are considered acceptable. Thus, the conclusion can be made that for evaluation of the source term upon re-entry of the reactor or of core fragments, loss of fission products from the core by diffusion during normal power operation can be neglected.

\subsubsection{Reactor Shutdown with Loss of Coolant}

\subsection{Analytical Evaluations}

Following normal power operation, hydrogen coolant is

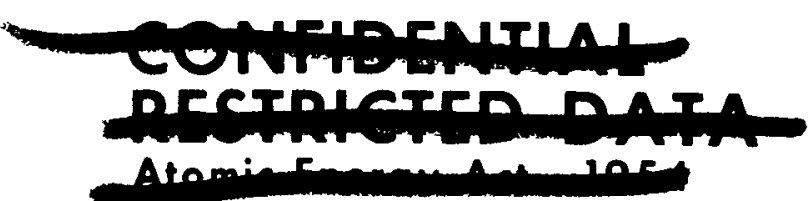


maintained during shutdown to remove gamma decay heat. If flow of coolant to the core should be lost immediately after shutdown, very high temperatures will be reached. If sufficiently high temperatures were attained, loss of fission products by diffusion will occur. The axial temperature profiles for the core and for reactor core components have been calculated for such a loss of coolant situation following each of several different reactor full power operating periods. These temperatures were calculated using the TNT (Thermal and Nuclear Transient) computer program. A description of the TNT program capabilities has been reported in WANL-TNR-128, Volume $111^{(15)}$. A detailed description of the reactor model used for these calculations, material properties incorporated, and the analytical method for distributing power to the components in core regions is reported in WANL-TME-483 ${ }^{(23)}$. Results of two such calculations are shown in Figures 3.8 and 3.9. Figure 3.8 shows the axial temperature profile for the fuel elements at periods of five seconds up to 90 seconds, following reactor shutdown after one minute of full power operation. Figure 3.9 shows the axial tie rod temperature profile for similar shutdown periods after one minute of power operation. These curves were based on the present TNT computer program which does not include provision for heat losses due to melting or vaporization of the component materials. These changes of phase must be considered for these loss of coolant cases, as Figures 3.8 and 3.9 show, to determine the temperature accurately. The core temperatures predicted (up to $8000^{\circ} \mathrm{R}$ or $4170^{\circ} \mathrm{C}$ ), should result in appreciable mass loss in the core due to sublimation of fuel $l_{p}$ and due to melting and vaporization of structural components, for example the tie rods. As a result the temperatures shown in Figures 3.8

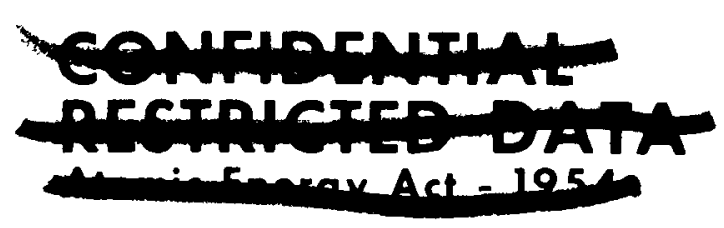



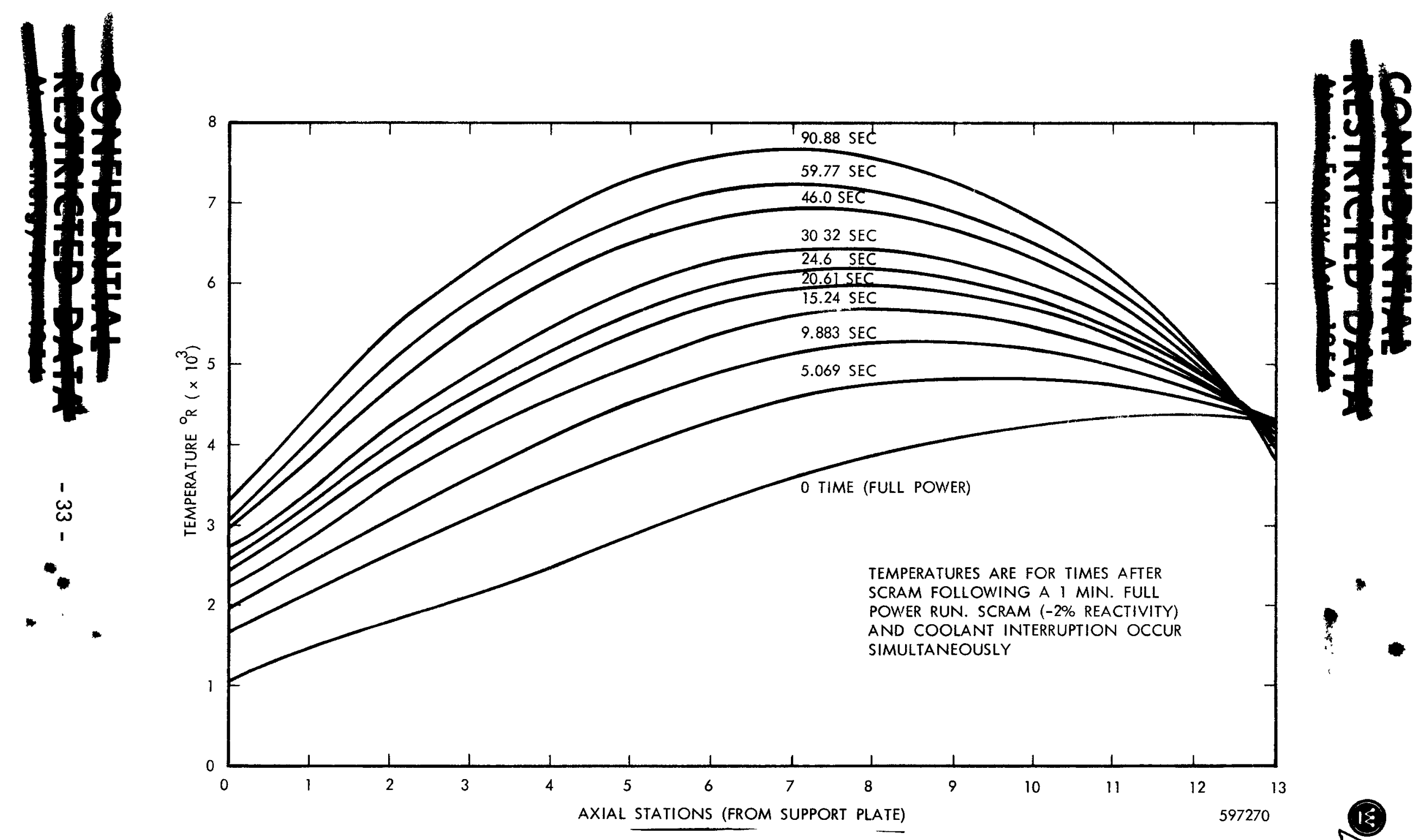

FIGURE 3.8

AVERAGE FUEL ELEMENT (CORE) TEMPERATURE

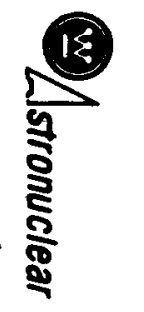



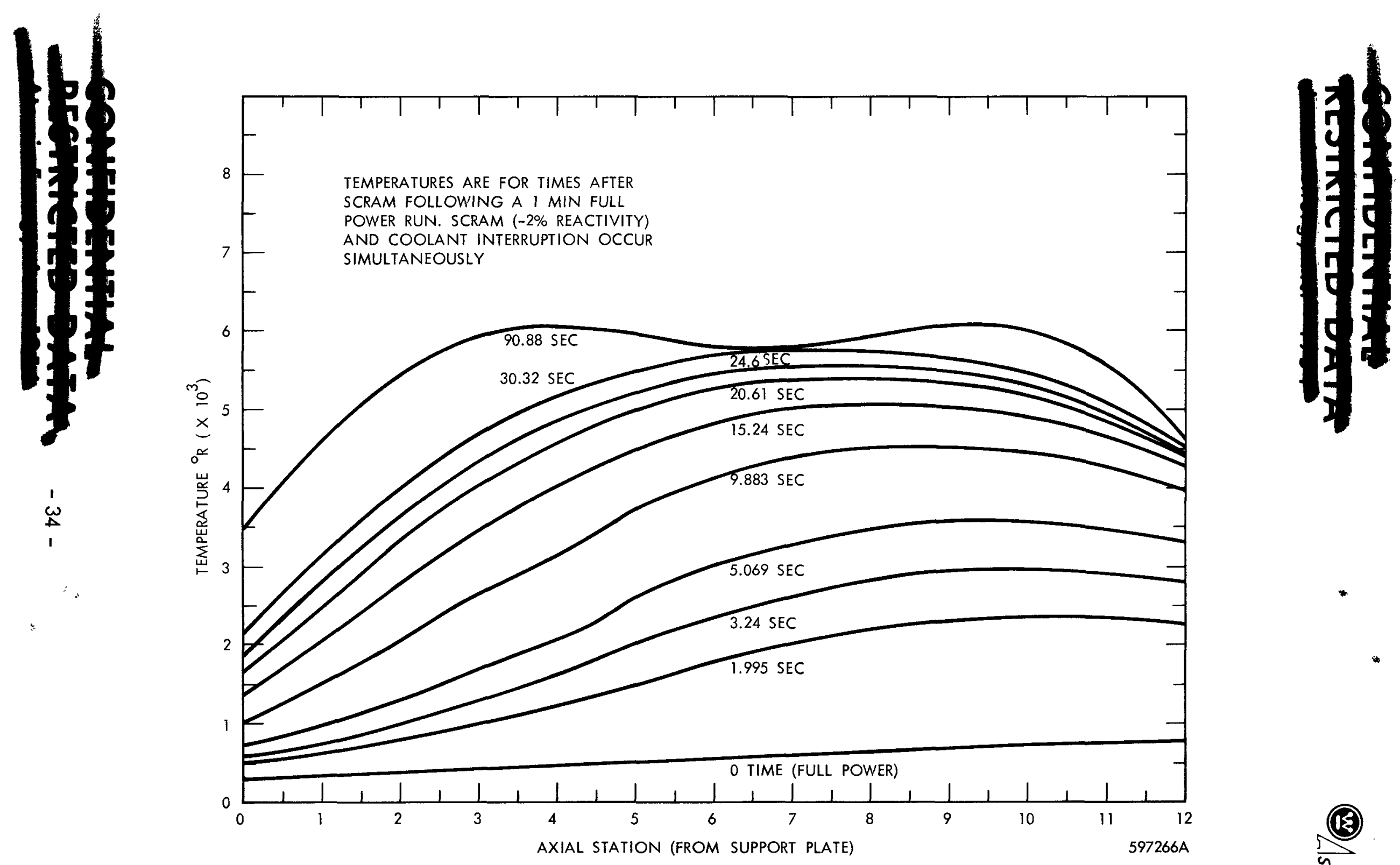

FIGURE 3.9 AVERAGE TIE ROD TEMPERATURES 

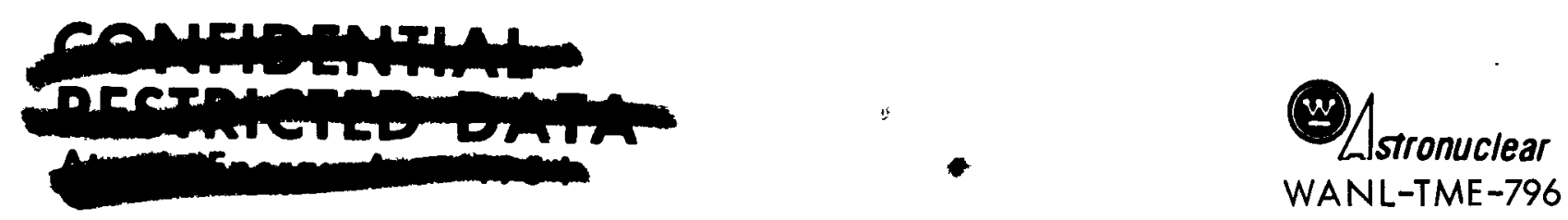

and 3.9 are undoubtedly too high. To obtain more accurate estimates of core temperatures upon loss of coolant, a new computer program is being developed. This program, called $N \varnothing F L \varnothing W$, will consider the change of phase properties of the core materials.

At these high temperatures the diffusion rate of fission products most certainly will be very rapid. This introduces a complication into the computer program, in that the heat source is being continuously diminished by the mass loss of fuel and the loss of fission products due to diffusion and sublimation. Provisions for estimating the decay heat power from a continuously reducing heat source will be included in the

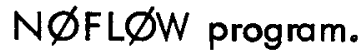

\subsection{Experimental Evaluations}

A preliminary experiment has been performed in order to estimate the gross release of fission products from fuel that is subjected to very high temperatures, such as might occur during a loss of coolant accident. NERVA fuel specimens, the same size as used in the diffusion experiments described earlier, were irradiated at the Westinghouse Reactor Evaluation Center at ambient temperature. These specimens were then subjected to a temperature of $2700^{\circ} \mathrm{C}$ for three minutes in a vacuum of $10^{-4} \mathrm{~mm} \mathrm{Hg}$ within two hours after irradiation time.

Duplicate samples showed a $74.1 \%$ and $67.5 \%$ gross release in gamma activity. The samples showed no apparent physical damage, and no detectable mass loss. Since only gross gamma activity was measured, loss of beta emitting fission products would not have been detected. Certainly at these temperatures essentially 


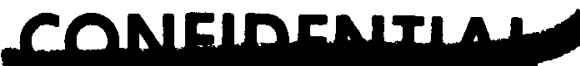 \\ astroctons}

Atomina

100\% release should have been obtained for Group 1 and Group 2 elements. It seems likely that the total release fraction for all isotopes in the fuel sample was about $80 \%$. The remaining $20 \%$ of the activity would be due to the elements of Group 4. Many of these elements, such as molybdenum, zirconium, and niobium form carbide refractory materials which have melting points of $2700^{\circ} \mathrm{C}$ and higher. These materials have low vapor pressure, and would not diffuse appreciably at $2700^{\circ} \mathrm{C}$. If higher temperatures were reached, such as those shown in Figure 6, the total release certainly should be greater. Such additional loss of fission products would be due not only to increased diffusion but additional reduction in activity due to sublimation of the material.

\subsection{Conclusions}

From re-entry safety considerations, shutdown without coolant flow following completion of the mission has merit. The resulting high temperatures would then significantly decrease the fission product inventor $y_{\theta}$ thereby reducing the radiological hazard upon re-entry of the reactor or of the core fragments. Further study on this point is required. One disadvantage must also be considered. At these high temperatures the structural members of the core, such as the tie rods, would fail or melt with the possibility of core fuel elements or fragments then being released into space. These fragments would then have a faster re-entry time in comparison with the intact reactor, and, as a consequence, a higher fission product inventory upon earth impaction will result. In order to determine the advisability of utilizing post-operational heat to enhance NERVA safety, 

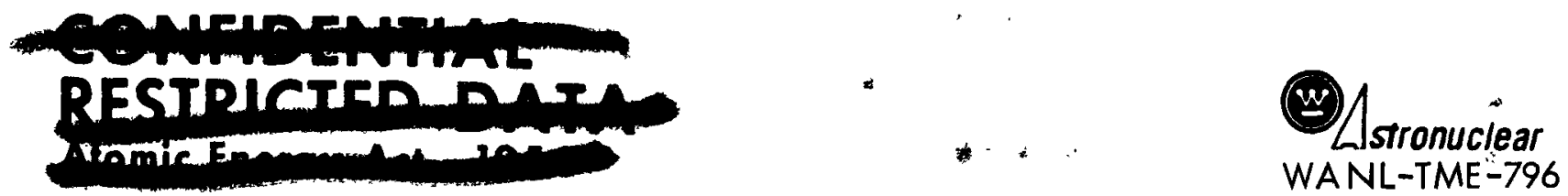

it will be necessary to weigh the advantages gained by fission product diffusion with the disadvantages associated with the shorter space residences of fuel elements and fragments.

\subsubsection{Reactor Excursions}

An alternative method that has been suggested for reducing the hazard of a radioactive NERVA engine returning to earth is to use nuclear destruct at mission completion. This destruct action permits the reactor to go on a nuclear excursion, thereby fragmenting and/or vaporizing the core. A possible disadvantage of such action arises from the increase of fission product inventory due to the excursion if insufficient loss of fission products occurs through vaporization or diffusion processes. In order to determine the approximate magnitude of fission product release during an excursion, NERVA fuel samples were irradiated in the TREAT reactor after a substantial inventory had been accumulated in the samples by irradiation in the GETR.

\subsection{Experimental Evaluation}

A complete description of these TREAT irradiations of NERVA fuel has been reported in WANL-TME-637 ${ }^{(24)}$. A brief description of these experiments is given here. First, samples of NERVA fuel were irradiated in GETR and allowed to decay for two months. These samples were then subjected to transient irradiation energies of 177, 451, and 806 megawatt seconds in the TREAT reactor. The transient radiation energies pertain only to the TREAT reactor. Equivalent NERVA fuel energies would be higher than these values, perhaps as much as a factor of 12 greater. Temperatures achieved during the irradiations were $1250^{\circ} \mathrm{C}$ for the 177 megawatt-second irradiation, $2200^{\circ} \mathrm{C}$ for
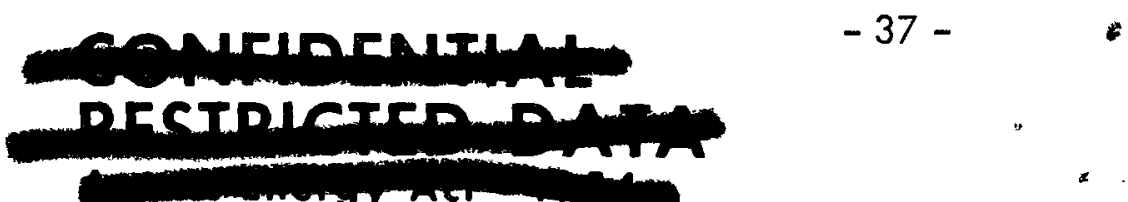
the 451 mws irradiation, and approximately $3000^{\circ} \mathrm{C}$ for the $806 \mathrm{mws}$ irradiation. Each irradiation was accomplished in approximately one second. The samples were measured for gross change in gamma activity and were analyzed radiochemically to determine specific nuclide diffusion losses.

The gross gamma activity increased for the first two irradiations by $4 \%$ and $10.7 \%$, respectively. For the third irradiation 806 mws $_{g}$ the gamma activity decreased by $6.4 \%$. The release fractions for various nuclides, as determined by radiochemical analysis, are summarized in Table 3.4. As can be seen from the table, some losses of $\mathrm{Ba}^{140}, \mathrm{Sr}^{89}$, and $\mathrm{Cs}^{137}$, occurred during the first two lower temperature irradiations, but with no loss of $\mathrm{Zr}^{95}, \mathrm{Y}^{91}$, and $\mathrm{Ce}^{144}$. During the 806 mws irradiation there was release of all nuclides, as reported, with the exception of $Y^{91}$. Substantial losses obtained for $\mathrm{Sr}^{89}, \mathrm{Ba}^{140}$, and $\mathrm{Cs}^{137}$ are, of course, not reflected in the gross gamma activity loss. This is true since the activity of these three nuclides represents only a small portion of the total activity present. Calculations show that these three elements comprise about $13.7 \%$ of the activity in the sample prior to the TREAT irradiation. A $50 \%$ reduction of these elements comprise about only $7 \%$ reduction in the gross activity, which is in qualitative agreement with the $6.4 \%$ value obtained by gross measurement.

\subsection{Conclusions}

Results of these TREAT excursions cannot be extrapolated completely to the results that would be obtained in a NERVA excursion. However, it appears that the temperatures obtained may not be sufficiently high or have a sufficiently long time 


\section{TABLE 3.4}

FRACTIONAL RELEASE OF FISSION NUCLIDES DURING TRANSIENT IRRADIATION IN TREAT

TREAT TRANSIENT

IRRADIATION ENERGY

MEGAWATT SECONDS

806
TEMPERATURE

(Deg. C)

2200

$\approx 3000$

50
$\mathrm{Ba}^{140} \mathrm{Sr}^{89}$

$C_{s}{ }^{137}$

$\mathrm{Zr}^{95}$

$Y^{91}$

$C e^{144}$

0.08

0.005

0.0175

0.00

0.00

0.00

0.164

0.109

0.0180

$0.086 \quad 0.00$

0.00

1
1
1

0.558

0.595

0.619

0.086

0.00

0.187 


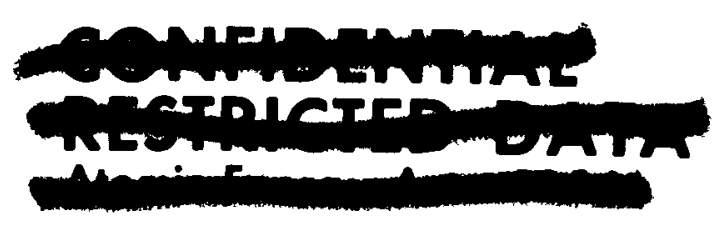

duration to give a significant reduction in the total fission product inventory. It therefore appears that a nuclear destruct may be inadequate as a method for reduction of the radioactive hazard with respect to reducing the fission product inventory by a diffusion mechanism.

\subsubsection{Diffusion During Re-Entry}

During re-entry, core fragments may reach temperatures in excess of $3200^{\circ} \mathrm{R}$ $\left(1500^{\circ} \mathrm{C}\right)$ due to aerodynamic heating. These fuel fragments will lose mass on re-entry due to oxidation (burn-up), resulting in a decrease in fission product activity proportional to the mass loss. However, the question arises-- are the particles at these high temperatures for a sufficiently long period to cause additional loss of fission products by diffusion.

\subsubsection{Analytical Evaluation}

To determine typical temperatures reached during the re-entry of core fragments, parametric studies were run using the Westinghouse NERO D-4 (WEREC) computer program. The WEREC computer code has been described in WANL-TNR-135 ${ }^{(25)}$. (A modified version of this code has been incorporated in the Source Term Computer Program, Volume II of this report.) In these parametric studies the fuel fragments were assumed to have an initial temperature of $4000^{\circ} \mathrm{R}$, and were assumed to re-enter from an initial altitude of 400,000 feet with variable initial velocities and initial re-entry angles.

The re-entry temperatures vs. the time at temperature for 1 " and $1 / 4^{n}$ spherical fuel particles are plotted in Figures 3.10 and 3.11 , respectively. Re-entry temperatures of particles of $1 / 8^{\prime \prime}$ and smaller were investigated, but their temperatures did not reach $3200^{\circ} \mathrm{R}$ upon re-entry. The time shown on these graphs is the time during which 

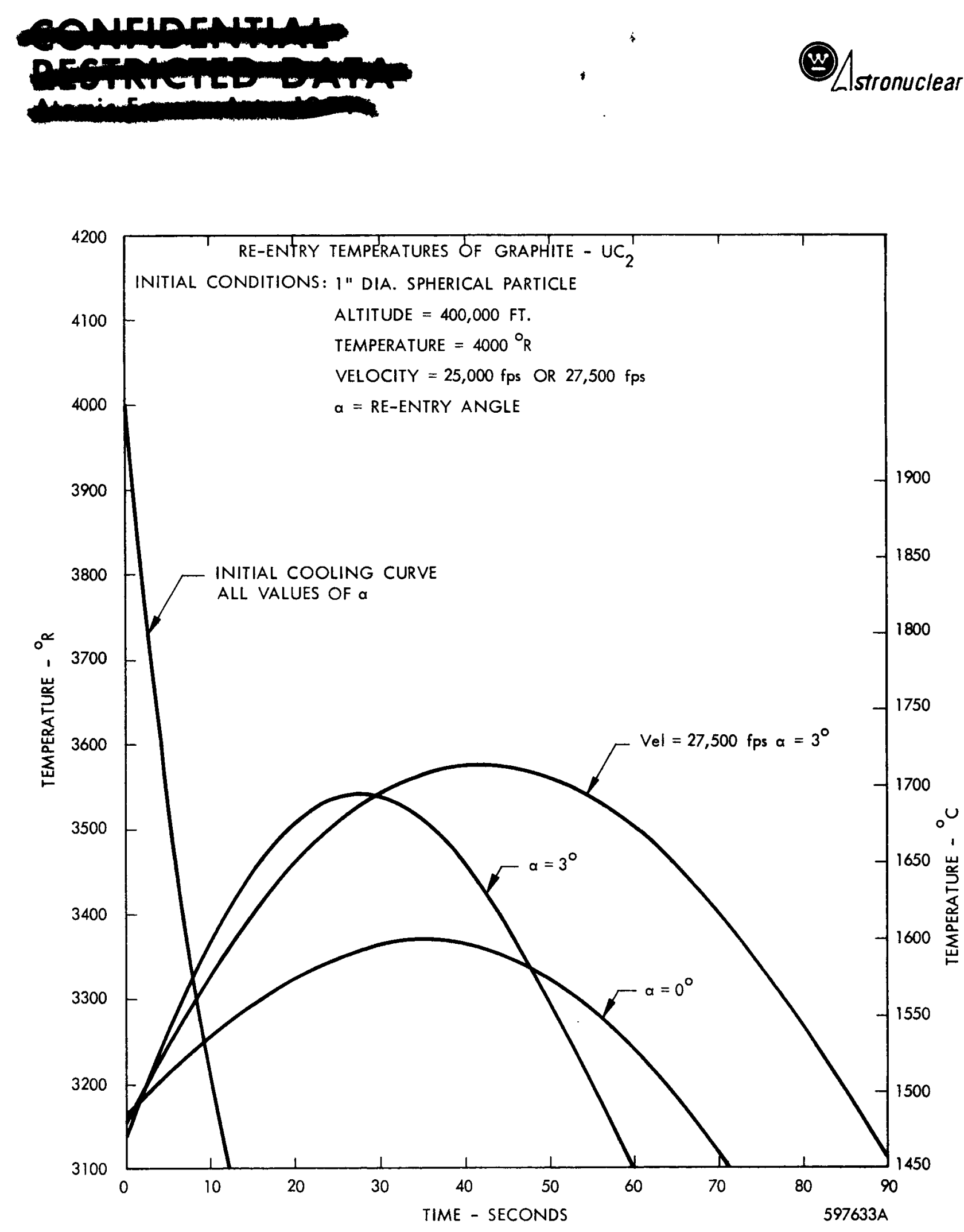

FIGURE 3.10

RE-ENTRY TEMPERATURES OF GRAPHITE - UC

(ONE INCH PARTICLE)

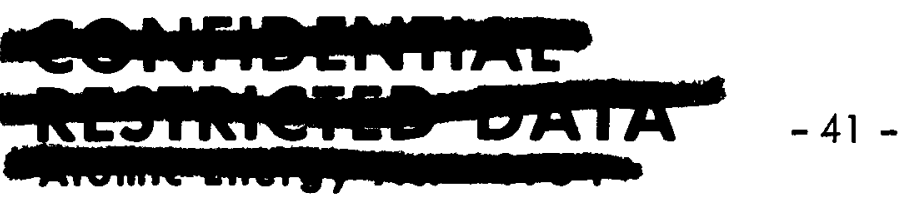




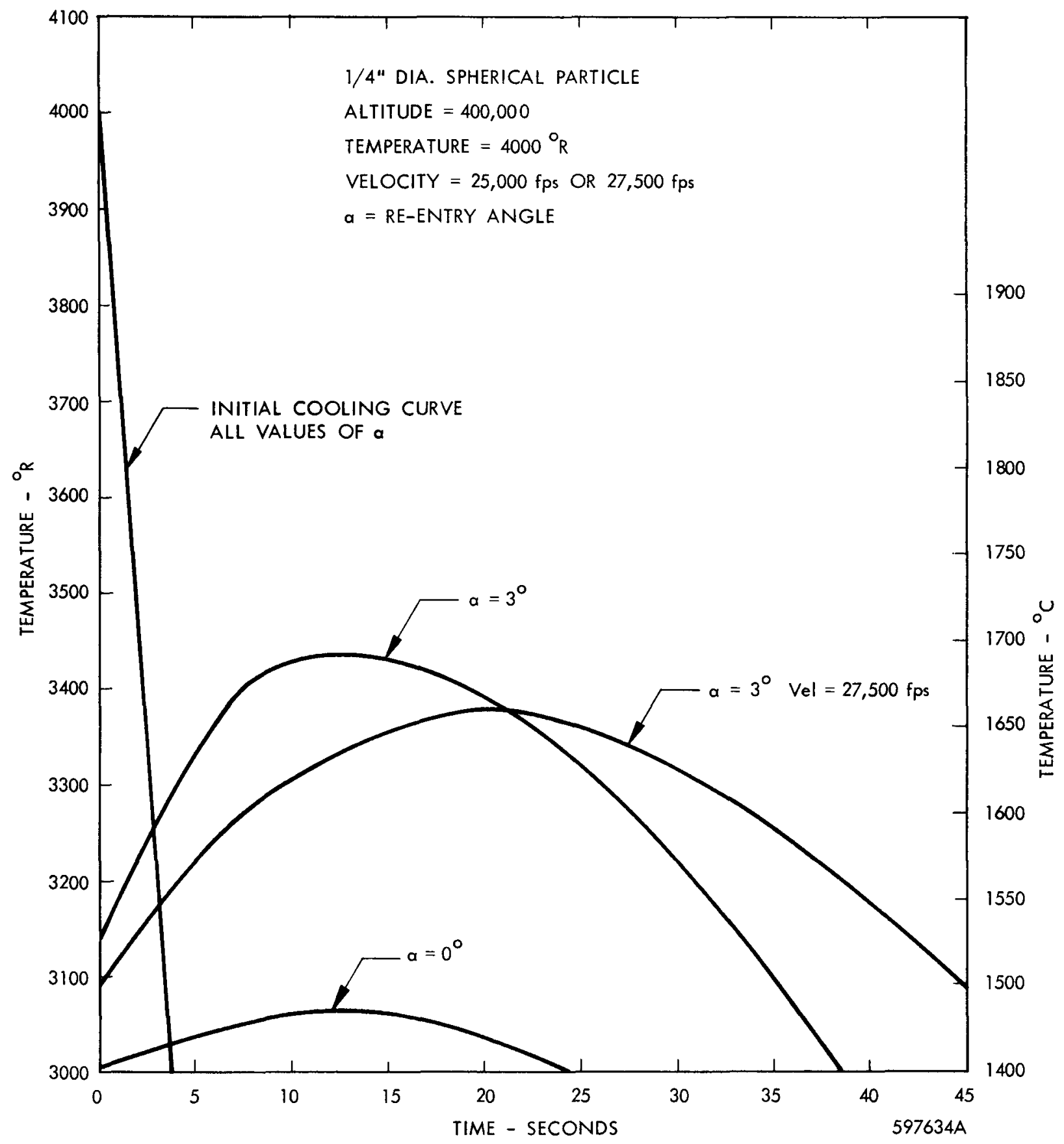

RE-ENTRY TEMPERATURES OF GRAPHITE $-\mathrm{UC}_{2}$

FIGURE 3.11 RE-ENTRY TEMPERATURES OF GRAPHITE - UC

(ONE-QUARTER INCH PARTICLE) 
the particles were at temperatures above $3000^{\circ} \mathrm{R}$, not the time measured from the start of re-entry. The temperatures plotted have been reached after initial cooldown from $4000^{\circ}$, followed by re-heating when the particle enters the denser atmosphere. The re-entry angles shown were limited to $3^{\circ}$, as this would be expected to be about the maximum resultant reentry angle of a particle formed from destruct action of the core with the reactor in a circular orbit. Initial re-entry angles up to $10^{\circ}$ were checked in the parametric study. At a steeper initial re-entry angle a higher temperature is reached, but the re-entry time at this temperature is considerably shorter. For example, with a 1 " particle and an initial reentry angle of $10^{\circ}$, the total time above $3200^{\circ} \mathrm{R}\left(1500^{\circ} \mathrm{C}\right)$ is approximately 30 seconds. The temperature is above $3600^{\circ} \mathrm{R}\left(1725^{\circ} \mathrm{C}\right)$ for a time of only 15 seconds. It would be predicted from these curves that although temperatures as high as $3650^{\circ} \mathrm{R}\left(1750^{\circ} \mathrm{C}\right)$ can be reached for a 1" particle, the length of time at these temperatures is too short to produce any significant loss of fission products by diffusion.

\subsubsection{Experimental Evaluation}

Experimental studies have verified these analytical results ${ }^{(26)}$. Irradiated NERVA fuel samples were tested in a plasmajet facility to simulate re-entry conditions. The specimens were irradiated in capsules FP-5A and FP-5A' in the GETR. The plasmajet test procedure has been described in detail in Reference 27 . The re-entry conditions simulated are summarized in Table 3.5. Figure 3.12 shows the relationship between mass loss and gamma activity loss for all specimens. This figure shows that for all specimens the mass loss was greater than the activity loss. Specific activity measurements before and 


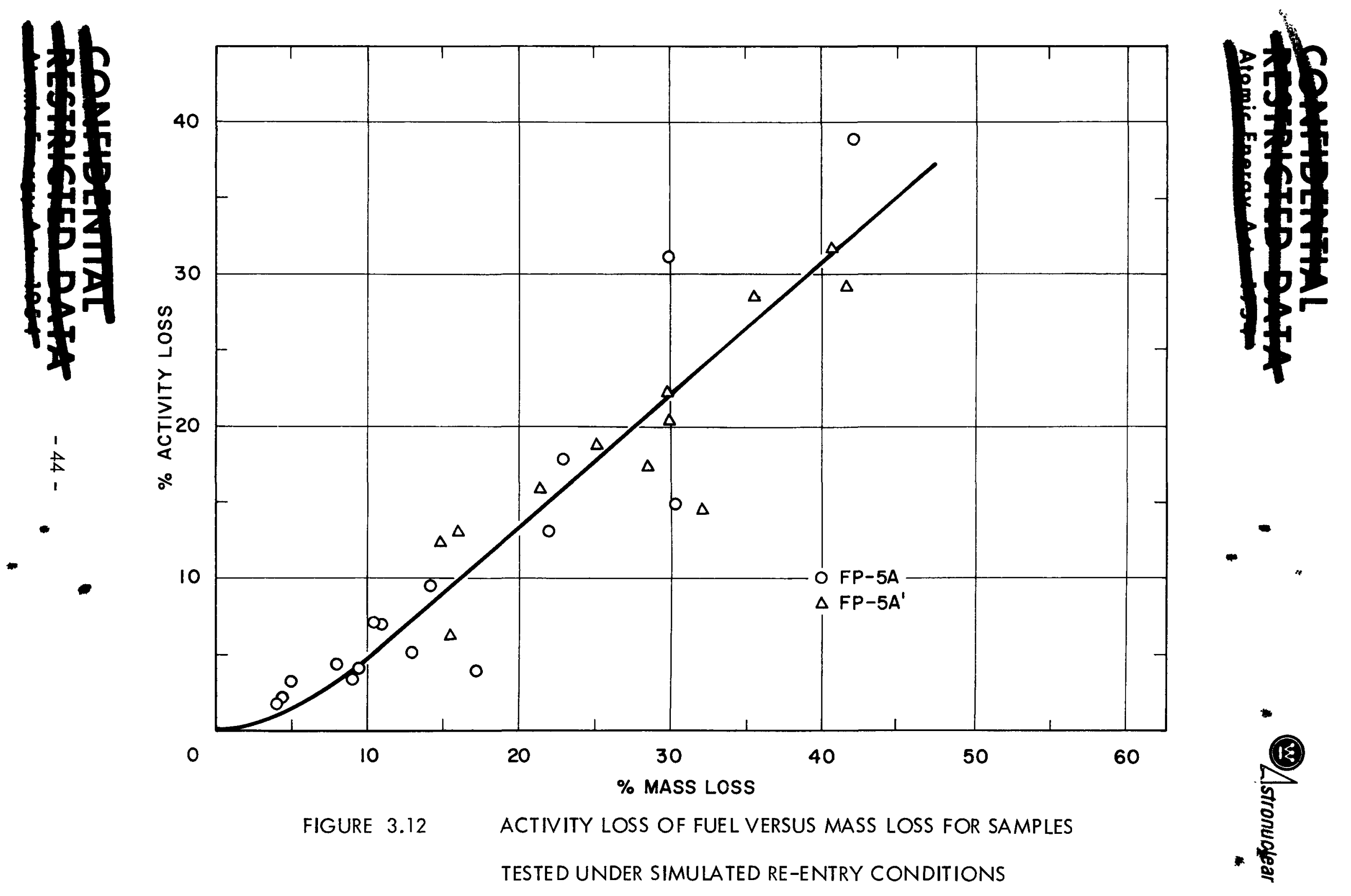




\section{TABLE 3.5}

\section{RE-ENTRY CONDITIONS SIMULATED IN THE INVESTIGATION OF BURNUP BEHAVIOR OF IRRADIATED NERVA FUEL}

\begin{tabular}{cccccc}
$\begin{array}{c}\text { Test } \\
\text { Point }\end{array}$ & Flow Regime & Altitude (ft.) & Velocity (ft./sec) & $\begin{array}{c}\text { Surface } \\
\text { Temperature }{ }^{\circ} \mathrm{C}\end{array}$ & $\begin{array}{c}\text { Time* } \\
(\mathrm{Sec} .)\end{array}$ \\
\hline 11 & Continuum & 250,000 & 25,000 & $2075 \pm 15$ & 30 \\
9 & Transition & 250,000 & 18,000 & $1005 \pm 50$ & 245 \\
1 & Continuum & 200,000 & 11,250 & $1150 \pm 25$ & 26 \\
14 & Continuum & 200,000 & 8,000 & $885 \pm 38$ & 228 \\
12 & Continuum & 150,000 & 6,000 & $915 \pm 20$ & 100
\end{tabular}

Time refers to the maximum time at which the particle was held at temperature. 

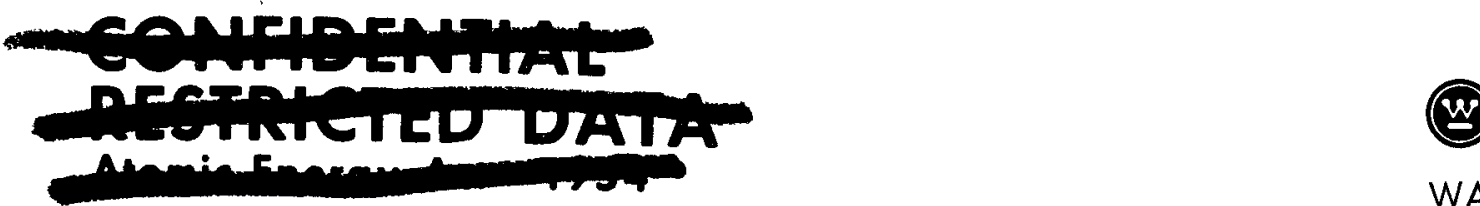

after the plasmajet tests reveal that the specific activity of the specimens (gross activity divided by mass of specimen) remained relatively constant. Since there was a loss in mass this would indicate the possibility of non-uniform distribution of the $\mathrm{UC}_{2}$ beads within the fuel, with the mass loss primarily due to oxidation of unfueled graphite. Since the mass losses in all cases were greater than the activity losses ${ }_{g}$ it was concluded that no fission product diffusion occurred under the test conditions.

\subsubsection{Conclusion}

It is concluded from the above data that further loss of fission products by diffusion during the re-entry of core fragments is negligible. Consequently, in calculating the source term and evaluating the radiological hazard upon re-entry of NERVA fuel, loss of fission products by diffusion during re-entry has been neglected.

\subsection{RE-ENTRY BURNUP OF FUEL MATERIALS}

Another means of reducing the fission product inventory of re-entering core fragments involves the burn-up of this debris during the re-entry process. Obviously, as the mass of a re-entering particle decreases, the fission inventory associated with this mass loss is diminished in direct proportion.

\subsubsection{Analytical Evaluation}

The same properties which make graphite an attractive core material for nuclear rockets are definite liabilities when it is desired to burn-up graphite by aerodynamic heating and oxidation. Graphite may be classified as a non-ablative material $I_{D} i_{\circ} e_{\circ g}$ it does not melt under ordinary conditions (only at high temperatures and pressures), and its rate of

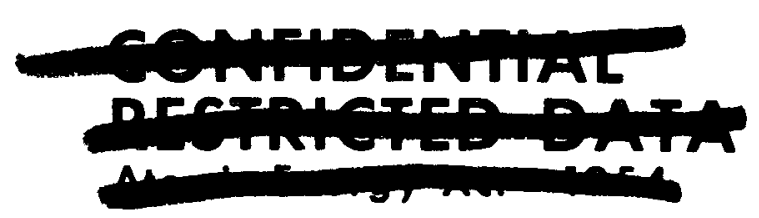


sublimation is insignificant up to temperatures of $5400^{\circ} \mathrm{R}$. Since temperatures of this order of magnitude are not achieved during re-entry from near earth orbits, mass losses of reentering graphite particles may be attributed to chemical reaction with the ambient gases, oxygen and nitrogen. However, the cyanogen reaction (with nitrogen) is negligible below approximately $5050^{\circ} \mathrm{R}$. Hence, from the foregoing considerations the problem reduces to a consideration of mass depletion by oxygen alone.

In order to evaluate graphite oxidation rates it is obvious that one requires a knowledge of (1) the rate of mass transfer of oxygen to the graphite surface and (2) the reaction rate between graphite and oxygen at the surface. The problem becomes even more complicated when one considers that during the re-entry of an individual fuel particle, the particle's size, velocity, and temperatures as well as the ambient pressure are constantly changing. Therefore, an analytical model is required to predict the mass loss rates for graphite during the re-entry process. This model involves the use of three separate but interdependent analytical expressions:

(1) Trajectory equations to predict the altitude and velocity of the re-entering particle as a function of time.

(2) Energy balance equations to predict the surface temperature of the body as a function of altitude and velocity.

(3) Mass loss rate equations to predict the extent of graphite oxidation as a function of altitude, velocity, and surface temperature. 


\subsubsection{Comparison of GE and WANL Analytical Results}

An analytical model of this type was developed by WANL and was incorporated into a computer program, "WEREC". The details of this model and program are discussed in WANL-TNR-135 ${ }^{(25)}$. Table 3.6 lists the percentage burnup expected during reentry for various sized graphite particles as a function of re-entry angle as calculated by the WEREC program.

A similar analytical model and computer program were developed by General Electric ${ }^{(28)}$. A list of results obtained by their computer program is shown in Table 3.7.

It is apparent from a comparison of the data shown in Tables 3.6 and 3.7 that fairly large differences exist in the extent of mass depletion predicted by the two computer programs. However, from a source term and from an overall safety approach both studies indicate that it is not possible to achieve complete burn-up of NERVA fuel during re-entry and that the source term of re-entering debris will not be altered to any large extent by mass depletion during the re-entry process.

\subsubsection{Comparison of WANL and GE Analytical Approaches}

Since the two analytical studies produce different results, it appears worthwhile at this point to examine the probable reasons for their divergence. In order to do so it is necessary to examine on a molecular scale what occurs when graphite oxidizes. The following steps are operative:

(1) An oxygen molecule is transported to the graphite surface. 


\section{TABLE 3.6}

PER CENT BURNUP AS A FUNCTION OF INITIAL PARTICLE SIZE AND RE-ENTRY

\section{ANGLE FROM WEREC COMPUTER PROGRAM}

\begin{tabular}{lccccccccc} 
Angle & \multicolumn{7}{c}{ Initial Particle Size (Diameter) } \\
\hline & 11 & $1 / 2^{\prime \prime}$ & $1 / 4^{\prime \prime}$ & $1 / 8^{\prime \prime}$ & $1 / 16^{\prime \prime}$ & $1 / 32^{\prime \prime}$ & $1 / 64^{\prime \prime}$ & $1 / 128^{\prime \prime}$ & $1 / 256^{\prime \prime}$ \\
$0^{\circ}$ & 7.0 & 12 & 20 & 33 & 40 & 52 & 43 & 42 & 41 \\
$-1^{\circ}$ & 6.9 & 12 & 20 & 33 & 40 & 53 & 43 & 42 & 41 \\
$-3^{\circ}$ & 6.0 & 10 & 19 & 33 & 40 & 52 & 43 & 42 & 41 \\
$-5^{\circ}$ & 5.2 & 10 & 17 & 33 & 40 & 52 & 43 & 42 & 41 \\
$-10^{\circ}$ & 4.3 & 8 & 14.5 & 25 & 38 & 49 & 43 & 42 & 41 \\
$-30^{\circ}$ & 3 & 7 & 10 & 18 & 34 & 43 & 43 & 42 & 41 \\
$-60^{\circ}$ & 2.3 & 7 & 8 & 15 & 25 & 41 & 43 & 42 & 41 \\
$-90^{\circ}$ & 2.2 & 7 & 7.4 & 14 & 25 & 40 & 43 & 42 & 41
\end{tabular}

Initial Conditions: Altitude $=400,000 \mathrm{ft}$.

Velocity $=25,000 \mathrm{fps}$ 
TABLE 3.7

PER CENT BURNUP AS A FUNCTION OF INITIAL PARTICLE SIZE

AND RE-ENTRY ANGLE FROM G.E。 COMPUTER PROGRAM

\begin{tabular}{lccccccc} 
Angle & \multicolumn{7}{c}{ Initial Particle Size (diameter) } \\
\hline & $2^{11}$ & $1^{\prime \prime}$ & $3 / 4^{\prime \prime}$ & $1 / 2^{11}$ & $1 / 4^{\prime \prime}$ & $1 / 8^{11}$ & $1 / 16^{11}$ \\
$-1.0^{\circ}$ & & & & 3.08 & & & \\
$-2.5^{\circ}$ & 2.92 & 3.44 & 3.87 & 3.93 & 2.91 & 1.86 & 1.10 \\
$-5.0^{\circ}$ & & & & 14.60 & & &
\end{tabular}

\author{
Initial Conditions: Altitude $=500,000 \mathrm{ft}$. \\ Velocity $=25,700 \mathrm{ft} / \mathrm{sec}$
}


(2) The $\mathrm{O}_{2}$ molecule collides with the surface. Upon collision the molecule may bounce off the surface or it may be chemisorbed. When chemisorbed, the oxygen molecute forms a definite chemical bond with a surface carbon atom.)

(3) The chemisorbed $\mathrm{O}_{2}$ molecule rearranges its bonds on the surface to become a chemisorbed $\mathrm{CO}_{2}$ molecule/or a chemisorbed $\mathrm{CO}$ malecule.

(4) The chemisorbed $\mathrm{CO}_{2}$ or $\mathrm{CO}$ molecule is desorbed from the surface.

(5) The desorbed molecule is then transported away from the surface.

Steps 1 and 5 represent mass transfer phenomena. Steps 2, 3, and 4 above fall into the realm of reaction rate kinetics. In these processes chemical bonds are being broken and formed, and the rate of the reaction for each of these steps may be written as:

$$
\text { Rate }=A e^{-E / R T}\left(\begin{array}{l}
P_{2} \\
O_{2}
\end{array}\right)^{n}
$$

where

$$
\begin{aligned}
& \text { A \& E are experimentally determined parameters called } \\
& \text { the Arrhenius parameters, } \\
& R=\text { the gas constant, } \\
& \mathrm{T}=\text { temperature, } \\
& \mathrm{PO}_{2}=\text { pressure of oxygen, } \\
& \mathrm{n}=\text { an exponent of which it may be generally said } \\
& 0 \leq n \leq 2
\end{aligned}
$$


Therefore, the above five steps may be summarized by two general

processes: (1) mass transfer as summarized by steps 1 and 5 and (2) chemical reaction as represented by steps 2,3 , and 4 . If the rate of mass transfer becomes slower than the rate of chemical reaction, the reaction rate is spoken of as being diffusion rate controlled. In general, the oxidation of graphite is diffusion rate controlled when the temperature of the graphite is greater than $1000^{\circ} \mathrm{C}$. In this case, it is only necessary to evaluate the rate of mass transfer of oxygen to the graphite surface in order to evaluate the mass loss rate. A theoretical evaluation of graphite oxidation under diffusion controlled conditions has been performed for the continuum flow region by Scala ${ }^{(29)}$ and has been shown by Bridges ${ }^{(27)}$ to predict reaction rates with a reasonable degree of certainty. This analytical model was used by both Westinghouse and $G$. E. in their analysis of re-entry oxidation under diffusion rate controlled conditions.

The basic difference in the two computer programs lies in their analysis of the rate of oxidation of graphite under chemical reaction rate controlled conditions (surface temperatures below $1000^{\circ} \mathrm{C}$ ) particularly in the free molecular flow and the near free molecular flow regimes. It is during re-entry in these flow regimes that surface temperatures are so low that diffusion may not be considered the rate controlling step in the oxidation process. Since small particles (those with diameters less than $1 / 16$ inch) spend most or all of their re-entry time in these flow regimes, the concept of reaction rate control in these regimes is quite important. The basic differences in the WANL and G. E. interpretations of reaction rates in these regimes will now be considered. 
In order to be exact in predicting the rate of graphite oxidation under chemical reaction rate control, it is necessary to know the rates of steps 2,3 , and 4 (providing one knows the mass transport steps as defined by steps 1 and 5). In general, however, workers in the field of surface kinetics have found that one of these steps $(2,3$, or 4) is much slower than the other two. This step is called rate determining. Thus, when one measures experimentally the temperature dependence of a reaction rate as shown in Equation 1, one is actually measuring the temperature dependence of the rate determining step.

The concept of rate determining steps becomes quite important in terms of oxidation during re-entry. If either steps 3 or 4 is the rate determining step, then the rate of the chemical reaction will be dependent upon the temperature of the solid surface. If step 2 is rate determining, the reaction rate is dependent upon both the gas temperature and the surface temperature.

At present, it is not possible to state with certainty which step in the rate process is rate determining. Eyring ${ }^{(30)}$ concluded as a result of his studies on graphite oxidation at low pressures that desorption (step 4) was rate determining. Gulbransen ${ }^{(31)}$ on the other hand, on the basis of his experimental results decided that adsorption (step 2) was rate determining.

In terms of the two computer programs under discussion, the basic difference in their approaches lies in the fact that the G. E. program assumed that the reaction rate was dependent only on surface temperature (step 3 or 4 determining) while the 
Westinghouse program assumed that step 2 was rate determining. However, in making this assumption, Westinghouse had to consider two additional problem areas:

(1) Existing high precision rate data on the kinetics of graphite oxidation have been done under experimental conditions such that the gas and the solid were at identical temperatures. Thus, the effect of variable gas temperature has not clearly been defined to date.

(2) In the case of hypersonic free molecular flow, what is the meaning of gas temperature? Generally, temperature is a statistical measure of the energy distribution in an extremely large number of particles. It is further assumed in speaking of reaction rate kinetics that the vibrational, rotational, and translational energy distributions in a group of molecules may be described by the same temperature. Such is not the case in free molecular flow where a gas molecule will have high translational energy with respect to the re-entering body but low vibrational and rotational energy.

Therefore, if one assumes adsorption to be rate determining, the problem of defining reaction rates is formidable. Obviously, fairly extensive theoretical and experimental programs of a basic nature would need to be undertaken. Lacking this basic information, Westinghouse assumed that every oxygen molecule hitting the surface reacted irregardless of the temperature of the surface. Such results should yield maximum burn-up and be excessively optimistic. 

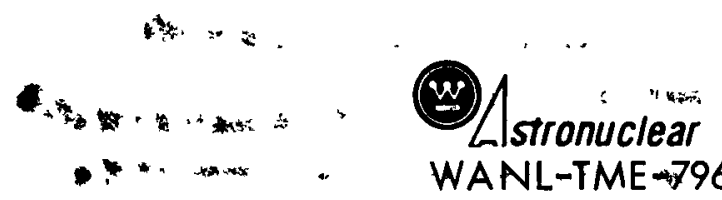

Returning now to the G. E. work with its assumption of solid surface temperature being reaction rate determining, it is easily seen why integrated mass losses would decrease with decreasing size of re-entering fragments. The smaller a re-entering body, the lower its surface temperature during re-entry. The lower the surface temperature, the lower the oxidation rates, and, hence, the lower the integrated mass losses.

In conclusion, the Westinghouse results represent an optimistic upper limit for fuel burn-up during re-entry while the General Electric results represent a pessimistic lower limit. However, since neither approach predicts any substantial decrease in the source strength of re-entering NERVA debris as a result of re-entry burn-up, it appears that any additional refinement of the two computer programs is unnecessary.

\subsubsection{Experimental}

\subsubsection{Graphite Oxidation}

A series of experiments were performed to determine the rate of oxidation of graphite under simulated re-entry conditions $(25,27)$. These tests were conducted in a plasmajet facility and were confined to examining oxidation under continuum and transition flow conditions. As has been mentioned earlier, the results of these experiments confirmed the applicability of Scala's analysis for graphite oxidation under diffusion rate controlled conditions. Figure 3.13 compares the experimentally determined rates with the theoretical ones which are represented by the solid lines. A more detailed presentation of experimental results is given in WANL-TNR-135. 


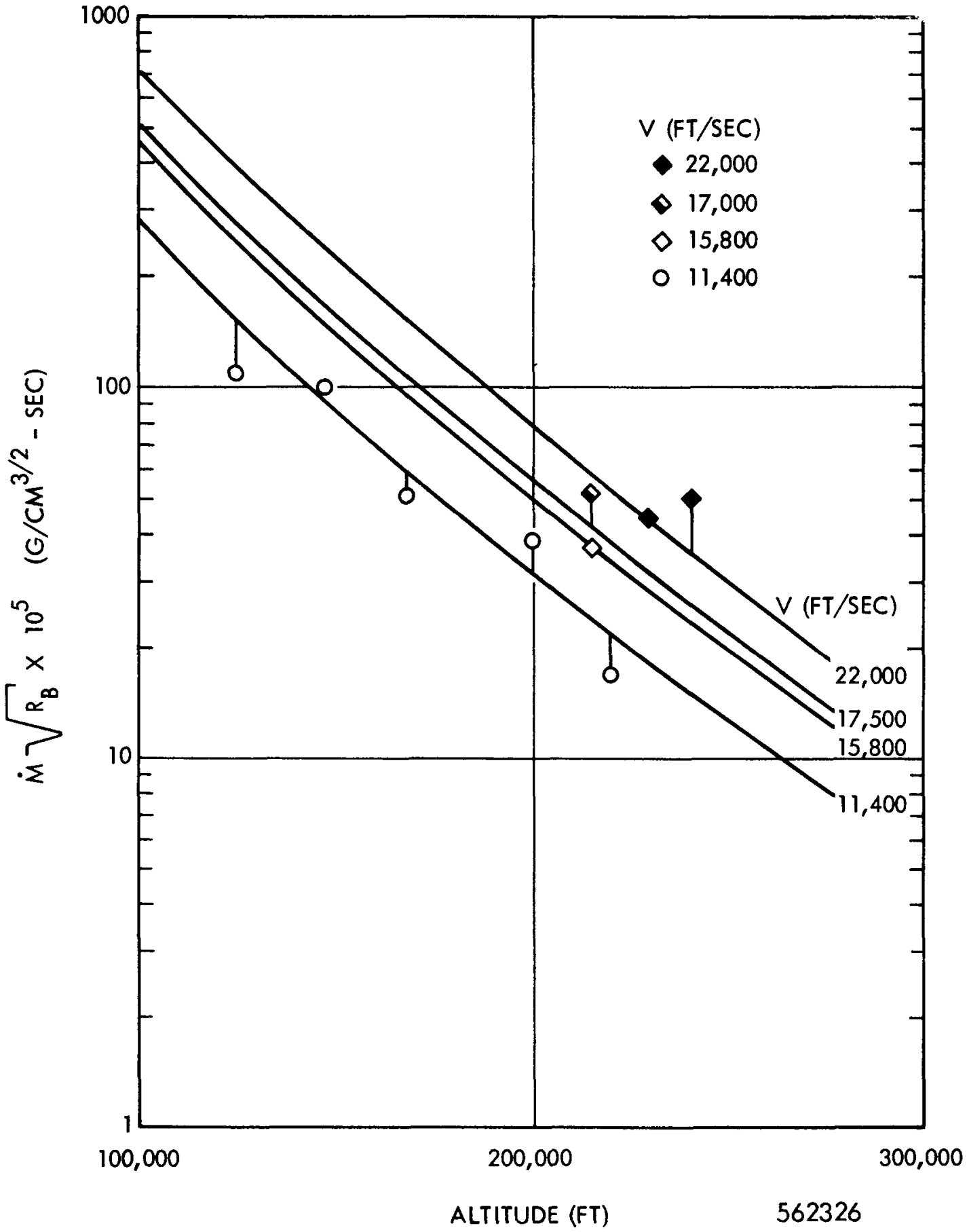

FIGURE 3.13 


\subsubsection{Effect of Additives}

In an attempt to enchance the burn-up of NERVA fuel during reentry a study of the influence of additives on the oxidation characteristics of NERVA fuel

was performed ${ }^{(32)}$. As a part of this study, the oxidation rate of a number of graphites containing small amounts of metallic additives were measured. The experimental tests were performed in a plasmajet facility under simulated re-entry conditions. The results of these tests are reported in Table 3.8.

It is apparent from an examination of the rate data presented in Table 3.8 that the presence of additives in fueled materials does little to enhance re-entry burn-up. In fact, for a number of materials the effect of additives is deleterious (i.e., those samples which had been sensitized). As a result of this study, it was concluded that the presence of metallurgical additives in NERVA fuel offers no particular advantage in enhancing the burn-up of NERVA fuel during re-entry.

\subsubsection{Effect of Irradiation on Re-Entry Burn-Up of Fuel}

In all the experimental re-entry studies thus far discussed, the materials examined were either graphite or NERVA fuel containing depleted uranium. In order to evaluate the effect of irradiation on re-entry oxidation rates, a number of samples of NERVA fuel containing enriched uranium were irradiated at GETR and then subjected to oxidation tests under simulated re-entry conditions ${ }^{(26)}$. The results of these tests are reported in Table 3.9. It is apparent from an examination of the data in Table 3.9 that irradiation does not affect the rate of oxidation of re-entering graphite. 
TABLE 3.8

OXIDATION RATES OF NERVA FUEL CONTAINING ADDITIVES

Material

Graphite
Graphite $+1 \mathrm{w} / \mathrm{o}$ Rhenium
Fueled Graphite
Fueled Graphite $+5 \mathrm{w} / \mathrm{o}$ Vanadium
Fueled Graphite $+1 \mathrm{w} / 0$ Rhenium
Fueled Graphite $+5 \mathrm{w} / 0$ Molybdenum
Fueled Graphite $+5 \mathrm{w} / 0$ Tungsten
Fueled Graphite $+5 \mathrm{w} / 0$ Molybdenum
(sensitized)*
Fueled Graphite $+5 \mathrm{w} / 0$ Tungsten
(sensitized)*

Simulated Altitude $(f t)$

Simulated Velocity $(\mathrm{ft} / \mathrm{sec})$

NOTE: All mass loss rates are $\mathrm{g} / \mathrm{cm}^{2}-\sec \times 10^{4}$

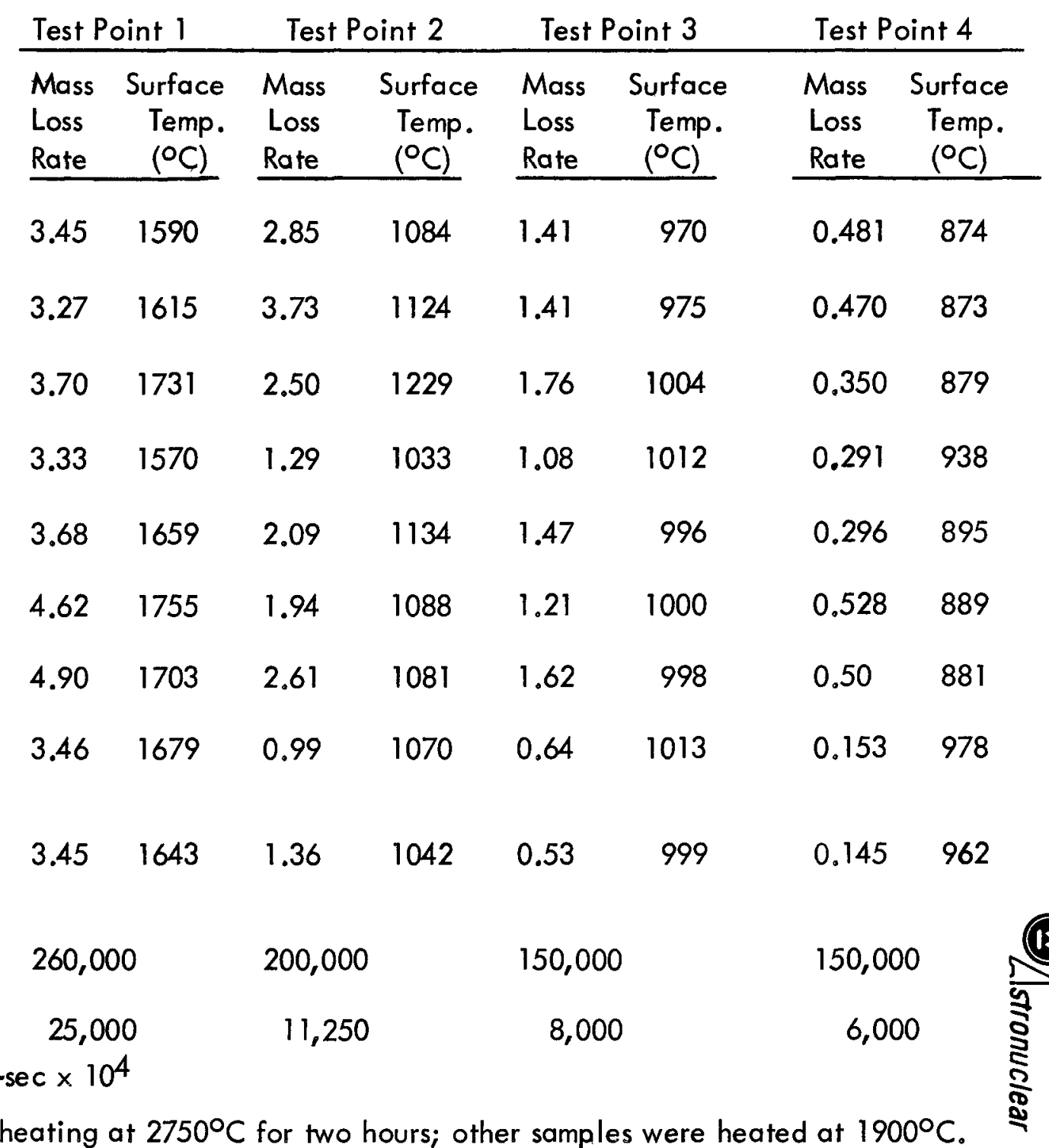

\footnotetext{
*Sensitized samples were pretreated by heating at $2750^{\circ} \mathrm{C}$ for two hours; other samples were heated at $1900^{\circ} \mathrm{C}$.
} 


\section{Mass Loss Rates}

\begin{tabular}{llccc}
$\begin{array}{c}\text { Test } \\
\text { Point }\end{array}$ & Altitude $(\mathrm{ft})$. & Velocity $(\mathrm{ft} . / \mathrm{sec})$ & $\begin{array}{c}\text { Graphite } \\
\left(\mathrm{g} / \mathrm{cm}^{2}-\mathrm{sec}\right)\end{array}$ & $\begin{array}{c}\text { Irradiated } \\
\text { NERVA Fuel } \\
\left(\mathrm{g} / \mathrm{cm}^{2} \text {-sec }\right)\end{array}$ \\
\hline 9 & 280,000 & 25,000 & $0.33 \times 10^{-4}$ & $0.36 \times 10^{-4}$ \\
11 & 250,000 & 25,000 & $7.00 \times 10^{-4}$ & $9.68 \times 10^{-4}$ \\
1 & 200,000 & 11,250 & $15.2 \times 10^{-4}$ & $12.0 \times 10^{-4}$ \\
14 & 200,000 & 8,000 & $1.4 \times 10^{-4}$ & $0.80 \times 10^{-4}$ \\
12 & 150,000 & 6,000 & $2.18 \times 10^{-4}$ & $1.89 \times 10^{-4}$
\end{tabular}




\subsubsection{General Conclusion}

As a result of both the analytical and experimental studies performed in the examination of the re -entry bum-up characteristics of NERVA fuel, it appears that the source term of re-entering debris is not substantially diminished by the oxidation processes occurring during re-entry. However, for the sake of completeness burn-up is considered in the WANL Source Term Program and is calculated according to the equations as used in the WEREC computer program. 


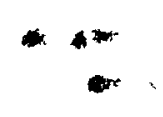

\subsection{SOURCE TERM DUE TO NEUTRON ACTIVATION PRODUCTS}

Evaluation of the radiological hazards associated with the operation and subsequent re-entry of the NERVA engine requires information on the total radioactive inventory of the engine and associated components. Included in this inventory are the materials that have become radioactive during reactor operation as a result of neutron activation. Calculations of the source strength and dose rates of specific reactor components, such as the tie rods, beryllium reflector, support plate, etc. were made $(33,34)$ in order to determine shielding requirements and the post-operational handling precautions required following ground testing of the NRX reactors. However, no calculations were made to determine the total source term originating from activation of all the structural materials in the NERVA reactor. Intuitively, it was felt that the fission product activity originating from the core would greatly exceed the total activity arising from neutron activation. In order to determine if this indeed were the case, the activation of all components within the reactor were calculated in order to evaluate the total source term.

\subsection{MATERIALS ACTIVATION CALCULATIONS}

Prior to source term studies, a computer program, "Activation Source Strength Program, $A C T$ I and ACT II"(35), was developed for use in radiation level and shielding calculations. This program calculates the source strength as a function of exposure time and decay time. However, it considers only the gamma ray radiation from materials exposed to neutron flux. For complete evaluation of the biological hazards associated with the release of these activated materials into the biosphere, the beta particle emissions from the materials must also be considered.

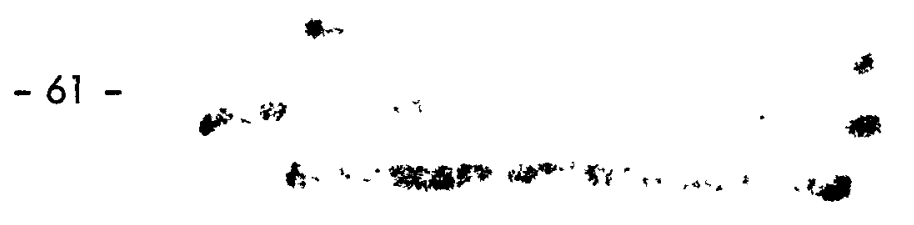


Therefore, a revised computer program was developed, "ACT II, Revised" (3Q). This program includes the calculation of the source strength gnd radioactivity originating from beta paritcle emissions. This revised program considers the formation of 178 radionuclides by 223 nuclear reactions on 48 different target elements.

The total weights and volumes of materials exposed to neutron irradiation were based on the standard NRX $-A$ configuration for radiation analyses ${ }^{(37)}$. This configuration provides an adequate representation of the NRX-A assembly, by dividing the reactor into 76 regions. Information provided in Reference (37) for each region includes the total weight and volume of each region the total weight and volume of each material in each region, the volume fraction of each material, and number density of each element. For our calculations the reactor was assumed to employ the lithium hydride stainless steel NRX shield and a titanium rather than an aluminum pressure vessel.

Values of neutron flux used as input to the computer program for the activation calculations were based on Figure Nos. 5-7 through 5-10 and Figure Nos. A-8 through A-12 given in WANLTNR-128, Vol. $11^{(38)}$. The neutron flux within the various regions of the reactor varies by as much as a factor of 50 when measured radially from the center of the core, and by even a greater factor measured axially along the core at a fixed radius. Therefore, in many cases for materials in regions which extend over wide dimensions of the core, best estimates were made of the average flux incident upon the materials. In all cases for which estimates were made, a very conservative approach was used; that is, fluxes were estimated to ba high. As a result high estimates of activity produced by the activation were determined. For example, the

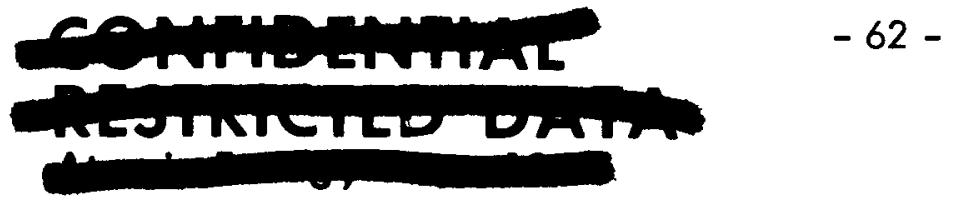




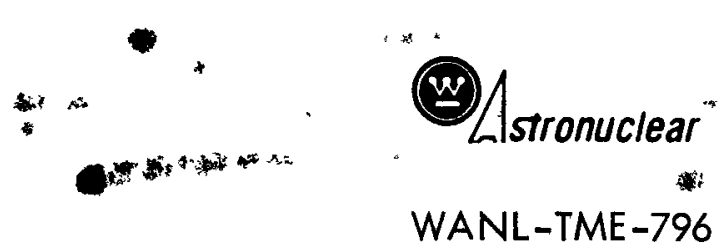

maximum flux values were used for all materials within Regions 1-30 (core regions). In addition, no corrections were made for neutron attenuation in the irradiation of thick regions, thereby overestimating the induced activity.

A listing of the weights of each material in each zone and the corresponding neutron fluxes used for calculation of the activation of the materials in each zone is presented in Table 4,1. This table lists only those structural components fabricated from stainless steel, Inconel-X, 2219 aluminum alloy, or titanium. Activation of components fabricated from these four materials comprises essentially all of the activity arising from neutron activation. Activation of other materials present in lesser amounts and of the beryllium reflector were also investigated. However, the contribution of these materials to the total activity source is negligible. For example, although there is a considerable mass of beryllium present in the reflector, the total gamma and beta energy source originating from the beryllium comprises less than $0.1 \%$ of the total activity arising from the above four materials.

\subsection{ACTIVATION PRODUCTS SOURCE STRENGTH}

The total gamma and beta source strengths due to the activated structural materials are summarized in Table 4.2. The activities given here are based on nine-minutes full power operation of the NERVA reactor. For comparison the total activity originating from the core fission products (assuming no loss by diffusion) in the case of nine-minutes power operation is also shown in Table 4.2. The relative contribution of each of the materials to the total activity source of the reactor are summarized in Table 4.3. It is evident from this table that activation 
TABLE 4.1

MATERIALS WEIGHTS AND NEUTRON FLUXES

USED IN ACTIVATION ANALYSIS

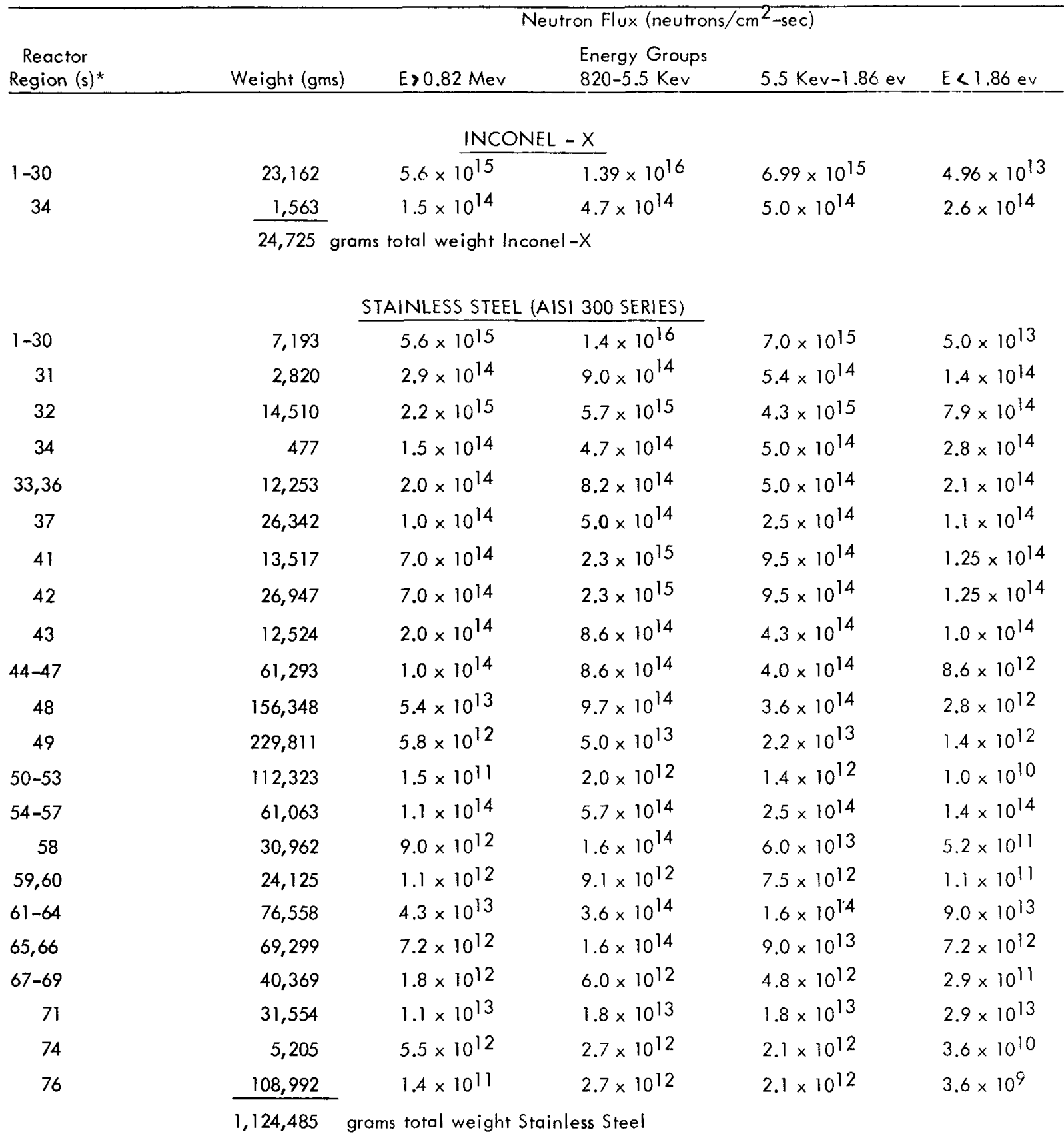




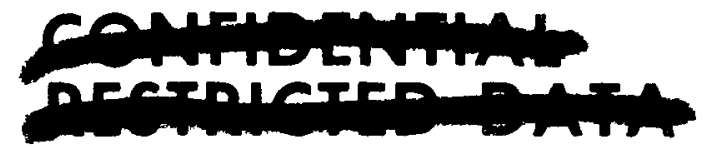

TABLE 4.1

MATERIALS WEIGHTS AND NEUTRON FLUXES USED IN ACTIVATION ANALYSIS

(CONTINUED)

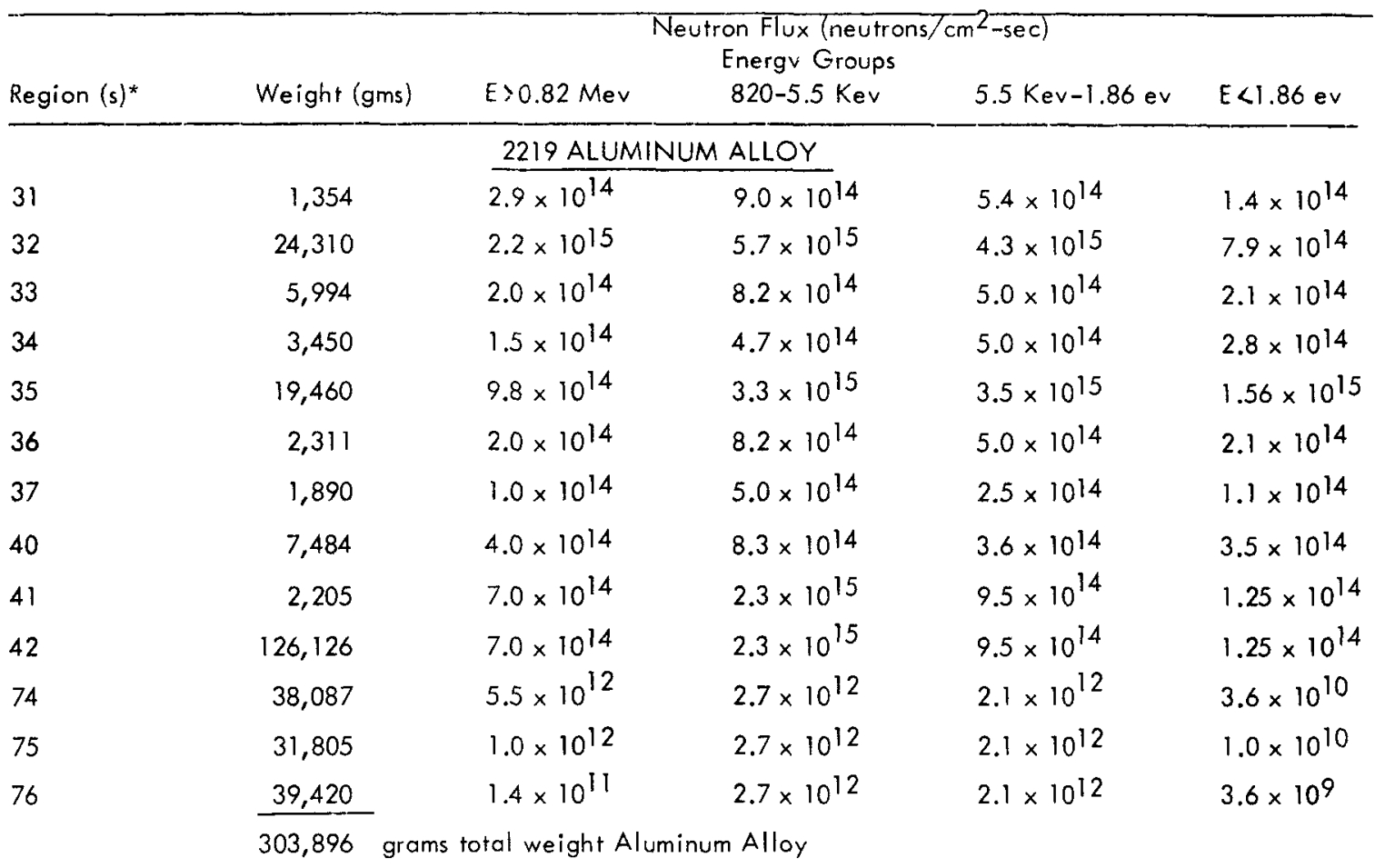

\begin{tabular}{llllll}
34 & \multicolumn{9}{c}{ TITANIUM } & \\
35 & 16,510 & $1.5 \times 10^{14}$ & $4.7 \times 10^{14}$ & $5.0 \times 10^{14}$ & $2.8 \times 10^{14}$ \\
36 & 26,200 & $9.8 \times 10^{14}$ & $3.3 \times 10^{15}$ & $3.5 \times 10^{15}$ & $1.56 \times 10^{15}$ \\
37 & 11,335 & $2.0 \times 10^{14}$ & $8.2 \times 10^{14}$ & $5.0 \times 10^{14}$ & $2.1 \times 10^{14}$ \\
38 & 4,796 & $1.0 \times 10^{14}$ & $5.0 \times 10^{14}$ & $2.5 \times 10^{14}$ & $1.1 \times 10^{14}$ \\
39 & 6,701 & $9.0 \times 10^{13}$ & $3.2 \times 10^{14}$ & $1.3 \times 10^{14}$ & $1.2 \times 10^{14}$ \\
40 & 6,735 & $2.5 \times 10^{14}$ & $8.3 \times 10^{14}$ & $4.5 \times 10^{14}$ & $3.1 \times 10^{14}$ \\
73 & 2,418 & $4.0 \times 10^{14}$ & $8.3 \times 10^{14}$ & $3.6 \times 10^{14}$ & $3.5 \times 10^{14}$ \\
& 257,037 & $9.0 \times 10^{13}$ & $2.0 \times 10^{14}$ & $2.6 \times 10^{14}$ & $2.4 \times 10^{14}$
\end{tabular}




\section{TABLE 4.2}

SOURCE STRENGTH OF

STRUCTURAL MATERIALS AND FISSION PRODUCTS OF NERVA

REACTOR AFTER 9 MINUTES AT $1120 \mathrm{MW}$

GAMMA ENERGY (MEV/SEC)

\begin{tabular}{|c|c|c|c|c|c|c|}
\hline Time After & & Stainless & & & Fission & \\
\hline Shutdown (Hrs.) & Inconel & Steel & Aluminum & Titonium & Products & Total \\
\hline 0 & $1.48 \times 10^{16}$ & $1.65 \times 10^{17}$ & $7.82 \times 10^{17}$ & $2.83 \times 10^{16}$ & $1.28 \times 10^{20}$ & $1.2899 \times 10^{20}$ \\
\hline 0.5 & $1.93 \times 10^{15}$ & $5.22 \times 10^{16}$ & $3.18 \times 10^{15}$ & $9.41 \times 10^{13}$ & $6.38 \times 10^{18}$ & $6.4374 \times 10^{18}$ \\
\hline 1 & $1.59 \times 10^{15}$ & $4.13 \times 10^{16}$ & $1.99 \times 10^{15}$ & $3.53 \times 10^{13}$ & $2.55 \times 10^{18}$ & $2.5952 \times 10^{18}$ \\
\hline 2 & $.1 .19 \times 10^{15}$ & $3.03 \times 10^{16}$ & $1.46 \times 10^{15}$ & $1.24 \times 10^{13}$ & $8.93 \times 10^{17}$ & $9.2596 \times 10^{17}$ \\
\hline 10 & $1.42 \times 10^{14}$ & $1.93 \times 10^{15}$ & $2.25 \times 10^{14}$ & $6.47 \times 10^{12}$ & $1.02 \times 10^{17}$ & $1.0430 \times 10^{17}$ \\
\hline 24 & $8.53 \times 10^{12}$ & $1.21 \times 10^{14}$ & $3.45 \times 10^{13}$ & $4.00 \times 10^{11}$ & $3.32 \times 10^{16}$ & $3.3364 \times 10^{16}$ \\
\hline 168 & $4.78 \times 10^{12}$ & $2.45 \times 10^{13}$ & $4.11 \times 10^{10}$ & $2.77 \times 10^{10}$ & $3.57 \times 10^{15}$ & $3.5993 \times 10^{15}$ \\
\hline 720 & $3.81 \times 10^{12}$ & $1.79 \times 10^{13}$ & $3.45 \times 10^{9}$ & $1.18 \times 10^{10}$ & $7.14 \times 10^{14}$ & $7.3572 \times 10^{14}$ \\
\hline 4320 & $8.53 \times 10^{11}$ & $6.30 \times 10^{12}$ & $1.33 \times 10^{9}$ & $2.83 \times 10^{9}$ & $5.10 \times 10^{13}$ & $5.8169 \times 10^{13}$ \\
\hline 8760 & $1.71 \times 10^{11}$ & $2.50 \times 10^{12}$ & $6.63 \times 10^{8}$ & $7.06 \times 10^{8}$ & $9.44 \times 10^{12}$ & $12.1124 \times 10^{12}$ \\
\hline 43800 & $4.43 \times 10^{9}$ & $5.50 \times 10^{11}$ & $2.39 \times 10^{8}$ & $5.59 \times 10^{5}$ & $5.10 \times 10^{11}$ & $10.6467 \times 10^{11}$ \\
\hline 87600 & $2.05 \times 10^{9}$ & $2.75 \times 10^{11}$ & $1.30 \times 10^{8}$ & $9.42 \times 10^{3}$ & $4.08 \times 10^{11}$ & $6.8518 \times 10^{11}$ \\
\hline
\end{tabular}

BETA ENERGY (MEV/SEC)

\begin{tabular}{lllllll}
\hline 0 & $9.09 \times 10^{15}$ & $9.35 \times 10^{16}$ & $4.38 \times 10^{16}$ & $2.21 \times 10^{16}$ & $5.87 \times 10^{19}$ & $5.8868 \times 10^{19}$ \\
0.5 & $9.67 \times 10^{14}$ & $3.30 \times 10^{16}$ & $1.99 \times 10^{15}$ & $3.59 \times 10^{14}$ & $4.34 \times 10^{18}$ & $4.3763 \times 10^{18}$ \\
1.0 & $6.82 \times 10^{14}$ & $1.81 \times 10^{16}$ & $1.00 \times 10^{15}$ & $1.53 \times 10^{14}$ & $1.53 \times 10^{18}$ \\
2 & $5.40 \times 10^{14}$ & $1.35 \times 10^{16}$ & $7.29 \times 10^{14}$ & $5.42 \times 10^{13}$ & $5.87 \times 10^{17}$ & $6.0182 \times 10^{17}$ \\
10 & $5.68 \times 10^{13}$ & $8.25 \times 10^{14}$ & $1.46 \times 10^{14}$ & $2.59 \times 10^{11}$ & $8.93 \times 10^{16}$ & $9.0328 \times 10^{16}$ \\
24 & $1.93 \times 10^{12}$ & $7.98 \times 10^{13}$ & $3.71 \times 10^{13}$ & $1.60 \times 10^{10}$ & $2.55 \times 10^{16}$ & $2.562 \times 10^{16}$ \\
168 & $1.36 \times 10^{11}$ & $1.07 \times 10^{13}$ & $3.85 \times 10^{10}$ & $5.57 \times 10^{9}$ & $1.66 \times 10^{15}$ & $1.6709 \times 10^{15}$ \\
720 & $1.08 \times 10^{11}$ & $9.35 \times 10^{12}$ & $3.98 \times 10^{9}$ & $8.39 \times 10^{8}$ & $3.83 \times 10^{14}$ & $3.9246 \times 10^{14}$ \\
4320 & $2.50 \times 10^{10}$ & $3.30 \times 10^{11}$ & $9.4 \times 10^{7}$ & $1.98 \times 10^{8}$ & $4.59 \times 10^{13}$ & $4.6255 \times 10^{13}$ \\
8760 & $4.83 \times 10^{9}$ & $1.24 \times 10^{11}$ & $3.05 \times 10^{7}$ & $4.88 \times 10^{7}$ & $1.79 \times 10^{13}$ & $1.8029 \times 10^{13}$ \\
43800 & $5.40 \times 10^{8}$ & $2.34 \times 10^{9}$ & $1.05 \times 10^{7}$ & $4.81 \times 10^{5}$ & $1.28 \times 10^{12}$ & $1.2829 \times 10^{12}$ \\
87600 & $4.77 \times 10^{8}$ & $1.32 \times 10^{9}$ & $6.10 \times 10^{6}$ & $2.37 \times 10^{5}$ & $7.65 \times 10^{11}$ & $7.6680 \times 10^{11}$
\end{tabular}


TABLE 4.3

CONTRIBUTION OF STRUCTURAL MATERIALS AND FISSION PRODUCTS

TO TOTAL SOURCE STRENGTH OF NERVA REACTOR

\begin{tabular}{|c|c|c|c|c|c|}
\hline \multirow[b]{2}{*}{$\begin{array}{l}\text { Time After } \\
\text { Shutdown (Hrs.) }\end{array}$} & \multicolumn{3}{|c|}{ GAMMA ENERGY, PERCENT } & \multirow[b]{2}{*}{ Titanium } & \multirow[b]{2}{*}{$\begin{array}{c}\text { Fission } \\
\text { Products } \\
\end{array}$} \\
\hline & Inconel-X & $\begin{array}{c}\text { Stainless } \\
\text { Steel } \\
\end{array}$ & Aluminum & & \\
\hline 0 & 0.01 & 0.13 & 0.61 & 0.02 & 99.23 \\
\hline 0.5 & 0.03 & 0.81 & 0.05 & 0.002 & 99.11 \\
\hline 1 & 0.06 & 1.59 & 0.08 & 0.001 & 98.26 \\
\hline 2 & 0.13 & 3.27 & 0.16 & 0.001 & 96.44 \\
\hline 10 & 0.14 & 1.85 & 0.21 & 0.006 & 97.79 \\
\hline 24 & 0.03 & 0.36 & 0.10 & 0.001 & 99.51 \\
\hline 168 & 0.13 & 0.68 & 0.01 & 0.008 & 99.19 \\
\hline 720 & 0.52 & 2.43 & 0 & 0.002 & 97.05 \\
\hline 4320 & 1.47 & 10.83 & 0.002 & 0.005 & 87.68 \\
\hline 8760 & 1.41 & 20.64 & 0.005 & 0.006 & 77.94 \\
\hline 43800 & 0.42 & 51.66 & 0.02 & 0.009 & 47.90 \\
\hline 87600 & 0.30 & 40.14 & 0.02 & 0 & 59.55 \\
\hline \multicolumn{6}{|c|}{ BETA ENERGY, PERCENT } \\
\hline 0 & 0.02 & 0.16 & 0.07 & 0.04 & 99.72 \\
\hline 0.5 & 0.02 & 0.75 & 0.05 & 0.008 & 99.17 \\
\hline 1.0 & 0.04 & 1.17 & 0.07 & 0.01 & 98.72 \\
\hline 2 & 0.09 & 2.24 & 0.12 & 0.009 & 97.54 \\
\hline 10 & 0.06 & 0.91 & 0.16 & 0 & 98.86 \\
\hline 24 & 0.008 & 0.31 & 0.14 & 0 & 99.53 \\
\hline 168 & 0.008 & 0.64 & 0.002 & 0 & 99.35 \\
\hline 720 & 0.03 & 2.38 & 0.001 & 0 & 97.59 \\
\hline 4320 & 0.05 & 0.71 & 0 & 0 & 99.23 \\
\hline 8760 & 0.03 & 0.69 & 0 & 0 & 99.28 \\
\hline 43800 & 0.04 & 0.18 & 0.001 & 0 & 99.77 \\
\hline 87600 & 0.06 & 0.17 & 0.001 & 0 & 99.77 \\
\hline
\end{tabular}


products contribute little to the total source term resulting from reactor operation. For periods up to one year after reactor shutdown, activity from the fission products accounts for at least $96 \%$ of the total gamma energy source. For intervals greater than one year after shutdown, gamma activity originating from the stainless steel becomes increasingly significant. However, even after 10 years decay the total activity of the fission products exceeds that from the stainless and other structural materials. Appreciable doses could be received from large compoents or fragments of structural materials. The dose rates from such materials can be readily calculated based on the power history and decay time of reactor operations. However, the conclusion to be drawn from the data of Table 4.3 is that the contribution of the activation products to the total source term inventory is not significant. Further consideration of the radiological hazards arising from the re-entry of radioactive fragments of structural materials are discussed in the following paragraphs.

\subsection{RE-ENTRY HAZARDS FROM ACTIVATION PRODUCTS}

The total inventory of activation products is small in comparison with the total activity due to the fission products in the core. However, in the event that reactor destruct is employed following completion of the NERVA mission, small fragments and particles of the re-entering debris could produce biological hazards. Of particular interest is the hazard potential of the very small paritcles. The hazard potential of small particles for two cases, direct ingestion of the particle by an individual and contamination of ocean waters are considered in the following paragraphs.

\subsubsection{Ingestion Hazards}

A reactor mission was assumed in which the reactor was started sub-orbitally, 

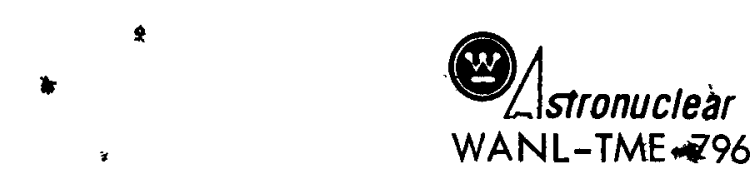

WANL-TME $\rightarrow 96$

followed by nine minutes power operation at full power and then destructed immediately. The beta and gamma source strength for a 1000 micron diameter spherical particle of the four structural materials was calculated at the time of ground impact of a particle and varying decay times up to 10 years thereafter. The 1000 micron particle was chosen as the maximum diameter of an ingestible particle ${ }^{(38)}$. No re-entry burnup was assumed.

Results of these calculations are summarized in Figures 4.1 and 4.2. The activity of a 1000 micron fuel particle for the same operating mission is also shown on these figures for the sake of comparison of the fission product inventory with the activation product inventory. The curves in Figures 4.1 and 4.2 reveal that aluminum alloy is the most highly activated material after reactor shutdown. The aluminum curve represents the activity of the core support plate which would represent the maximum reactivity of aluminum in the reactor. The majority of the radionuclides formed from aluminum have short half lives, and the total activity decays rapidly in comparison with the Inconel-X and stainless steel. For times beyond one-half hour after shutdown, both Inconel-X and stainless steel offer the greatest potential hazard of all the activated materials in the NERVA engine. Long-lived radioisotopes are formed from both these materials. In the case of Inconel $X, \mathrm{Co}^{57}\left(\mathrm{~T}_{1 / 2}=267\right.$ days), $\mathrm{Co}^{58}\left(\mathrm{~T}_{1 / 2}=72\right.$ days $)$ and $\mathrm{Co}^{60}\left(\mathrm{~T}_{1 / 2}=5.3\right.$ years $)$ are formed from nickel and cobalt. These same nuclides plus $\operatorname{Ta}^{182}\left(T_{1 / 2}=115\right.$ days $)$ are formed in the case of the stainless steel. From radiological considerations it is the beta particle emissions from an ingested particle that are of greatest concern. Comparison of the curves in Figure 4.2 reveals that the beta source strength from a fuel particle (due to fission products) always exceeds the

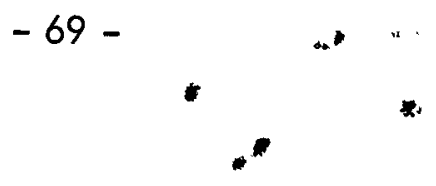



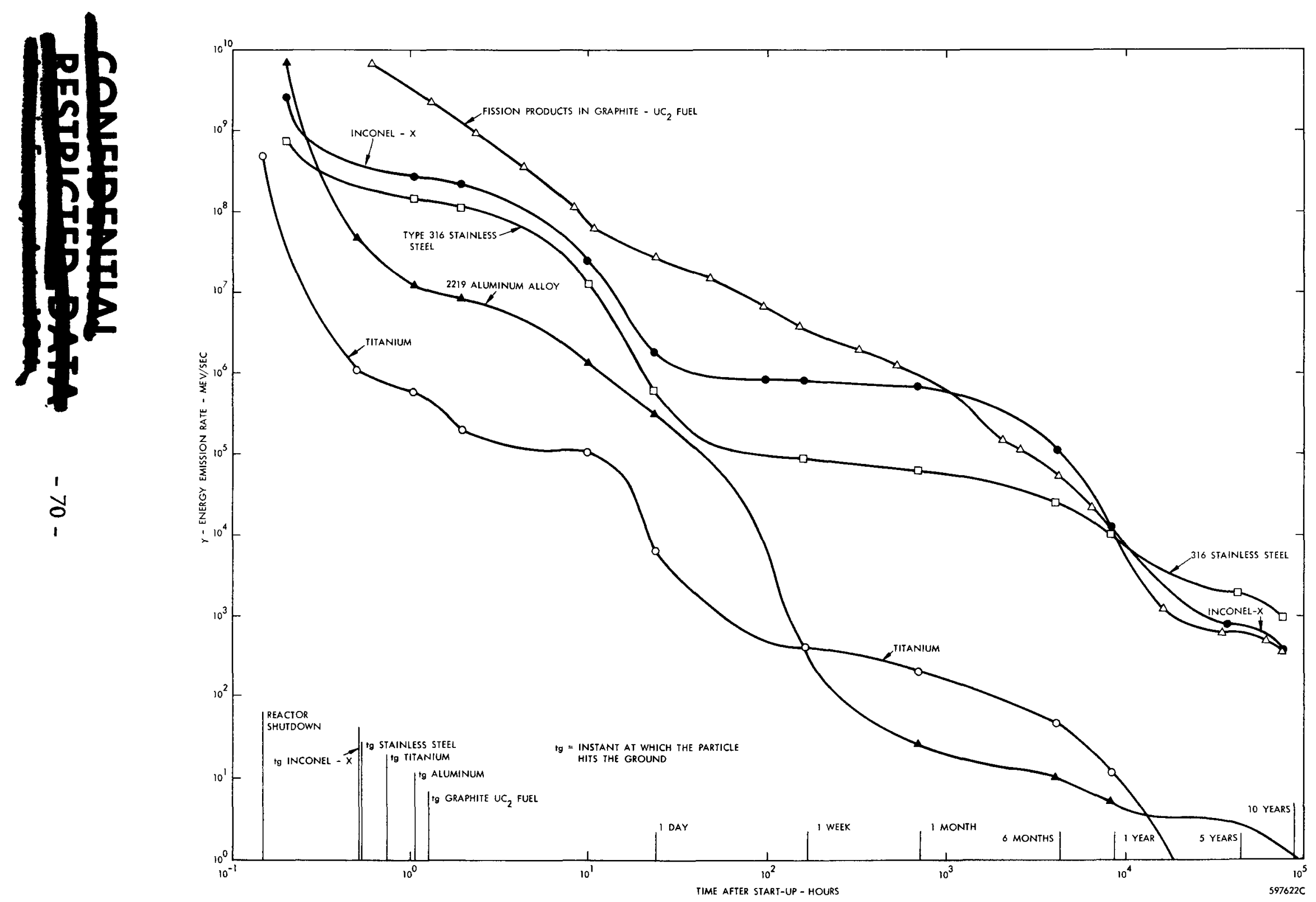

TOTAL $\gamma$-ENERGY EMISSION RATE OF A $1000 \mu$ DIAMETER PARTICLE OF STRUCTURAL MATER IA LS AND NERVA FUEL FOLLOWING SUBORBITAL START W ITH 9 MINUTES FULL POWER OPERATION FOLLOWED BY DESTRUCT 

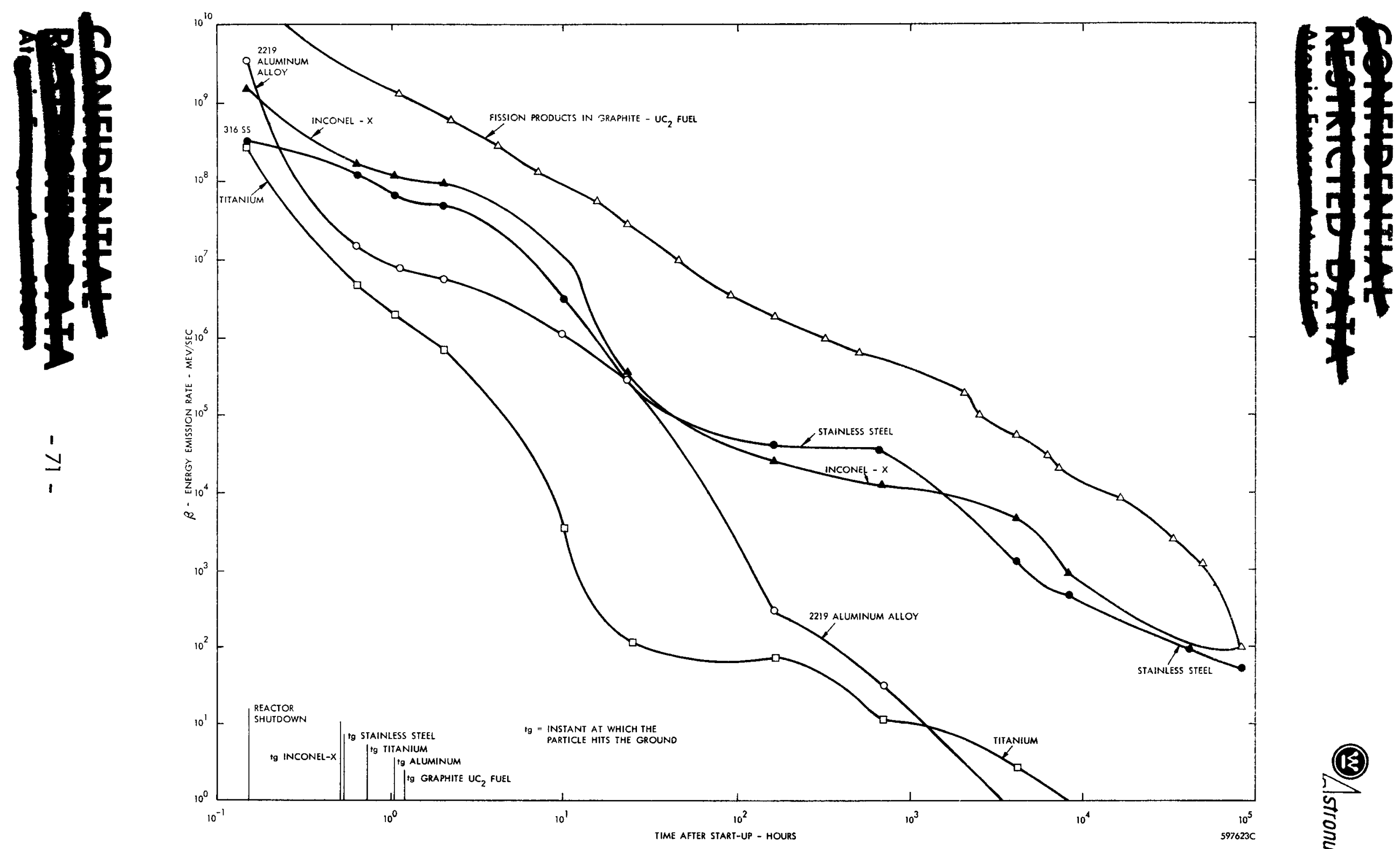

$\stackrel{1}{1}$

TOTAL $\bar{\beta}$-ENERGY EMISSION RATE OF A $1000 \mu$ DIAMETER PARTICLE OF STRUCTURAL MATERIALS AND NERVA FUEL. FOLLOWING SUBORBITAL START WITH 9 MINUTES 
activity of the stainless steel or Inconel particle by a factor of 50 to 100 . The conclusion is then made that the dose received from a particle of activated structural material would be insignificant in comparison with the dose received from an equal volume sized particle of fuel material. This conclusion is based on the assumptions that both particles are insoluble during the residence time within the body. The dose received from the ingestion of the metal particle is complicated by the biological and chemical behavior of the element within the human body.

\subsubsection{Contamination of Ocean Waters}

An evaluation has been made of the extent of contamination of ocean waters by radioactive structural materials resulting from destructive action of the NERVA reactor. Dispersal of the radioactive debris in the sea is of interest because of the uptake of the radioactive materials by marine organisms, with subsequent exposure of man via the food chain. Elements that are heavily concentrated by sea food organisms include $\mathrm{Cu}, \mathrm{P}, \mathrm{Fe}, \mathrm{Co}$, $\mathrm{Cr}, \mathrm{Mn}$, and $\mathrm{Al}$. Since the structural materials contain all these elements, the question arises whether the neutron activation of these materials is sufficiently great to exceed the maximum permissible concentration of these radionuclides when dispersed in the sea water.

\subsubsection{Calculations}

The basic assumptions made and the methods of calculating the activity of the ocean water were as follows:

(1) The NERVA reactor is destructed by high energy explosives following a nine-minute full power suborbital start. Activation of the structural materials 
was calculated using the ACT II revised computer program.

Only the contributions from aluminum titanium, stainless

steel, and Inconel were considered. No corrections were made for neutron attenuation in thick sections of the materials.

(2) A simplified destruct and re-entry model proposed by Decker ${ }^{(39)}$ was used in order to calculate the distribution of particles on the ocean's surface. Itwas assumed that upon destruct the particles were scattered isotropically with the particles assuming a Maxwellian energy distribution. It was further assumed the velocity of the particles with respect to the center of mass of expanding debris remained constant until atmospheric re-entry dampened out their initial motion. Under these conditions, the fraction, $f$, of the particles or of the total mass which would impact on the ocean's surface at a distance $r$ from the center of mass is given by:

$$
f(r, t)=\frac{3}{4 T^{\prime}(K E) t^{2}} e^{-\left(\frac{3 r^{2}}{4(K E) t^{2}}\right)}
$$

where

$(K E)=$ the average kinetic energy per unit mass imparted by the destruct explosion,

$r=$ the distance (radius of circle) on the earth's surface from the center of mass of the debris, 
$t=$ the time that particles scatter until their velocity is damped out by re-entry forces.

(3) Upon impact with the ocean's surface, the particles are assumed to be uniformly dissolved or dispersed in the water only one meter deep. Further dilution by settling of particles into deeper water, diffusion, and transport by ocean currents is neglected. Any loss of activity due to re-entry burnup is also neglected.

(4) The values of the variables in the equation that were assumed for the calculation are as follows:

(a) $r=0$, the point of maximum surface density,

(b) $(\mathrm{KE})=10^{5} \mathrm{ft}^{2} / \mathrm{sec}^{2} \cong 4 \mathrm{BTU} / \mathrm{Ib}$ mass,

(c) $t=5$ minutes, that is the particles are considered to travel for 5 minutes at constant velocity before re-entry drag forces instantaneously decelerate the particles to zero velocity. At this time the particles are considered to settle vertically.

(d) the activity of the ocean water is calculated after 12 hours decay from the time of destruct. This 12 hours can be considered to include settling time and residence time in the ocean. In any case, 12 hours would be the minimum time possible for the radioactive material to enter the human food chain. 
The results of these calculations are summarized in Table 4.4. This table lists the concentration in microcuries per milliliter for 24 different radionuclides formed by neutron activation of NERVA structural materials. These 24 radionuclides comprise greater than $99.9 \%$ of the total activity that is formed from stainless steel, Inconel, aluminum, and titanium after 12 hours decay. The total concentration of each nuclide is compared with the maximum permissible concentration of radioisotopes in sea water $(40)$ and with the maximum permissible concentration in drinking water $(41)$. Blank values in the table indicate there is no data available for these radioisotopes in References (40) and (41).

Additional structural materials of the engine not considered in this analysis (nozzle, piping, etc.) would add to the inventory. However, these additional materials have a low specific activity because of their relatively greater distance from the core and thus they are exposed to neutron fluxes at least two orders of magnitude lower than the materials in the reactor. Consequently, these additional materials would contribute only slightly to the specific activity of the sea water.

\subsubsection{Conclusions}

It is concluded from the results of Table 4.4 that contamination of ocean waters from radioactive debris of the structural materials of the NERVA engine does not pose a significant radiological hazard. Two nuclides, $\mathrm{Co}^{58}$ and $\mathrm{Cu}^{64}$ exceed the MPCC for sea water. However, these values are not considered to be hazardous. The assumptions made on the distribution of the radioisotopes in the ocean water are extremely conservative. Most certainly, the debris would not remain in water at only one meter depth, but the larger 
TABLE 4.4

CONTAMINATION OF OCEAN WATER BY RE- ENTRY OF

RADIOACTIVE NERVA REACTOR STRUCTURAL MATERIALS

\begin{tabular}{|c|c|c|c|c|c|c|c|c|}
\hline \multirow[b]{2}{*}{ Symbol } & \multirow[b]{2}{*}{$t-1 / 2$} & \multicolumn{3}{|c|}{ Sea Water Activity, $\mu \mathrm{c} / \mathrm{ml}$} & \multirow[b]{2}{*}{$\begin{array}{l}\text { Titanium } \\
\text { (Incl. Press Vess) }\end{array}$} & \multirow[b]{2}{*}{ Total } & \multirow{2}{*}{$\begin{array}{l}\text { Permissable } \\
\text { Sea Water } \\
\text { MPCC- } \mu \mathrm{c} / \mathrm{ml}^{*}\end{array}$} & \multirow{2}{*}{$\begin{array}{l}\text { Concentration } \\
\text { Drinking Water } \\
M P C, \mu \mathrm{c} / \mathrm{ml}\end{array}$} \\
\hline & & $\begin{array}{c}316 \\
\text { Stainless } \\
\text { Steel }\end{array}$ & Inconel-X & $\begin{array}{l}2219 \\
\text { Aluminum }\end{array}$ & & & & \\
\hline $\mathrm{Na}^{24}$ & $15 h$ & ----- & $2.8 \times 10^{-10}$ & $6.0 \times 10^{-8}$ & $9.2 \times 10^{-10}$ & $6.3 \times 10^{-8}$ & & $3 \times 10^{-5}$ \\
\hline $\mathrm{Si}^{31}$ & $2.6 \mathrm{~h}$ & $2.7 \times 10^{-8}$ & $2.2 \times 10^{-10}$ & ---- & ---- & $2.7 \times 10^{-8}$ & & $2 \times 10^{-4}$ \\
\hline p32 & $14.3 d$ & $2.7 \times 10^{-10}$ & ---- & +-- & ---- & $2.7 \times 10^{-10}$ & $2.8 \times 10^{-9}$ & $2 \times 10^{-5}$ \\
\hline $\mathrm{Sc}^{46}$ & $84 d$ & ---- & $\cdots$ & ---- & $5.9 \times 10^{-11}$ & $5.9 \times 10^{-11}$ & & $4 \times 10^{-5}$ \\
\hline $\mathrm{Sc}^{47}$ & $3.4 \mathrm{~d}$ & $-\cdots$ & ----- & ---- & $6.6 \times 10^{-11}$ & $6.6 \times 10^{-11}$ & & $9 \times 10^{-5}$ \\
\hline$V^{\prime} \mathrm{Sc}^{48}$ & $44 \mathrm{~h}$ & ---- & $\cdots-$ & $-\cdots$ & $4.1 \times 10^{-10}$ & $4.1 \times 10^{-10}$ & & $3 \times 10^{-5}$ \\
\hline $\mathrm{Cr}^{51}$ & $28 d$ & $5.8 \times 10^{-8}$ & $1.6 \times 10^{-8}$ & ---- & --- & $7.4 \times 10^{-8}$ & $2.0 \times 10^{-7}$ & $2 \times 10^{-3}$ \\
\hline $\mathrm{Mn}^{54}$ & $314 d$ & $3.2 \times 10^{-10}$ & $5.0 \times 10^{-11}$ & ---- & --- & $3.7 \times 10^{-10}$ & $6.7 \times 10^{-9}$ & $1 \times 10^{-4}$ \\
\hline$M n^{56}$ & $2.6 \mathrm{~h}$ & $2.3 \times 10^{-6}$ & $4.0 \times 10^{-7}$ & $7.8 \times 10^{-7}$ & --- & $3.5 \times 10^{-6}$ & & $1 \times 10^{-4}$ \\
\hline $\mathrm{Fe}^{59}$ & $45 d$ & $5.5 \times 10^{-10}$ & $2.2 \times 10^{-11}$ & ---- & --- & $5.7 \times 10^{-10}$ & $3.0 \times 10^{-9}$ & $5 \times 10^{-5}$ \\
\hline $\mathrm{Co}^{57}$ & $267 d$ & $5.8 \times 10^{-10}$ & $3.6 \times 10^{-9}$ & $--\infty$ & ---- & $4.2 \times 10^{-9}$ & $5.0 \times 10^{-8}$ & $4 \times 10^{-4}$ \\
\hline $\mathrm{Co}^{58 \mathrm{M}}$ & $9 \mathrm{~h}$ & $5.0 \times 10^{-7}$ & $3.1 \times 10^{-7}$ & $-\cdots$ & $-\cdots$ & $8.1 \times 10^{-7}$ & & $2 \times 10^{-3}$ \\
\hline $\mathrm{Co}^{58}$ & $71 \mathrm{~d}$ & $7.3 \times 10^{-10}$ & $4.4 \times 10^{-8}$ & -- - & --- & ** $4.5 \times 10^{-8}$ & $1.0 \times 10^{-8}$ & $9 \times 10^{-5}$ \\
\hline $\mathrm{Co}^{60}$ & $5.3 y$ & $7.3 \times 10^{-10}$ & $5.3 \times 10^{-10}$ & ---- & --- & $1.3 \times 10^{-9}$ & $5.0 \times 10^{-9}$ & $3 \times 10^{-5}$ \\
\hline $\mathrm{Ni}^{63}$ & $92 y$ & $8.1 \times 10^{-11}$ & $1.5 \times 10^{-10}$ & -- - & --- & $2.3 \times 10^{-10}$ & & $3 \times 10^{-5}$ \\
\hline $\mathrm{Ni} 65$ & $2.6 \mathrm{~h}$ & $9.0 \times 10^{-9}$ & $1.5 \times 10^{-8}$ & ---- & ---- & $2.4 \times 10^{-8}$ & & $1 \times 10^{-4}$ \\
\hline $\mathrm{Cu}^{64}$ & $12.9 \mathrm{~h}$ & ---- & $4.2 \times 10^{-8}$ & $7.0 \times 10^{-6}$ & - - & $* * 7.0 \times 10 * 6$ & $6.0 \times 10^{-9}$ & $2 \times 10^{-4}$ \\
\hline
\end{tabular}


TABLE 4.4 CONTINUED

\begin{tabular}{|c|c|c|c|c|c|c|c|c|}
\hline \multicolumn{2}{|c|}{ Nuclide } & \multicolumn{3}{|c|}{ Sea Water Activity, $\mu \mathrm{c} / \mathrm{ml}$} & \multirow[b]{2}{*}{$\begin{array}{l}\text { Titanium } \\
\text { (Incl. Press Vess) }\end{array}$} & \multirow[b]{2}{*}{ Total } & \multirow{2}{*}{$\begin{array}{l}\text { Permissable } \\
\text { Sea Water } \\
{\text { MPCC }-\mu \mathrm{c} / \mathrm{ml}^{*}}^{*}\end{array}$} & \multirow{2}{*}{$\begin{array}{l}\text { Doncentration } \\
\text { Drinking Water } \\
M P C, \mu \mathrm{c} / \mathrm{ml}\end{array}$} \\
\hline Symbol & $t-1 / 2$ & $\begin{array}{c}316 \\
\text { Stainless } \\
\text { Steel }\end{array}$ & Inconel-X & $\begin{array}{c}2219 \\
\text { Aluminum }\end{array}$ & & & & \\
\hline $\mathrm{Nb}^{97}$ & $72 \mathrm{~m}$ & $3.6 \times 10^{-12}$ & ---- & $-\cdots$ & --- & $3.6 \times 10^{-12}$ & & $9 \times 10^{-4}$ \\
\hline Mo99 & $66 \mathrm{~h}$ & $2.4 \times 10^{-7}$ & --- & $-\cdots-$ & --- & $2.4 \times 10^{-7}$ & & $4 \times 10^{-5}$ \\
\hline$S_{n} 113$ & $118 d$ & --- & ---- & $-\cdots-$ & $4.8 \times 10^{-11}$ & $4.8 \times 10^{-11}$ & $4.5 \times 10^{-7}$ & $8 \times 10^{-5}$ \\
\hline$S n^{121}$ & $25 \mathrm{~h}$ & --- & $-\cdots$ & ---- & $1.4 \times 10^{-8}$ & $1.4 \times 10^{-8}$ & & \\
\hline$S n^{123}$ & $125 d$ & ---- & ---- & $-\cdots$ & $5.9 \times 10^{-11}$ & $5.9 \times 10^{-11}$ & & \\
\hline$S_{n} 125$ & $9.4 \mathrm{~d}$ & ---- & ---- & ---- & $8.1 \times 10^{-11}$ & $8.1 \times 10^{-11}$ & & $2 \times 10^{-5}$ \\
\hline $\mathrm{Ta}^{182}$ & $115 d$ & $1.3 \times 10^{-8}$ & ---- & ---- & ---- & $1.3 \times 10^{-8}$ & $4.0 \times 10^{-7}$ & $4 \times 10^{-5}$ \\
\hline
\end{tabular}

$V_{1}^{1}$

Assuming sea water density of $1 \mathrm{gm} / \mathrm{cc}$. 
particles would settle to the bottom. In addition, these metal particles are insoluble, and it is extremely conservative to consider that these materials would be uniformly dispersed or dissolved in the waters within a 12-hour period. Therefore, the most likely concentrations of the radioisotopes in the sea water would probably be several orders of magnitude less than that shown in Table 4.4. 

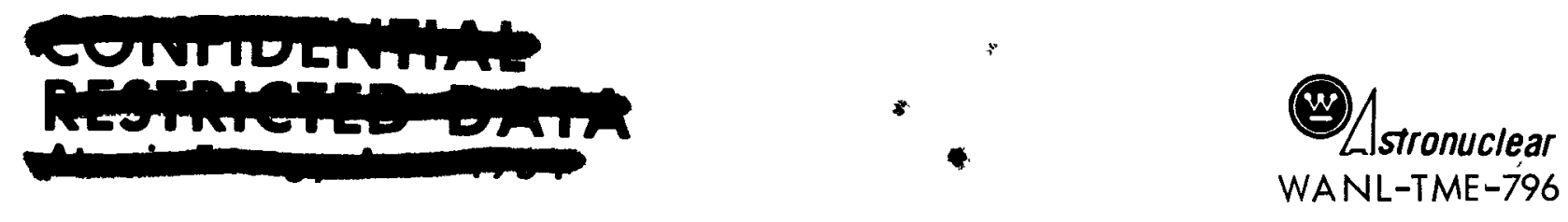

\subsection{DESTRUCT - CHEMICAL}

If the NERVA reactor ceases to be operational prior to achieving escape velocity, it will obviously re-enter the earth's biosphere bringing with it the fission product inventory generated during reactor operation. One means of minimizing the hazard associated with reactor re-entry is to degrade the core into a number of small particles which will re-enter in a widely dispersed pattern on the earth's surface. The concept of degrading the core into a number of particles involves the utilization of a destruct system. To date, three types of systems have been investigated--explosive, nuclear, and chemical. The investigation of the latter system was the responsibility of WANL and is reported in detail in WANL-TME-399 ${ }^{(42)}$. A summary of this study follows.

\subsection{ADVANTAGES AND DISADVANTAGES OF CHEMICAL DESTRUCT}

When destruct action is employed, a multitude of small particles will be created. In the case of nuclear and explosive techniques, the destruct will be essentially instantaneous, and the resultant particles will acquire a velocity vector from the destruct action. If this velocity vector is opposite the flight path of the reactor, the resultant core debris will no longer exist in a stable orbit and may re-enter immediately. In addition, the small particles created by destruct will have low ballistic parameters in comparison with that of an intact reactor. Since the orbital lifetime of an object in space is proportional to the ballistic parameter of that object ${ }^{(43)}$, it follows that the nuclear debris thus created will have relatively low space residence times. Thus, the possibility of using fission product decay to reduce the hazards associated with re-entering debris is diminished considerably when either
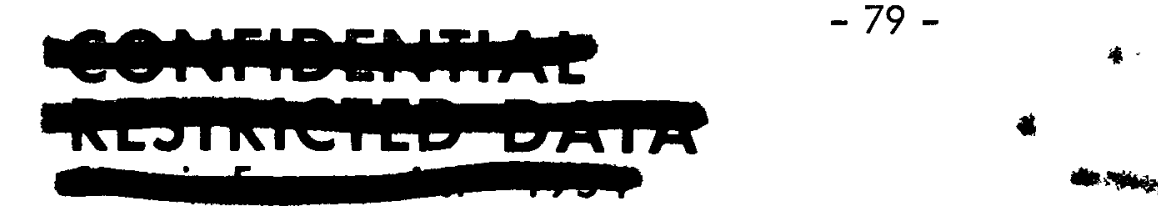


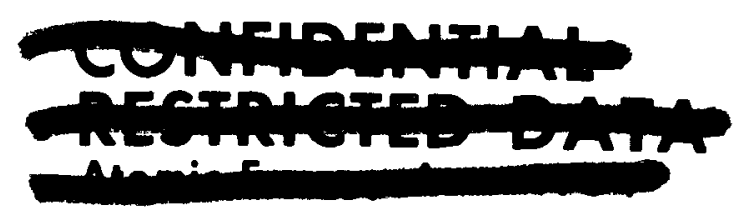

explosive or nuclear desturct is employed. However? in the case of chemical destruct, it is quite possible that the resultant debris will have zero destruct velocity vector and will, hence $e_{\theta}$ be contained within the reactor pressure vessel. Thus the ballistic parameter of the debris will be governed by that of the intact reactor. High space residence times will result, and as a consequence fission product decay will reduce the source strength of re-entering debris considerably,

On the other hand, with the employment of a chemical destruct, fechnique problems may arise. These problems are enumerated below:

(1) Little is known regarding the types of chemicals which will react with a fueled graphite core.

(2) Chemical reactions will generally proceed at a sufficiently fast rate over a relatively narrow temperature region. (Below this temperature region the reaction rate will be too low. Above it the rate may be so high that, if the reaction is exothermic, an explosion will result.)

(3) While explosive techniques react instantaneously a firite length of time is required for the employment of chemical destruct.

(4) If the reaction between the graphite core and the chemical reagent is stoichiometric, the weight of reagent required may be prohibitively high depending on the mission under consideration.

(5) The use of chemical destruct involves development of a complex delivery system. 

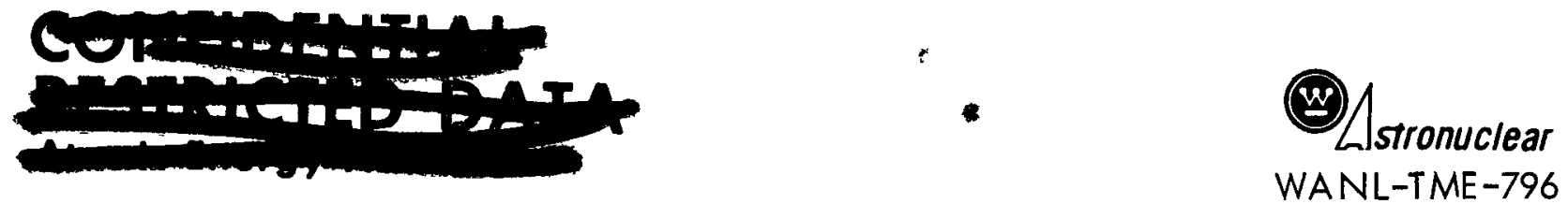

\subsection{SUMMARY OF CHEMICAL DESTRUCT STUDIES}

In order to ascertain the feasibility of utilizing chemical destruct, an extensive laboratory screening program was undertaken. In this program, small samples of NERVA fuel were tested in a flow system with a number of reagents. The experimental approach employed in these studies is reported elsewhere ${ }^{(42,44)}$. Table 5.1 lists the reagents examined, the weight of reagent required to degrade an entire core*, and the temperature region in which chemical destruct may be employed.

An examination of the data in Table 5.1 indicates that only two chemicals, $K$ and chlorine trifluoride $\left(\mathrm{ClF}_{3}\right)$, offer promise from a weight basis. However, in the case of both reagents, the core must be maintained at relatively low temperatures for destruct to be feasible. In addition, the use of $\mathrm{ClF}_{3}$ involves preconditioning the core at $2500^{\circ} \mathrm{C}$ before using chemical destruct. However, since post-operational heat is available, it is not possible to rule out the applicability of utilizing this chemical.

In summary, it appears that both $\mathrm{K}$ and $\mathrm{ClF}_{3}$ offer promise as destruct reagents. However, before any final conclusions may be drawn about their feasibility additional testing of larger samples is required and the concept of a delivery system must be developed.

* This number was evaluated by extrapolating test results from small scale tests.

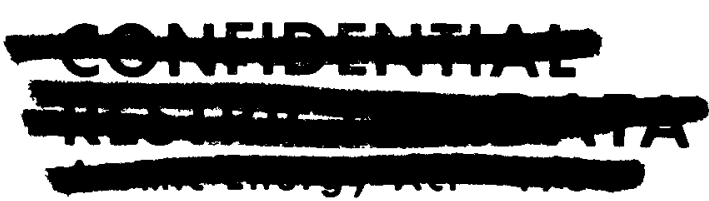




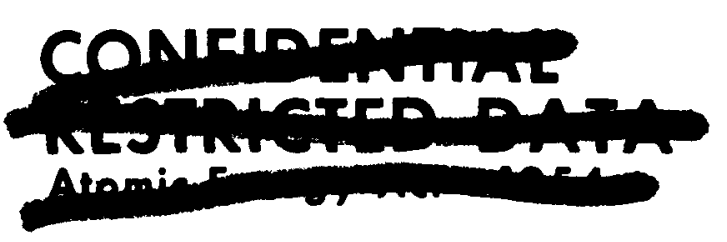

\section{TABLE 5.l}

\section{CHEMICAL DESTRUCT LABORATORY TEST EXTRAPOLA " INS}

$25-2000^{\circ} \mathrm{C}$

List of Reagents with Estimared Minimum Reagent Weigh* in Full Scale System

\section{Non-Halides}

$\mathrm{O}_{2}-6000 \mathrm{lb}$

$\mathrm{H}_{2} \mathrm{O}$ - Prohibitive*

$\mathrm{H}_{2} \mathrm{O}_{2}$ - Prohibitive*

$\mathrm{HNC}_{3}$ - Prohibitive*

$\mathrm{N}_{2}$ - Prohibitive*

$\mathrm{K}-1000-2700 \mathrm{lb}<350^{\circ} \mathrm{C}$

Freons

$\mathrm{CF}_{4}-$ Prohibitive*

$\mathrm{CCl}_{3} \mathrm{~F}$ - Prohibitive*

$\mathrm{CCl}_{2} \mathrm{~F}_{2}-$ Prohibitive*

*Weight of reagent equal to that of sample left $>90 \%$ of sample intact.

**Fuel must be preconditioned by heating to $2500^{\circ} \mathrm{C}$ prior to using chemical destruct.

$$
\begin{aligned}
& \frac{\text { Halides }}{\mathrm{HF}-\text { Prohibitive* }} \\
& \mathrm{HCl} \text { - Prohibitive* } \\
& \mathrm{Cl}_{2}-\text { Prohibitive* } \\
& \mathrm{BCl}_{3}-\text { Prohibitive* } \\
& \mathrm{CrO}_{2} \mathrm{Cl}_{2}-\text { Prohibitive* } \\
& \mathrm{FeCl}_{3}-\text { Prohibitive } \\
& \mathrm{BBr}_{3}-4000 \text { lbs. at } 1000^{\circ} \mathrm{C} \text { only } \\
& \mathrm{Br}_{2}-6000 \text { !bs. at } 2000^{\circ} \mathrm{C} \text { only }
\end{aligned}
$$

\begin{tabular}{|c|c|c|}
\hline & $\begin{array}{l}\text { High Temp. } \\
400^{\circ} \mathrm{C}\left(1200^{\circ} \mathrm{R}\right)\end{array}$ & $\begin{array}{r}\text { Low Temp. } \\
<400^{\circ} \mathrm{C}\left(1200^{\circ} \mathrm{R}\right)\end{array}$ \\
\hline$F_{2}$ & $6,000 \mathrm{lb}$ & $\begin{array}{l}\text { Prohibitive without } \\
\text { subsequen* nu =lear } \\
\text { transient }\end{array}$ \\
\hline $\mathrm{BrF}_{3}$ & $14,000 \mathrm{lb}$. & Prohibitive \\
\hline $\mathrm{BrF}_{5}$ & $10,000 \mathrm{lb}$. & $2000 \mathrm{lb}$ \\
\hline $\mathrm{ClF}_{3}$ & $8,000 \mathrm{lb}$. & $650 \mathrm{lb} . * *$ \\
\hline $\mathrm{F}_{5}$ & $14,000 \mathrm{lb}$. & $4000 \mathrm{lb}$. \\
\hline$U_{6}$ & Prohibitive* & $9000 \mathrm{lb}$ \\
\hline
\end{tabular}

Fluorine and Fluorides 


\section{BIBLIOGRAPHY}

1. Rymer, G. T., Henninger, W. A., and Grandy, G. L., "The Release of Fission Products from UC 2 Graphite Fuels," WANL-TME-542, August 1963 (CRD).

2. General Electric Co., Aircraft Nuclear Propulsion Division, "Fission Product Decay Gamma Energy Spectrum," APEX-134, Evandale, Ohio, 1953 (U).

3. Blomeke, J. O., and Todd, Mary F., "Uranium-235 Fission Product Production as a Function of Thermal Neutron Flux, Irradiation Time, and Decay Time," ORNL-2127, December 1958 (U).

4. Clark, F. H., "Decay of Fission Product Gammas," NDA-27-29, December $1954(\mathrm{U})$.

5. Burrell, M. O., Duncan, G.F., and Perkins, J.F., "The Computation of Gamma Activity and Related Effects from the Cyclic Operation of a U-235 Reactor," Lockheed Georgia Company, Nuclear Report-39, August 1958 (U).

6. Perkins, J. F. and King, R. W., "Energy Release from the Decay of Fission Products," Nuc. Sci. Eng. 3, 726, (1958) (U).

7. Lockheed Missile and Space Company, "Nuclear Flight Executive Program, Nuclear Vehicle Flight Safety Study, Phase III Report," LMSC-A-304973, January $1964(U)$.

8. Speigler, P., "Energy Release from Decay of Fission Products," USAEC Report NAA-SR-Memo-4126, July 1959 (U)。

9. J. Griffin, "Beta Decays and Delayed Gammas from Fission Fragments," LA-2811, December 1962 (U).

10. Engle and Fisher, "Energy Time Dependence of Delayed Gamma from Fission," LAMS-2642, July 1962 (U).

11. Call, D. W., "Fission Product Inventory Program," WANL-TME-537, September $1963(U)$.

12. Bridges, J. M., Trammell, $M_{0}$ R., and Brown, W. Sog "Radioactive Level of Small Particles Resulting from Operation and Destruct of the NERVA Reactor Core," WANL-TME-703, February 1964 (CRD). 
13. Trammell $M_{0} M_{0} R_{0}$ and Hernirger, W。 A. "Nuclear Data Liben, tor the Fission Product Program," WANL-TME -574, October 1963 (U).

14. Rymer, G. T。, Henninger, W. A。 and Grandy, G. Lo Private Tommunication to be published Jume 1964, WANL。

15. Reactor Analysis Departmer $r_{g}$ WANL "Reactor Analysis of NR $x$ A Thermal and Fluid Flow Analysis, Vol. 111" "WANL-TNR-128, September 196. CRD).

16. Bryant, E. A.g et al "Rates ard Mecharisms of the Loss of Fission Products from Uranium-Graphite Fuel Materials," Nuc。Sci. Erg. 15, 288 (1963) (U)。

17. King L. D.P. and Stratton W.R. "The Response of KIW! Reactors to Abnormal Reactivity Insertions," RFS-135, pg. 162, Los Alamos Scientific Laboratory (CRD)。

18. Rymer, G. Tog Herminger, W. $A_{\circ,}$ and Grandy, G. L L "Release of Fission Products from WANL Capsule FP -4 WANL-TME-650, January 1964 (CRD).

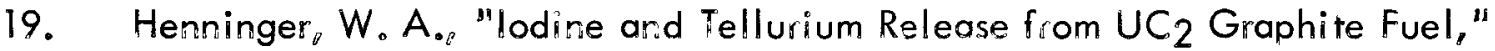
WANL-TME -589 , January 1964 (CRD).

20. Crank, Jog The Mathematics of Diffusiom Oxford, (1956) (U).

21. Call, D. W. Cleary, J。D. Roll,$J_{\circ}$ A $_{\circ}$, and Roidr, M. "WANL Nuclear Excursion Analysis Program," WANL-TME =735 April 1, 1964 (CRD).

22. Hemmerle $E_{8} \mathrm{H}_{\circ}$ "Safery Analysis Repo- NRX Testing "WANL - TNR-148 Revision 1, April 1964 (CRD).

23. Knecht, W. Lo "NRX-A Reactor Model for Systems Analysis" "WANL-ivic-40, July 31, 1963 (CRD)。

24. Rymer, G. T。, "Fission Product Diffusion Studies in the First Series of TREAT Irradiated NERVA Fuel," WANL-TME-637, Jaruary 1964 (CRD)。

25. Bridges, J.M. Hargrove H. G , and Hoecker ${ }_{\nu} D_{\circ g}$ "Summary Report of the Theoretical, Analytical, and Experimental Studies Performed in the Investigation of the Re-Entry Burr -up of NERVA Fuel," WANL -TNR-135, September 1963 (U).

26. Grandy, G. L。 and Pinchok, R。No, "Irvestigation of the Fission Product Diffusior and Burnup Characteristics of NERVA Fuel Under Re-Entry Conditions, "WANL TME -739, April 1964 (CRD). 
27. Bridges, J. M., "Experimental Study of the Re-Entry Oxidation of NERVA Fuel," WANL-TNR-072 October 1962 (CRD).

28. Engel, M. J., et al, "The Effects of Atmospheric Re-Entry on Graphite Particles," DIN: 214 - L28F, January 1964 (U).

29. Scala, S. M., "A Study of Hypersonic Ablation," TIS Document No. R-5950348 September $1959(U)$.

30. Blyholder, G. and Eyring, H., J. Phys. Chem. 63, 10004 (1958) (U).

31. Gubransen, E. A., Andrews, K.F., and Brassart, F. A., "Ablation of Graphite in $\mathrm{Oxygen}$ and $\mathrm{Air}$ at $1000^{\circ} \mathrm{C}$ to $1400^{\circ} \mathrm{C}$ under Flow Conditions, "Westinghouse Research Laboratory, Scientific Paper 63-139-120-PL, March 1963 (U).

32. Bridges, J. M., Rymer, G. T., and Korposh, M. E., "Result of Plasmajet Test of Fueled Materials Containing Additives," WANL-TME-602, November 1963 (U).

33. Ricks, L. O., "Radiation Source Strengths and Dose Rates for the NRX Reactor Assembly and Components," WANL-TNR-080, October 1962 (CRD).

34. Reactor Analysis Department, WANL, "Reactor Analysis of NRX-A, Radiation Analysis, Vol. II of III," WANL-TNR-128, September 1963 (CRD).

35. Heiser, P.C. and Ricks, L。O., "Activation Source Strength Program, Act I, for the IBM 7090 Computer," and "Activation Source Strength Program, Act II," WANL-TNR-063, and WANL-TNR-063, Revised September 1962 (U).

36. Brown, W. S., Ricks, L. O., and Heiser, P. C., "Materials Activation Program, Act II, Revised" WANL-TME-598, November 1963 (U).

37. Capo, M. A., Nassano, R. N., Soltesz, R. G., "NRX-A Configuration for Radiation Analysis," WANL-TME-291, April 1963 (CRD).

38. Goldman, M. I., et al, "Radiobiological Considerations in Re-Entry of Nuclear Reactor Fragments," Nuclear Utility Services, Inc. NUS-145, July 1963 (CRD).

39. Decker, R. S., Private Communications, November 1963. 
40. National Academy of Sciences, National Research Council, "Jisposal of Low Level Radioactive Waste into Pacific Coastal Waters." NAS "NRC Publication 985, Washington, D. C. 1962 (U).

41. U. S. Department of Commerce, "Maximum Permissable Body Lurdens and Maximum Permissable Concentrations of Radionuclides in Air and in Water for Occupational Exposure," National Bureau of Standards His thook 69, Washington, D. C. June 5, 1959 (U).

42. Roll, J. A., Vollmer, R. $M_{0 \gamma}$ and Wilks, $P_{0} H_{0,}$ "Summary Screening Report on Chemical Destruct System", WANL-TME-399, June 1963 (CRD).

43. Hargrove, H. G., and Hoecker, D. A , "Flight Mechanics of NERVA Re-Entry and Orbital Lifetime Studies" "WANL-TME-635, December 1963 (U).

44. Roll, J. A., et al, "Preliminary Investigation of NERVA Core Destruct Chemicals", WANL-TNR-075, October 1962 (CRD).

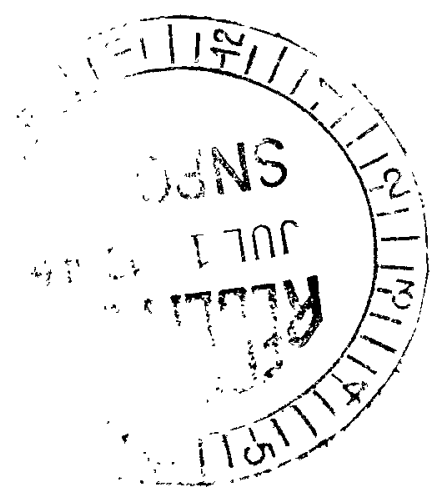

